SERVIÇO DE PÓS-GRADUAÇÃO DO ICMC-USP

Data de Depósito:

Assinatura:

\title{
Processamento de consultas por similaridade em imagens médicas visando à recuperação perceptual guiada pelo usuário
}

\section{Marcelo Ponciano da Silva}

Orientadora: Profa. Dra. Agma Juci Machado Traina

Dissertação apresentada ao Instituto de Ciências Matemáticas e de Computação - ICMC-USP, como parte dos requisitos para obtenção do título de Mestre em Ciências - Ciências de Computação e Matemática Computacional.

USP - São Carlos

Fevereiro/2009 
Processamento de consultas por similaridade em imagens médicas visando à recuperação perceptual guiada pelo usuário 
"Quando a sabedoria penetrar em teu coração, e o conhecimento for agradável à tua alma, o bom siso te guardará e a inteligência te conservará." 

À minha família, meu tesouro e razão de todo meu esforço. Em especial, à minha amada esposa Lívia e meus filhos Ester e Pedro, bem como aos meus pais, Donizete Ponciano e Maria Terezinha e minha querida irmã Fernanda. Dedico 



\section{Agradecimentos}

Primeiramente a Deus, pela vida e oportunidade de fazer parte de um plano eterno de crescimento e progresso. Meu Criador, minha fortaleza e provedor de tudo que possuo.

À minha família querida, meus pais que tanto me apóiam e incentivam. Mesmo à distância nunca deixaram de estar presentes nos momentos importantes.

À minha amada esposa, tão dedicada, paciente e amorosa, por ser meu porto seguro e minha fonte de energia incondicional. À minha filha Ester, pelos momentos de brincadeiras e descontração, que sempre me ajudaram a relaxar e renovar meus ânimos. E ao meu filho Pedro que, mesmo no ventre da mãe, foi uma fonte de paz, tranqüilidade e motivação.

À minha orientadora, pela confiança e por acreditar em mim, dando-me apoio, incentivo e sempre demonstrando um carinho e preocupação de mãe pelo meu bem estar e sucesso.

Ao Prof. Dr. Joaquim Cezar Felipe, pela amizade cultivada desde a graduação, pelo incentivo, apoio e por permitir a minha estada no laboratório ImagCom, junto ao DFM FFCLRP.

Ao Prof. Dr. Paulo Mazzoncini de A. Marques, pela amizade, incentivo e por permitir a realização da parte prática desse trabalho, dando-me acesso ao HCFMRP - USP e ao CCIFM.

Aos médicos radiologistas Prof. Dr. Valdair Francisco Muglia, Prof. Dr. Jorge Elias Júnior, Prof. Dr. Clóvis Simão Trad e Prof. Dr. Antônio Carlos dos Santos e aos residentes da radiologia do HC-FMRP-USP, pela preciosa ajuda na parte da aplicação médica desse trabalho.

Aos amigos do GBDI, especialmente ao Pedro, Carolina, André, Marcela e Daniel por sempre estarem dispostos a me ajudar no trabalho.

À FAPESP e CNPq pelo apoio financeiro.

Enfim, a todos que direta ou indiretamente contribuíram para a realização desse trabalho. MUITO OBRIGADO. 
PONCIANO-S, M. Processamento de Consultas por Similaridade em Imagens Médicas Visando à Recuperação Perceptual Guiada pelo Usuário, São Carlos, 2009. 97p. Dissertação de Mestrado - Instituto de Ciências Matemáticas e de Computação ICMC, USP.

\section{Resumo}

O aumento da geração e do intercâmbio de imagens médicas digitais tem incentivado profissionais da computação a criarem ferramentas para manipulação, armazenamento e busca por similaridade dessas imagens. As ferramentas de recuperação de imagens por conteúdo, foco desse trabalho, têm a função de auxiliar na tomada de decisão e na prática da medicina baseada em estudo de casos semelhantes. Porém, seus principais obstáculos são conseguir uma rápida recuperação de imagens armazenadas em grandes bases e reduzir o "gap semântico", caracterizado pela divergência entre o resultado obtido pelo computador e aquele esperado pelo médico. No presente trabalho, uma análise das funções de distância e dos descritores computacionais de características está sendo realizada com o objetivo de encontrar uma aproximação eficiente entre os métodos de extração de características de baixo nível e os parâmetros de percepção do médico (de alto nível) envolvidos na análise de imagens. O trabalho de integração desses três elementos (Extratores de Características, Função de Distância e Parâmetro Perceptual) resultou na criação de operadores de similaridade, que podem ser utilizados para aproximar o sistema computacional ao usuário final, visto que serão recuperadas imagens de acordo com a percepção de similaridade do médico, usuário final do sistema. 
PONCIANO-S, M. Similarity Queries Processing Aimed at Retrieving Medical Images Guided by the User's Perception, São Carlos, 2009. 97p. MSc Dissertation - Instituto de Ciências Matemáticas e de Computação - ICMC, USP.

\section{Abstract}

The continuous growth of the medical images generation and their use in the day-to-day procedures in hospitals and medical centers has motivated the computer science researchers to develop algorithms, methods and tools to store, search and retrieve images by their content. Therefore, the content-based image retrieval (CBIR) field is also growing at a very fast pace. Algorithms and tools for CBIR, which are at the core of this work, can help on the decision making process when the specialist is composing the images analysis. This is based on the fact that the specialist can retrieve similar cases to the one under evaluation. However, the main reservation about the use of CBIR is to achieve a fast and effective retrieval, in the sense that the specialist gets what is expected for. That is, the problem is to bridge the semantic gap given by the divergence among the result automatically delivered by the system and what the user is expecting.

In this work it is proposed the "perceptual parameter", which adds to the relationship between the feature extraction algorithms and distance functions aimed at finding the best combination to deliver to the user what he/she expected from the query. Therefore, this research integrated the three main elements of similarity queries: the image features, the distance function and the perceptual parameter, what resulted in searching operators. The experiments performed show that these operators can narrow the distance between the system and the specialist, contributing to bridge the semantic gap. 


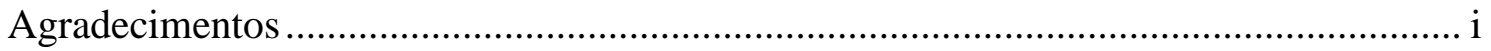

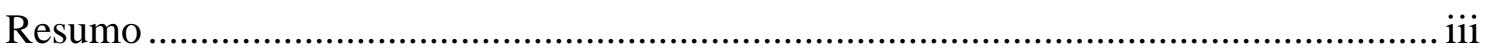

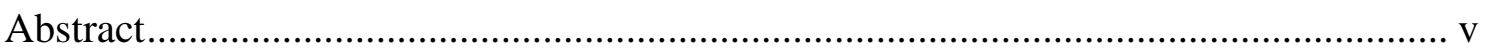

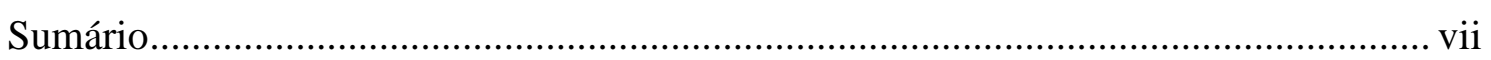

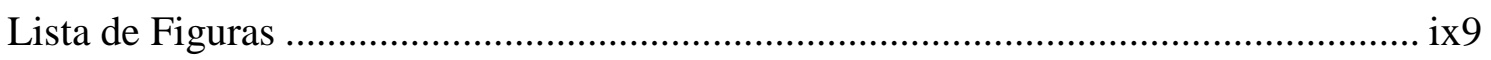

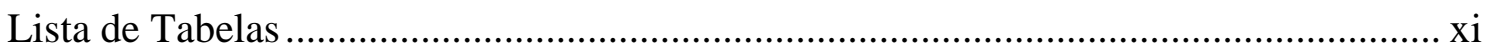

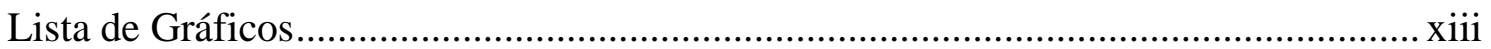

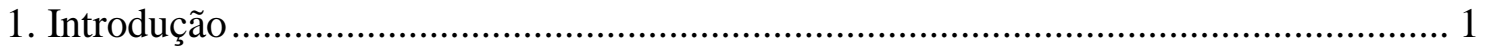

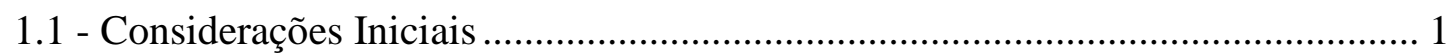

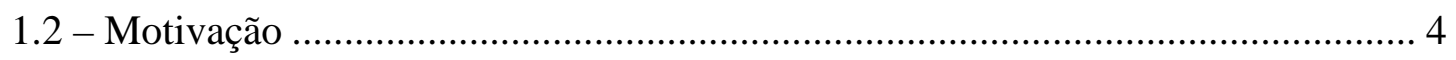

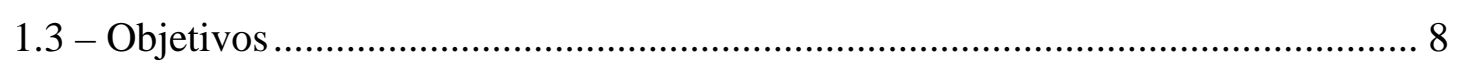

1.4 - Organização do Trabalho................................................................................... 9

2. Recuperação de Imagens Médicas por Conteúdo..................................................... 11

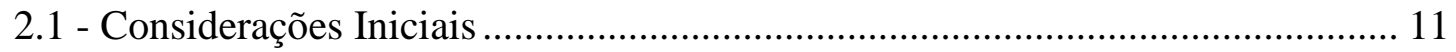

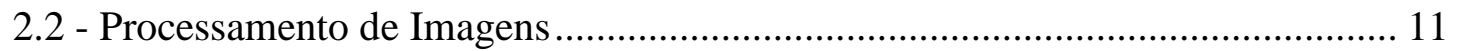

2.3 - Análise de Imagens e Extração de Características............................................ 13

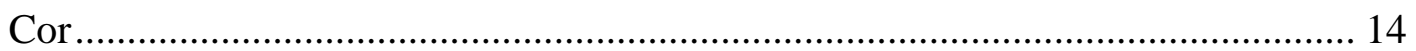

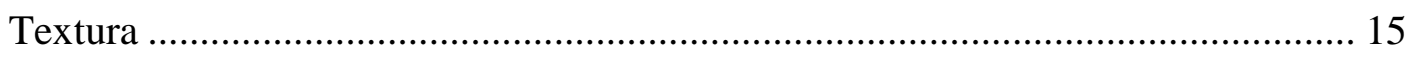

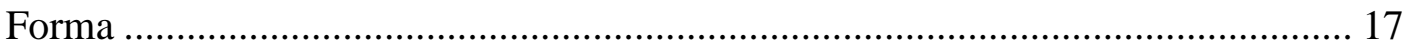

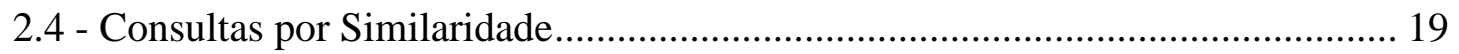

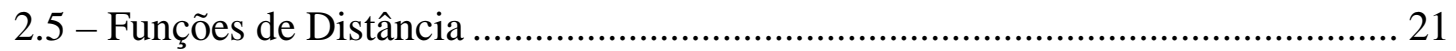

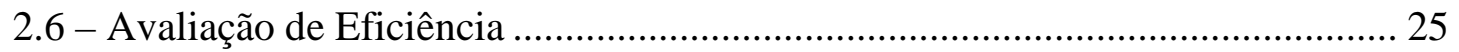

2.7 - CBIR em um Ambiente Real........................................................................ 27

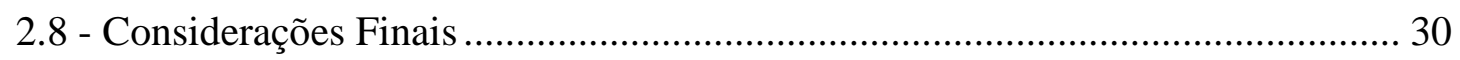

3. Inclusão da Percepção do Especialista em Consultas por Similaridade ..................... 33

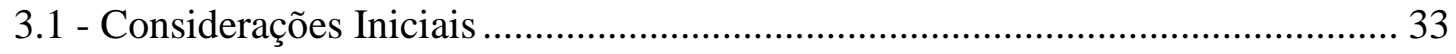

3.2 - Conceitos de Similaridades em Recuperação por Conteúdo ............................. 33

3.3 - "Parâmetro Perceptual”: Intuição e Definição..................................................... 36 
3.4 - Parâmetros de Percepção em imagens de Tomografia Computadorizada de Pulmão

3.5 - Considerações Finais

4. Métodos de Extração Baseados nos Parâmetros Perceptuais ...................................... 49

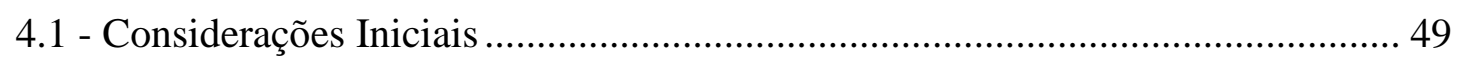

4.2 - Incluindo o Parâmetro Perceptual no pré-Processamento .................................. 50

4.3 - Construindo Extratores de Características Específicos para o Contexto ............ 53

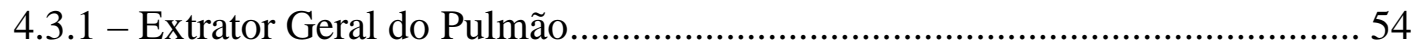

4.3.2 - Extrator Completo do Pulmão....................................................................... 54

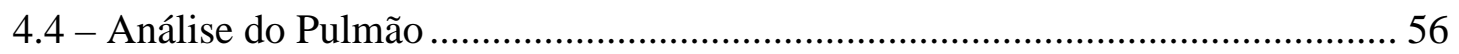

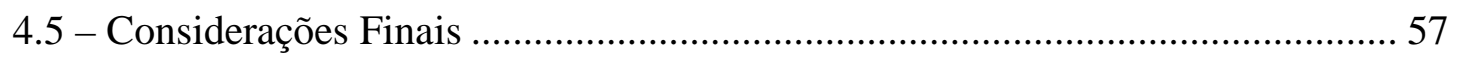

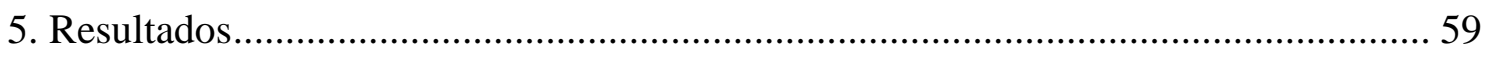

5.1 - Considerações Iniciais ..................................................................................... 59

5.2 - Parâmetros Perceptuais no Pré-Processamento ................................................... 60

5.2.1 - Experimento 1: Histograma com 256 níveis de cinza................................. 61

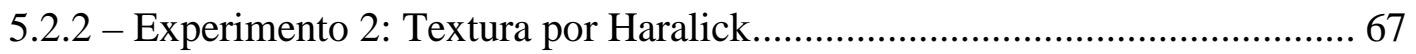

5.2.3 - Conclusões Parciais ................................................................................ 71

5.3 -Extração de Características Específicas ao Contexto ......................................... 72

5.3.1 - Experimento 3: Extrator Geral do Pulmão................................................ 72

5.3.2 - Experimento 4: Extrator Completo ......................................................... 75

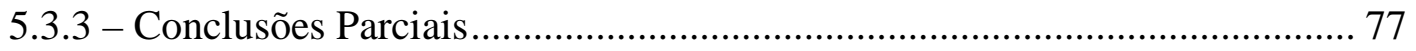

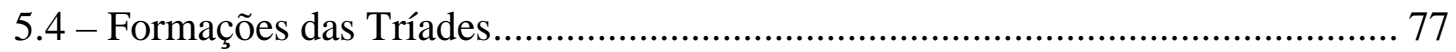

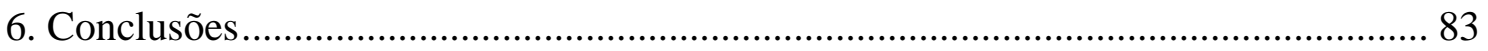

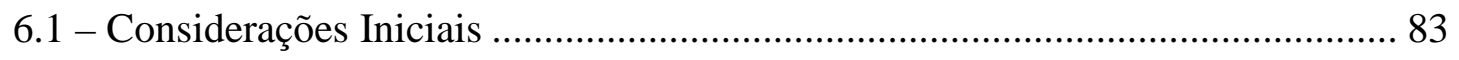

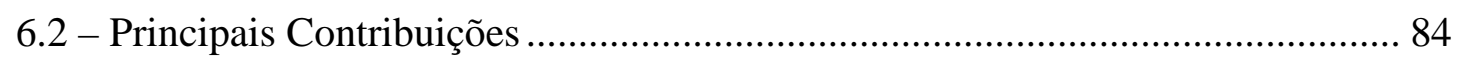

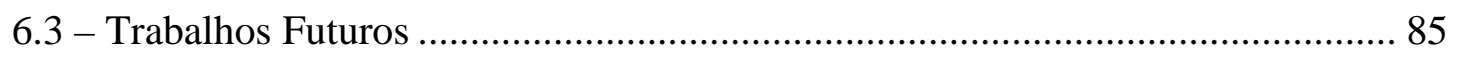

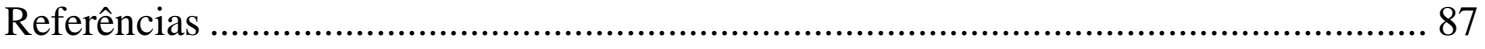




\section{Lista de Figuras}

Figura 1: Interações entre os sistemas HIS, RIS e PACS ............................................... 2

Figura 2: Tríade -- Formação de Operadores de Similaridade ........................................ 8

Figura 3 - Exemplo da operação de Janelamento ........................................................ 12

Figura 4: Processo Geral de Extração de Características ................................................. 14

Figura 5: Representação da Imagem por Histograma de Intensidade de pixels .............. 15

Figura 6: Representação dos Conjuntos de Imagens Relevantes (R) e Recuperadas (A) para definição de valores de precisão $((\mathrm{R} \cap \mathrm{A}) / \mathrm{A})$ e $\operatorname{Revocação(}(\mathrm{R} \cap \mathrm{A}) / \mathrm{R})$................ 26

Figura 7 - Exemplo de Gráfico de Precisão vs. Revocação............................................ 26

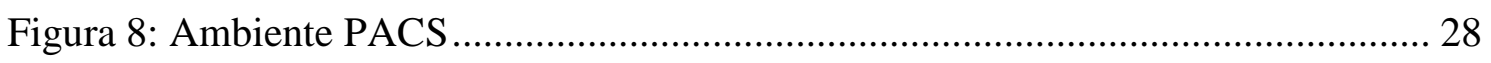

Figura 9: Níveis de Especificidade para Definição de Critérios de Similaridade .......... 35

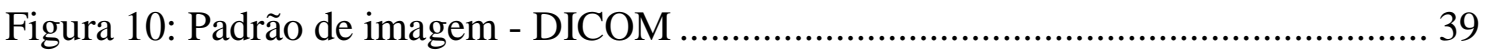

Figura 11: Efeito do Convolution Kernel: B80s na imagem da esquerda e B20s na imagem da direita

Figura 12: a) Imagem Original b) Imagem Janelada em W1400/C-600 - ideal para visualizar pulmão c) Imagem janelada em W300/C50 - ideal para partes moles do mediastino d) Imagem janelada em W1800/C800 - ideal para visualizar osso ............. 43

Figura 13: Imagens com achados de alta atenuação...................................................... 46

Figura 14: Imagens com achados de baixa atenuação .................................................. 47

Figura 15 - Histogramas de Imagem DICOM. (a) Original. (b) Histograma de imagem requantizada em 256 níveis de intensidade. (c) Histograma com Janelamento W1200/600 (d) Histograma com Janelamento W600/C-800 (e) Histograma com Janelamento W600/C-400

Figura 16 - (a) Imagem Original, (b) Imagem Janelada W600/C-800, (c) Imagem

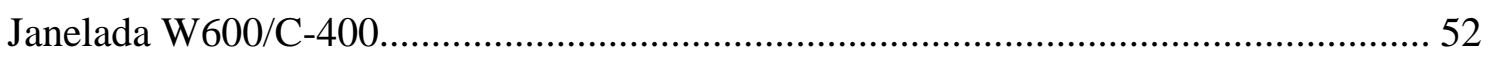

Figura 17 - Ilustração do Algoritmo de Segmentação do Pulmão .................................. 56

Figura 18: Integração do "trinômio" para CBIR ………………………............................ 79 


\section{Lista de Tabelas}

Tabela 1: Alguns descritores propostos por Haralick.................................................. 16

Tabela 2: Levantamento dos principais achados e seus parâmetros perceptuais ........... 45

Tabela 3: Formação das tríades, operadores de similaridade para as 6 classes de achados discutidos nesta dissertação. 80 


\section{Lista de Gráficos}

Gráfico 1 - Precisão e Revocação - "Histograma Tradicional" 62

Gráfico 2 - Precisão e Revocação - "Histograma Baixa".. 62

Gráfico 3 - Precisão e Revocação para o extrator "Histograma Alta". 63

Gráfico 4: Precisão e Revocação para a classe Consolidação considerando a "dupla" extrator (histograma) e função de distância em sua melhor configuração

Gráfico 5: Precisão e Revocação para a classe Vidro Fosco considerando a "dupla" extrator (histograma) e função de distância em sua melhor configuração

Gráfico 6: Precisão e Revocação para a classe Favo de Mel considerando a "dupla"

extrator (histograma) e função de distância em sua melhor configuração

Gráfico 7: Precisão e Revocação para a classe Enfisema considerando a "dupla" extrator (histograma) e função de distância em sua melhor configuração 66

Gráfico 8: Precisão e Revocação para a classe Normal considerando a "dupla” extrator (histograma) e função de distância em sua melhor configuração 67

Gráfico 9: Precisão e Revocação - Textura Tradicional 68

Gráfico 10: Precisão e Revocação - Dupla: Textura Tradicional - Canberra 69

Gráfico 11: Precisão e Revocação - Enfisema.................................................................. 70

Gráfico 12: Precisão e Revocação - Consolidação......................................................... 70

Gráfico 13: Precisão e Revocação - Extrator Geral ..................................................... 72

Gráfico 14: Precisão e Revocação - Extrator Geral ..................................................... 73

Gráfico 15: Precisão e Revocação para a classe Favo de Mel considerando a dupla extrator e função de distância em sua melhor configuração.

Gráfico 16: Precisão e Revocação para a classe Enfisema considerando a dupla extrator e função de distância em sua melhor configuração. 74

Grafico 17: Precisão e Revocação das classes utilizando o "Extrator Completo". 75 Gráfico 18: Precisão e Revocação da base de imagens utilizando o "Extrator Completo" 
Gráfico 19: Precisão e Revocação para a classe Consolidação, considerando a dupla extrator e função de distância em sua melhor configuração.

Gráfico 20: Precisão e Revocação dos extratores e do método com a Tríade (operadores) considerando todas as imagens da base como centro de consulta.

Gráfico 21: Precisão dos extratores e do método com a Tríade (operadores) considerando todas as imagens da base como centro de consulta com um $\mathrm{K}=10$. 81 


\section{Introdução}

\section{1 - Considerações Iniciais}

Com o crescente avanço tecnológico e o barateamento relativo das tecnologias de coleta de dados e imagens, a maioria dos hospitais, clínicas, laboratórios e até alguns consultórios médicos já fazem uso de ferramentas computacionais que gerenciam, armazenam e organizam as informações clínicas dos pacientes. Nos hospitais, os Sistemas de Informações Hospitalares (Hospital Informations System - HIS) são responsáveis por gerenciar, armazenar e prover informações textuais dos pacientes. Os médicos que os utilizam fazem consultas à base de dados textuais do hospital para obter o histórico de atendimentos, procedimentos realizados e demais informações de determinado paciente.

Paralelamente a essa automação de informações textuais temos percebido o surgimento de aparelhos de exames radiológicos mais potentes, que geram imagens digitais com melhor definição a custos não tão exorbitantes. Com a evolução no campo do diagnóstico por imagens e a necessidade cada vez maior de se chegar a um diagnóstico rápido e preciso, o número de solicitações de exames que geram imagens digitais tem aumentado consideravelmente. Com isso, hospitais e centros médicos produzem e armazenam quantidades significativas de imagens médicas digitais. Nesse ambiente de diagnóstico por imagem, o PACS (Picture Archiving and Communication System) é o sistema responsável por receber as imagens dos diversos dispositivos de aquisição (Raio X, Ressonância Magnética, Tomografia Computadorizada, entre outros), deixá-las disponíveis para que médicos ou outros sistemas computacionais possam acessá-las e ainda armazená-las de maneira organizada em bases ou mídias específicas [Pare_2005]. Ainda nesse ambiente, os Sistemas de Informações Radiológicas (Radiology Informations System - RIS) foram criados para controlar processos como geração e agendamento de exames, manutenção e geração de laudos e relatórios [Azevedo-Marques_2000]. 
Na Figura 1 são esboçados os três sistemas (HIS, RIS e PACS). Cada um desses sistemas apresenta interações de recursos e informações com outros. Por esse motivo a correta integração entre eles é fundamental para o bom andamento das atividades hospitalares [Azevedo-Marques_2005b, Morioka_2005]. Essa integração de todas as informações do paciente (textos, imagens, gráficos) em um só sistema tem sido o grande interesse dos médicos, hospitais e clínicas [Furuie_2007]. Outra vertente importante nessa área da informática em saúde tem sido a incorporação de outras funcionalidades nesses sistemas, como por exemplo, ferramentas para treinamento de novos especialistas ou ferramentas de auxílio ao diagnóstico e tomada de decisão. Essa busca por novas funcionalidades têm sido o foco de estudo dos pesquisadores da área nesses últimos anos [Doi_2005].

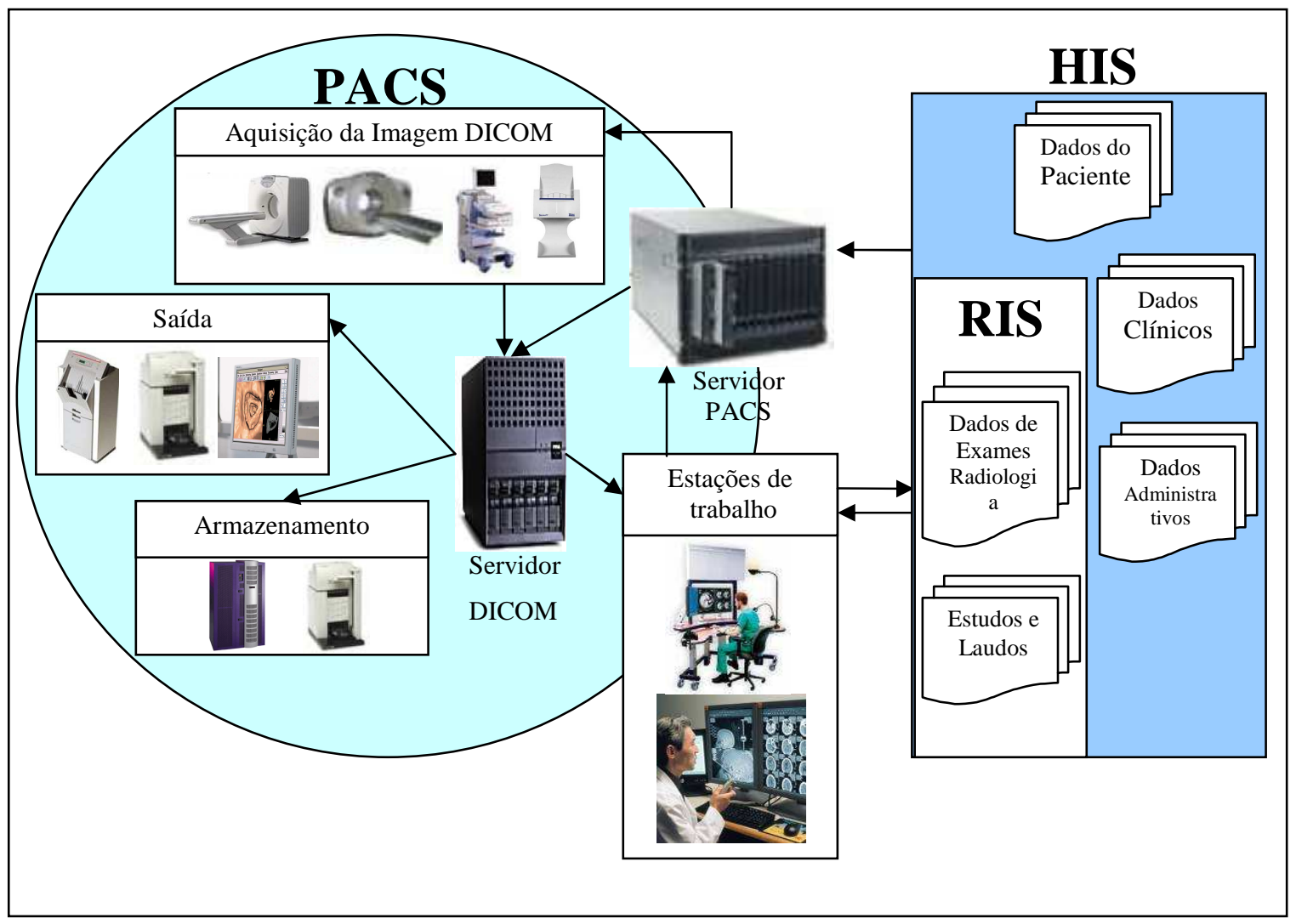

Figura 1: Interações entre os sistemas HIS, RIS e PACS

Todos esses sistemas que provêem armazenamento e manipulação eficiente das informações nos hospitais ajudam na criação e manutenção de bases de dados contendo dados clínicos de diversos atendimentos de inúmeros pacientes. Essas bases de dados se tornam uma fonte de informações preciosas que podem ser extremamente úteis durante a prática da medicina baseada em evidências. Essa prática é comum entre os médicos e é concebida em um contexto onde a experiência clínica é integrada com a capacidade do 
médico de analisar e aplicar de forma racional as informações obtidas através de uma busca de casos clínicos semelhantes, visando assim melhorar a qualidade da assistência médica [Lopes_2000]. A possibilidade de tratamento computacional de imagens e dados textuais do paciente permite também o desenvolvimento de ferramentas para o diagnóstico auxiliado por computador (Computer-Aided Diagnosis - CAD) [Yin_2004], as quais têm se mostrado capazes de promover um aumento da qualidade do trabalho dos radiologistas [Doi_2006].

Visando a aproximação da tecnologia da informação à rotina habitual dos médicos, o PACS pode ter seu conjunto de funcionalidades estendidas de modo a suprir aquilo que os radiologistas geralmente fazem em seu cotidiano de preparo de laudos, ao recordarem-se de casos previamente analisados. Por exemplo, ao analisar um Raio-X de tórax, o radiologista visualiza uma anomalia no pulmão que já havia analisado anteriormente em outro paciente e discutido com outros colegas. Porém, não têm em mãos tais informações da discussão, nem o resultado final da análise realizada. Ou seja, o especialista não tem como acessar rapidamente e utilizar conhecimento resultante de atividades anteriores, o que seria de extremo benefício para a prática clínica. Tal conhecimento é geralmente resgatado através de juntas médicas, onde cada especialista traz sua experiência prévia.

Um modo de permitir que o especialista resgate a análise e resultados anteriores que se apliquem ao caso em estudo é através da busca de imagens ou casos similares. Assim, esse radiologista poderia obter tais informações através de uma busca do tipo "recuperar todas as imagens obtidas por Raio-X de tórax, que são similares àquela imagem sendo analisada". Nesse caso, o cruzamento das informações independe de chaves de busca tradicionais, baseadas em dados numéricos ou textuais associados a uma imagem (como nome ou data do exame). Esse novo tipo de busca leva em consideração o conteúdo intrínseco das imagens, fazendo com que as imagens que possuam características visuais próximas sejam consideradas como imagens semelhantes.

$\mathrm{Na}$ área da computação onde se desenvolvem sistemas de Recuperação de Imagens Baseada em Conteúdo (Content-Based Image Retrieval - CBIR), um dos principais campos de aplicação é o campo das imagens médicas digitais. O uso dessa tecnologia tem impulsionado pesquisas envolvendo imagens médicas nos últimos anos [Datta_2008, Müller_2004a]. Os sistemas CBIR representam as imagens por meio de 
suas características intrínsecas relacionadas a descritores que buscam associar-se com a percepção humana de cor, textura e formato. Por meio dessa representação passa a ser possível a realização de buscas por casos semelhantes a partir de uma imagem inicial de referência. Essa facilidade de recuperação de imagens baseada em conteúdo é um dos recursos mais almejados para incorporação aos sistemas PACS [Fischer_2008]. Os sistemas PACS que possuírem esse suporte serão potencialmente uma ferramenta eficaz no auxílio ao diagnóstico médico, porém seu desenvolvimento envolve o tratamento de diversos desafios, entre eles a proposta de extratores de características adequados ao domínio, de algoritmos de indexação e recuperação, e de métodos de comparação entre imagens [Guld_2007].

\section{2 - Motivação}

Os sistemas de informação na medicina têm por objetivo disponibilizar a informação necessária ao médico de modo rápido e preciso visando assim melhorar a qualidade do cuidado à saúde. A aplicação das técnicas de CBIR incorporadas aos sistemas PACS proporcionará um avanço na busca por imagens armazenadas, antes vinculadas a um identificador do paciente ou de um exame. Com essa nova abordagem essas buscas passam a ser realizadas por meio de comparações diretas entre imagens, possibilitando busca por similaridade e abrindo novos caminhos para utilização do computador e das imagens médicas em atividades de auxílio ao diagnóstico.

Acompanhando a evolução dos projetos e pesquisas que abordam métodos para CBIR, um dos grandes obstáculos encontrados é o que os pesquisadores da área chamam de "gap" ou descontinuidade semântica [Deserno_2008]. Esta descontinuidade consiste na distância entre a similaridade definida pelo médico, obtida a partir de análises de conteúdo de alto nível das imagens, e a similaridade definida pelo computador, obtida pela análise de conteúdo de baixo nível (pixels) das imagens. Pesquisadores procuram diminuir esse problema aplicando contextos bastante específicos para a definição dos métodos de CBIR, o que indiretamente permitiria o uso de conhecimento médico prévio sobre a modalidade ou o contexto das imagens pesquisadas. Porém essa abordagem gera várias restrições de aplicação, por exemplo, o “context gap" descrito em [Deserno_2007], que poderiam fazer com que o sistema 
deixasse de ser interessante para um ambiente PACS real, onde se deseja aplicar recuperação por conteúdo independente do contexto ou modalidade das imagens.

Entretanto, independentemente de se estar abordando um contexto geral ou específico, a representação puramente numérica de uma imagem por meio de um vetor de características, por si só, já caracteriza um gap semântico significativo, uma vez que esta representação está relativamente distante da forma como o radiologista interpreta a imagem. Outro fator importante no aumento desse distanciamento entre a percepção humana e a percepção proporcionada pelo computador é a forma de comparação desses vetores de características que representam as imagens [Felipe_2005a]. Geralmente são utilizadas as métricas $\mathrm{L}_{\mathrm{p}}$ (a família de funções de distância Levenstein) como funções para calcular a distância entre vetores extraídos das imagens. A distância $L_{2}$ ou Euclidiana é uma das mais conhecidas e utilizadas na literatura. Porém, tais funções não conseguem representar diretamente o sentimento que o analista humano tem ao comparar duas imagens [Tversky_1977]. Assim, os resultados de comparações entre imagens deverão ser mais apropriados e efetivos, se for feito uso de funções ajustadas às características mais específicas do domínio de aplicação. Porém, um dos principais desafios na construção de sistemas CBIR é a escolha eficiente das características da imagem que irão compor o vetor de características que a representará e a escolha da função de distância a ser utilizada para calcular a dissimilaridade entre os vetores [Kak_2002].

Outro agravante na procura de soluções para a busca de imagens médicas similares é o de que os próprios médicos divergem quanto à semântica referente à análise das imagens. Há décadas já se tem conhecimento da variabilidade inter e intraobservador na avaliação de exames radiológicos [Garland_1949]. Essa subjetividade no conceito de similaridade reforça o fato de que para a construção de sistemas CBIR eficientes, a percepção visual médica aplicada ao diagnóstico por imagem deve ser considerada como um dos princípios básicos [Brandão_2006]. Fatores humanos podem contribuir efetivamente no processo de recuperação de imagens por conteúdo. A percepção do radiologista deve ter um papel importante no processo de construção desses sistemas, porque ao se dispor de tais regras perceptivas, novas inferências e descobertas, ou novos resultados poderão ser obtidos [Alexandre_2007].

Geralmente, a escolha dos descritores ou características de imagens a serem adotados na recuperação por conteúdo baseia-se em testes empíricos sobre um domínio 
específico, verificando-se quais deles produzem resultados mais satisfatórios. Para que esses descritores e as funções de distância, que definem o grau de similaridade entre as imagens, apresentem resultados realmente próximos à similaridade perceptual humana, características humanas de análise e comparação devem ser consideradas no momento da realização dos testes. Já usados no desenvolvimento de sistemas computadorizados de detecção em imagens médicas, estudos na área de percepção visual médica aplicado ao diagnóstico por imagem também podem ser importantes na construção de sistemas de recuperação por conteúdo [Brandão_2006].

Em um ambiente médico de análise de imagens para o diagnóstico é comum que um grupo de radiologistas se reúna para discutir e avaliar casos em que a imagem de referência gera dúvidas no diagnóstico. A percepção visual é o resultado da interação intrínseca entre as informações adquiridas pela visão e as informações baseadas no conhecimento previamente adquirido. É comprovado que experiências passadas alteram a percepção humana [Alexandre_2007] e por esse motivo, diferentes radiologistas podem apresentar diferentes interpretações para imagens visualmente idênticas.

Ao analisar uma imagem para a escrita do laudo, o radiologista leva em consideração a modalidade da imagem que está sendo analisada, a região anatômica e algumas vezes a hipótese diagnóstica que levou à execução do exame. Portanto, a "situação diagnóstica" de análise da imagem para confecção do laudo é definida pelo conjunto de parâmetros ditados pelo exame em que o paciente foi submetido. Essa situação diagnóstica é dada pela modalidade da imagem, pela parte do corpo que está sendo analisada e pelo tipo de achado (hipótese diagnóstica) que levou à execução do exame. O fato de em situações diagnósticas distintas os radiologistas considerarem algumas características visuais com maior ou com menor relevância perceptual (ou influência sobre a similaridade) é o que é considerado neste trabalho como divergência perceptual do médico na situação diagnóstica em questão. Desse modo, acredita-se que esses fatores perceptuais podem ser mapeados por (ou traduzidos em) palavras chaves, que são chamadas nesse trabalho de "parâmetros perceptuais", que podem discriminar, antes de uma consulta por similaridade, quais as características visuais devem ser consideradas de maior ou menor influência no processamento da consulta por similaridade. Por exemplo, na situação onde o médico analisa uma mamografia cuja hipótese diagnóstica é nódulo, o parâmetro perceptual utilizado pelo médico é quem ditará a diferença daquela imagem com imagens normais ou imagens contendo nódulo 
maligno ou benigno analisadas anteriormente. Na mente do médico, provavelmente ele usará o parâmetro "contorno" para comparar a imagem referência com as lesões benignas que ele tenha visto em exames anteriores e ao comparar a mesma imagem referência com lesões malignas ele poderá focar mais na "forma" do nódulo, caso fosse treinado desse modo. Outro médico, em contrapartida, analisando as mesmas imagens pode intrinsecamente não ressaltar a "forma", mas sim focar em outras características como "textura" do nódulo ao compará-lo com imagens vistas anteriormente. Por esse motivo, a consideração do "parâmetro perceptual" faz muita diferença quando se trata de comparações entre imagens.

O intuito geral desta pesquisa foi melhorar o resultado de consultas por similaridade em sistemas CBIR, incluindo nas consultas um fator de similaridade que aproxima o médico do contexto de busca desejado, fornecendo ao especialista um conjunto de casos visual e semanticamente semelhantes ao do paciente em questão. Deste modo o médico poderá analisar comparativamente o tipo de tratamento dado a pacientes com casos semelhantes e assim julgar um melhor tratamento para seu paciente. Esse tipo de abordagem nunca substituirá o médico na análise da imagem, mas poderá apontar alternativas para o tratamento do paciente.

Neste projeto foram analisados e propostos pares "extrator de características de imagens médicas e função de distância" que melhor representem cada situação diagnóstica. Esses pares foram unidos a "parâmetros perceptuais" envolvidos no processo médico de análise diagnóstica de imagens, como ilustrado na Figura 2, de modo a permitir a comparação entre imagens mantendo sua semântica natural. Esses parâmetros perceptuais foram levantados com o auxílio de médicos que trabalham em um ambiente real de análise e laudo de exames radiológicos. 


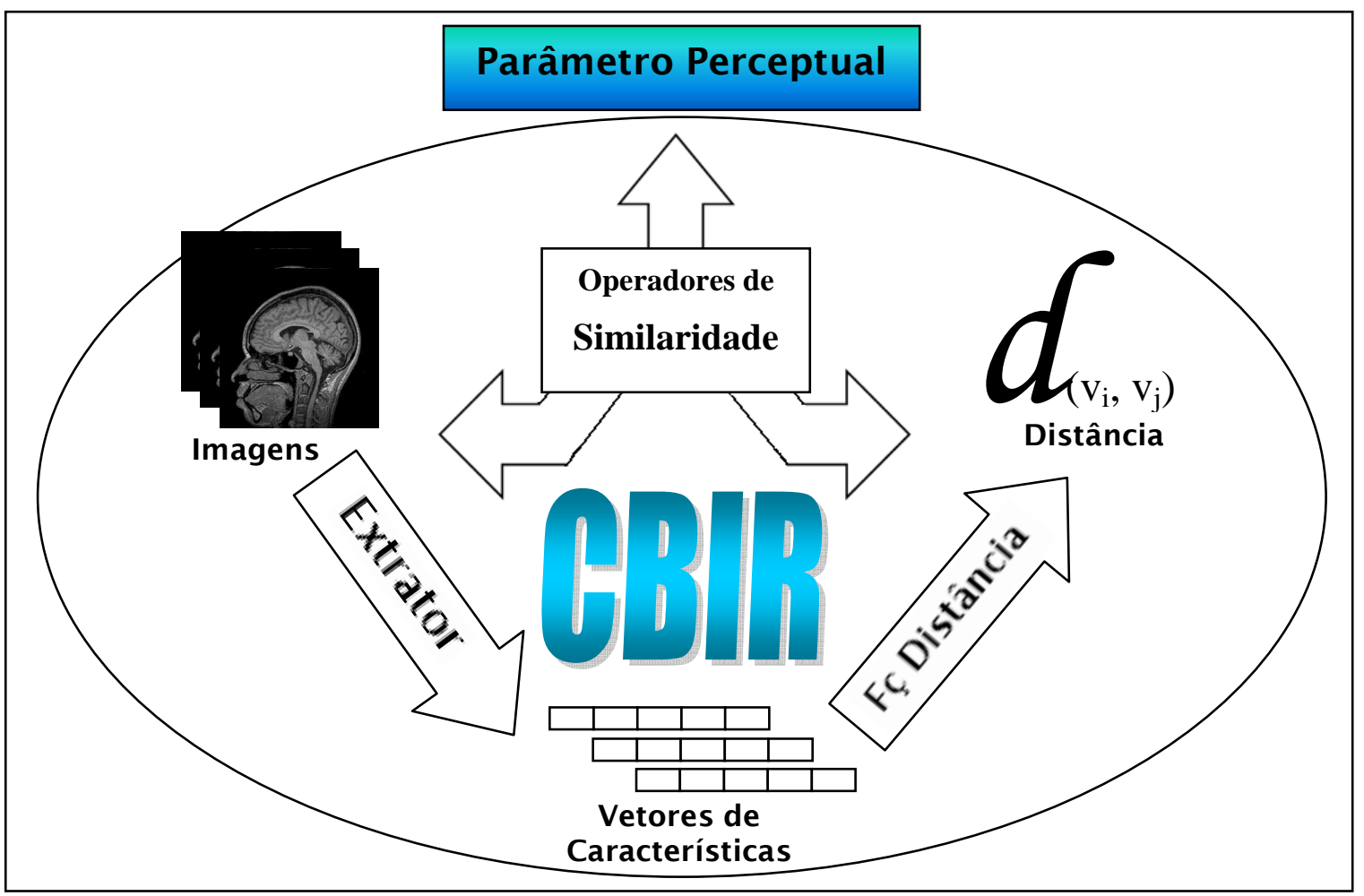

Figura 2: Tríade -- Formação de Operadores de Similaridade

\section{3-Objetivos}

Há na literatura uma grande diversidade de extratores de características desenvolvidos para representar imagens médicas. Cada um deles é utilizado para descrever diferentes percepções visuais como forma, distribuição dos níveis de cinza ou distribuição de texturas. Existe também uma grande diversidade de funções de distância para a realização de consultas por similaridade. A proposta deste trabalho é estudar e analisar extratores de características e funções de distâncias para propor pares que melhor representem cada aspecto perceptual que os radiologistas encontram em ambientes de análise de imagens médicas. Os pares, "extrator de característica" e "função de distância" serão associados aos "parâmetros perceptuais", conforme indicados nos estudos apoiados por especialistas médicos envolvidos nesse processo.

Com essas tríades (extrator, função de distância e parâmetro perceptual) deverão ser construídos operadores para efetuar as consultas por similaridade. Assim, será possível responder a consultas utilizando diferentes características e funções de distância, de modo a retornar o que é mais próximo do esperado pelo humano, de maneira transparente e sem que o usuário precise determinar qual extrator ou função de distância deva ser utilizada. É importante ressaltar que o especialista médico não 
deve/precisa deter conhecimentos específicos de computação para conseguir resultados às consultas por similaridade que atendam a sua percepção de semelhança. Nesse caso, os parâmetros das consultas (extrator e função de distância) serão escolhidos automaticamente pelo sistema proposto e, caso o médico queira personalizar a consulta especificando um parâmetro de entrada, esse será o "parâmetro perceptual" (já de conhecimento habitual dos médicos). Esse parâmetro perceptual estará atrelado a um extrator e a uma função de distância específica (devido aos operadores implantados no sistema), criando-se assim um modo de representar mais apropriadamente o sentimento do analista humano ao comparar as imagens em questão. Tal representação tem um grande potencial para auxiliar e suportar o diagnóstico médico por imagens.

\section{4 - Organização do Trabalho}

Esta dissertação de mestrado apresenta a seguinte organização:

No presente capítulo foram apresentadas as considerações iniciais, a motivação para o desenvolvimento do trabalho, os objetivos de seu desenvolvimento e a organização desse documento.

No capítulo 2 são introduzidos os conceitos relacionados ao trabalho, consultas por similaridade em bases de dados multimídia, utilização de espaços métricos para abstrair os domínios de dados complexos e suas aplicações em sistemas de bases de dados e imagens com suporte a busca por conteúdo, processamento e análise de imagens para extração de características e adequação de sistemas CBIR para inclusão em ambientes reais de diagnóstico por imagem.

No capítulo 3 é definido o uso de parâmetros perceptuais, contribuição inovadora do trabalho, e apresentada a metodologia de inclusão da percepção médica nas consultas por similaridade;

No capítulo 4 são descritos os métodos de extração de características desenvolvidos baseados nos parâmetros perceptuais levantados e descritos no capítulo anterior.

No capítulo 5 são apresentados os resultados dos experimentos realizados, que mostram o desempenho da inclusão dos parâmetros perceptuais nas consultas por similaridade. 
No capítulo 6 são discutidas as conclusões finais, as contribuições desse trabalho bem como sugestões para a continuação em trabalhos futuros. 


\section{Recuperação de Imagens Médicas por Conteúdo}

\section{1 - Considerações Iniciais}

Sistemas baseados em CBIR (Content-based Image Retrieval) são desenvolvidos para permitir recuperar informações em bases de imagens sem a utilização de chaves de busca tradicionais, que são baseadas em dados numéricos ou textuais, como o nome do paciente ou a data do exame. Nesses sistemas as chaves de busca são as próprias imagens, representadas por seu conteúdo intrínseco. Esse termo "conteúdo intrínseco" diz respeito às características visuais próprias das imagens, tais como cor, textura, forma, posição espacial de elementos ou de regiões. Essas características, quando extraídas das imagens armazenadas se tornam informações que podem servir como base para cálculos envolvendo similaridade [Lew_2006]. A extração dessas características é realizada por técnicas automáticas de processamento de imagens seguida de uma análise detalhada de seus níveis de cinza (características de baixo nível), onde extratores de características calculam valores numéricos específicos que descrevem as características visuais intrínsecas à imagem.

\section{2 - Processamento de Imagens}

Imagens digitais são armazenadas no computador como uma matriz bidimensional $\mathrm{I}(\mathrm{m}, \mathrm{n})$. Cada elemento $(\mathrm{m}, \mathrm{n})$ da matriz corresponde a um pixel da imagem cujo valor de intensidade está armazenado nesse elemento. Para imagens monocromáticas a intensidade de cada pixel é representada por valores discretos de níveis de cinza, normalmente 256 (8 bits) para armazenamento digital. A grande quantidade de pixels necessários para representar uma imagem torna praticamente inviável a comparação de imagens baseada diretamente nos valores de intensidade de cada pixel. Por esse motivo, 
buscam-se formas de representação que sejam mais práticas e capazes de manter as características originais da imagem.

O processamento das imagens pode ser parte essencial no processo de recuperação por conteúdo, pois é desse processamento que características visuais de interesse podem ser evidenciadas para assim melhorar a qualidade das características que representem essas imagens.

Nesse trabalho, um método espacial de processamento de imagens é muito citado nos experimentos por ser bastante utilizado por médicos na visualização de imagens médicas no padrão DICOM. Os médicos o conhecem como "janelamento" da imagem (será mantida essa denominação ao método). Porém, ele também é conhecido como "realce por alargamento de contraste". É um método de processamento espacial ponto-a-ponto onde se utiliza uma função $(\mathrm{T})$ de transformação de níveis de cinza (também chamada mapeamento e apresentada na Figura 3) do tipo:

$$
\mathrm{g}(\mathrm{x}, \mathrm{y})=\mathrm{T}(\mathrm{f}(\mathrm{x}, \mathrm{y}))
$$

para se obter um contraste maior entre determinados valores de níveis de cinza.

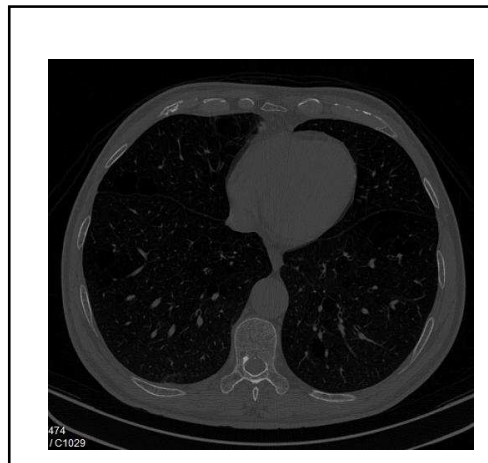

a) Imagem Original - $\mathbf{f}(x, y)$

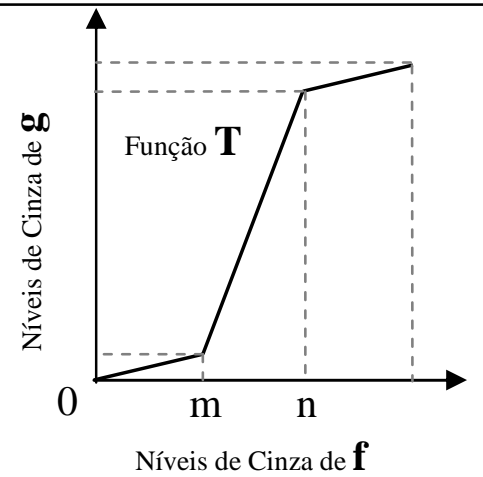

b) Função de Janelamento - T

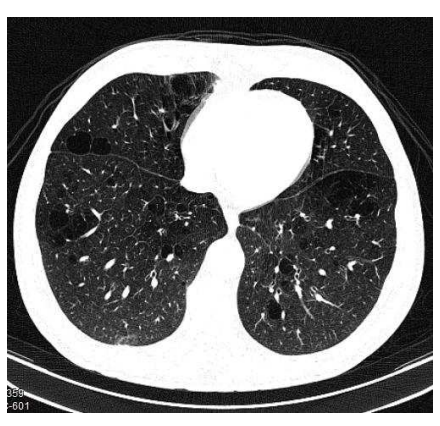

c) Imagem Janelada $-\mathbf{g}(\mathrm{x}, \mathrm{y})$

Figura 3 - Exemplo da operação de Janelamento

O gráfico apresentado acima representa a função de transformação $\mathrm{T}$ e o efeito que ela produz. A partir de uma imagem $\mathrm{f}(\mathrm{x}, \mathrm{y})$ é construída uma imagem processada $\mathrm{g}(\mathrm{x}, \mathrm{y})$ de contraste diferente da original. Esse efeito ocorre através do escurecimento dos níveis abaixo de $m$ e do clareamento dos níveis acima de $n$. Dessa forma, os valores abaixo de $m$ e acima de $n$ são comprimidos pela função de transformação em uma estreita faixa de cinza, enquanto os valores situados entre $m$ e $n$ (chamados de "janela de ampliação de contraste") são expandidos. O tamanho e centro dessa janela de contraste podem variar de acordo com a informação que se deseja evidenciar na imagem. $O$ centro do janelamento (representado pela letra “C”): $C=(m+n) / 2$, e seu tamanho 
(representado pela letra "W"): $W=n-m$, são os parâmetros determinantes desse realce por alargamento de contraste.

O processamento bem sucedido de uma imagem pode enfatizar características peculiares a ela, fazendo com que os atributos extraídos representem seu conteúdo de modo eficiente. São essas características numéricas, que descrevem as características intrínsecas das imagens, que serão utilizadas para indexação e comparações entre imagens. O processamento prévio da imagem é alternativo e depende do contexto e das características intrínsecas que serão extraídas. Como parte desse processamento pode-se destacar não só o realce, mas também a aplicação de filtros, a compressão, a reconstrução tridimensional ou aplicação de transformadas como Wavelets ou Fourier [Gonzalez_2000]. Todos esses tipos de processamento visam à obtenção de condições apropriadas para uma aplicação específica, podendo assim extrair características como cor, forma ou distribuição de texturas, mais apropriadas ao contexto.

\section{3 - Análise de Imagens e Extração de Características}

Na Figura 4 é representado o processo geral de extração de características de uma dada imagem. Nela percebemos que o processo real de extração depende de algoritmos de análise de imagens. Consideramos algoritmos de análise de imagens aqueles que fazem segmentação, matching, detecção de alterações em sequências, reconhecimento e classificação de texturas, reconhecimento e classificação de formas e contornos, estimativas de área, volume ou medição de parâmetros anatômicos e fisiológicos, no caso de imagens médicas, como, por exemplo, Tomografia Computadorizada (CT) ou Ressonância Magnética (RM). Todas essas possíveis análises podem ser utilizadas para retirada de valores numéricos que representem o conteúdo visual da imagem. Contudo, devido à grande amplitude de possibilidades de processamentos e análises, a maioria das pesquisas desenvolvidas tenta concentrar-se fortemente em contextos específicos de imagens, com objetivos clínicos bem definidos [Felipe_2005c]. 


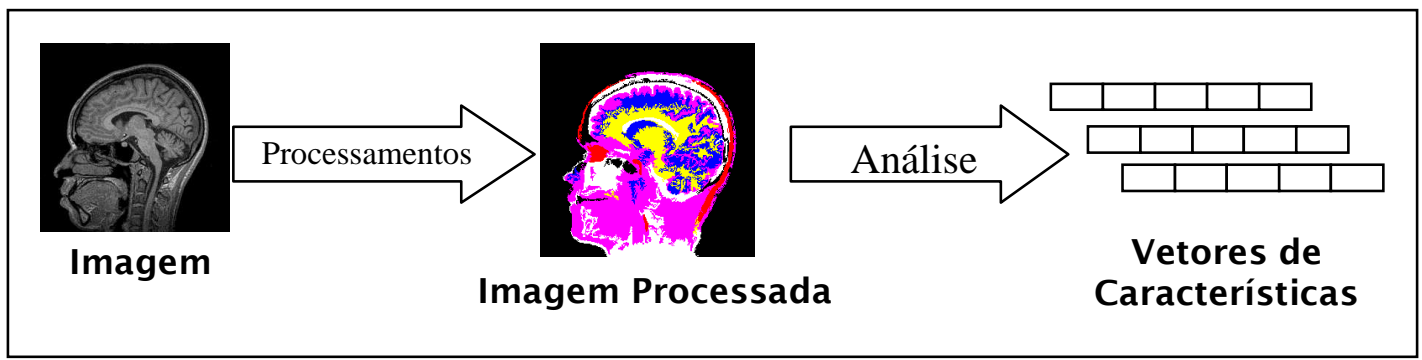

Figura 4: Processo Geral de Extração de Características

Os atributos utilizados para representar uma imagem são, usualmente, oriundos do tratamento de seus descritores. Esses descritores são estímulos visuais que podem ser modelados numericamente permitindo a representação e manipulação computacional da imagem. Os descritores para os quais as comunidades de Processamento de Imagens e Visão Computacional já conseguiram desenvolver modelos com um relativo grau de maturidade são: cor, textura e forma [Aslandogan_1999].

\section{Cor}

Cor é uma propriedade relacionada a ondas eletromagnéticas com diferentes comprimentos dentro de um espectro visível. Essas ondas, emitidas ou refletida por diferentes objetos, são detectadas pelo olho humano como sendo uma combinação de cores primárias. No caso de imagens monocromáticas, foco desse trabalho, a cor é representada pela variação da intensidade da luz emitida ou refletida pelo objeto. Cada nível de intensidade é detectado pelo olho humano como sendo uma tonalidade diferente entre o preto (ausência de luz) e o branco (luminância total).

A estrutura mais comum utilizada para representação da distribuição das cores de uma imagem é o Histograma de Intensidades. Esse histograma quantifica a freqüência de ocorrência dos valores de luminância apresentada pelos pixels da imagem. Ao representar uma imagem, esse histograma é invariante à rotação, translação e escala (se seus valores forem normalizados). Porém, um mesmo histograma pode representar imagens visivelmente distintas. Isso acontece pelo fato desse método estatístico não apresentar informações sobre a distribuição espacial das cores, e por isso, quando duas imagens distintas apresentam a mesma freqüência de intensidades de pixels, seus histogramas serão considerados idênticos. Outro ponto a ser considerado diz respeito à elevada dimensão dos vetores de características gerados, visto que na maioria das representações por histograma são considerados 256 níveis de cinza Na Figura 5 é apresentada graficamente uma representação da imagem feita por seu histograma. 


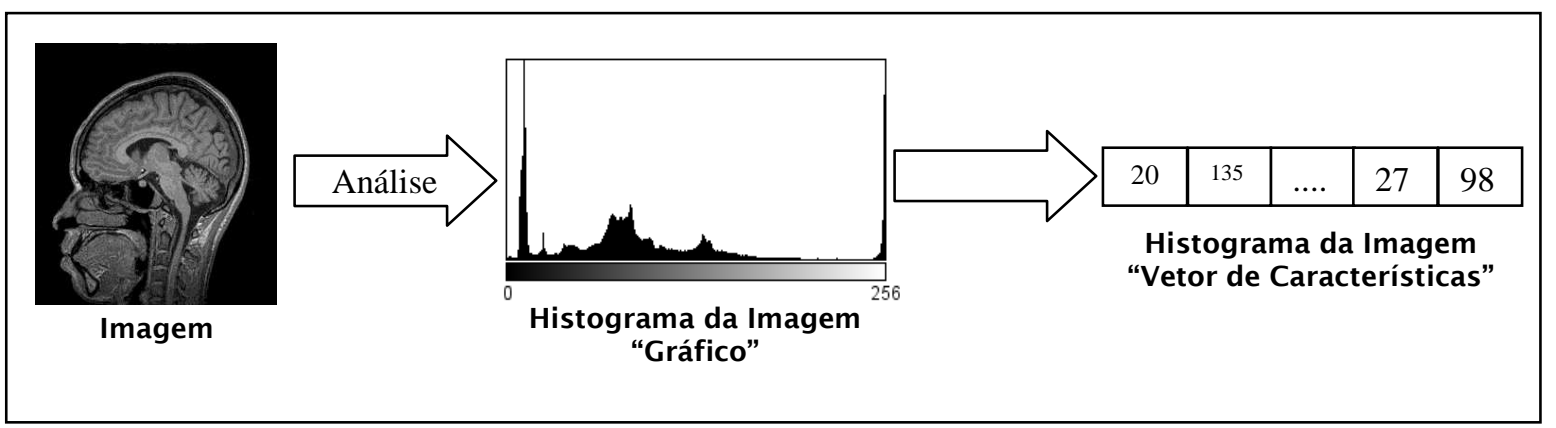

Figura 5: Representação da Imagem por Histograma de Intensidade de pixels

$\mathrm{Na}$ literatura, muitos trabalhos abordam essa estrutura de histograma e suas variações em sistemas CBIR, por exemplo: em [Bugatti_2008a] são selecionados os bins mais relevantes considerando sua entropia, em [Felipe_2006b] busca-se trabalhar os pontos de saliência do histograma para o caracterizá-lo, e em [Traina_2003] os histogramas são sumarizados através de suas aproximações lineares-por-parte.

Variações dessa idéia de representação de imagens através de padrões de cor por freqüência de ocorrências de valores de níveis de luminância podem ser encontrados também em [Hadjidemetriou_2004] e [Bueno_2002]. Nesse último foi proposto o Histograma Métrico. Tal método comparativo conserva a curva original do histograma tradicional, mantendo a informação deste, porém reduzindo o número de bins do histograma. Essa redução se dá pelo agrupamento de um conjunto de bins, formando-se um bucket que passa a representar a forma original do conjunto dos bins substituídos. Essa abordagem otimiza o custo computacional da operação de comparação entre duas imagens. Os histogramas métricos, por serem dependentes da forma do histograma original, apresentam um número de buckets variável, problema que o impede de ser comparado pelas funções de distâncias tradicionais. Portanto, [Traina_2002] desenvolveu uma função chamada Distância Métrica que se baseia no cálculo de diferença de áreas entre dois histogramas. Assim, a diferença entre dois histogramas métricos pode ser determinada pelo grau de sobreposição de suas áreas de distribuições de freqüência.

\section{Textura}

Apesar de ainda não se ter uma definição formal para textura, ela é reconhecida pelo sistema visual humano através de características tais como "fina" ou "grosseira", "lisa" ou "áspera", "homogênea" ou "não homogênea", entre outras [Theodoridis_1999]. A região de uma imagem tem sua textura determinada pela forma 
como os níveis de cinza estão distribuídos nos seus pixels. Para esse tipo de análise são considerados a distribuição dos níveis de cinza e o inter-relacionamento entre eles.

Existe na literatura uma grande variedade de técnicas para se extrair características de texturas de imagens [Gonzalez_2000]. Uma abordagem que tem sido amplamente utilizada por gerar resultados satisfatórios tem sido a análise realizada a partir da Matriz de Co-ocorrência da imagem [Felipe_2003]. Nessa matriz os índices das linhas e colunas representam os diferentes valores de níveis de cinza e o valor armazenado em cada um de seus elementos é a freqüência com que esses pares de níveis de cinza ocorrem dois a dois em uma certa direção a uma determinada distância de vizinhança. Usualmente as direções tratadas são as de $0^{\circ}, 45^{\circ}, 90^{\circ}$ e $135^{\circ}$ e as distâncias variam de 1 a 10 pixels. Para cada dupla (direção e distância) uma matriz de coocorrência é gerada. Essa representação se resume em analisar um conjunto de matrizes de co-ocorrência para se caracterizar a textura à qual elas se referem, utilizando-se um ou mais descritores. Um conjunto de 14 descritores é proposto em [Haralick_1973]. Na Tabela 1 são apresentados os mais utilizados [Felipe_2005a]. P(i,j) é o valor do elemento (i,j) na matriz de co-ocorrência.

Tabela 1: Alguns descritores propostos por Haralick

\begin{tabular}{|c|c|c|}
\hline Descritor & Equação & Significado \\
\hline Variância & $\sum_{i} \sum_{j}(i-j)^{2} P(i, j)$ & Nível de contraste da Imagem \\
\hline Entropia & $\sum_{i} \sum_{j} P(i, j) \log P(i, j)$ & Suavidade da Imagem \\
\hline Energia & $\sum_{i} \sum_{j} P^{2}(i, j)$ & Uniformidade da Imagem \\
\hline Homogeneidade & $\sum_{i} \sum_{j} P(i, j) /(1+|i-j|)$ & $\begin{array}{l}\text { Homogeneidade da distribuição } \\
\text { dos pixels }\end{array}$ \\
\hline $\begin{array}{l}\text { Momentos de } \\
3^{\text {a } \text { Ordem }}\end{array}$ & $\sum_{i} \sum_{j}(i-j)^{3} P(i, j)$ & Nível de distorção da Imagem \\
\hline Variância Inversa & $\sum_{i} \sum_{j} P(i, j) /(i-j)^{2}$ & Nível inverso de contraste \\
\hline
\end{tabular}

$\mathrm{Na}$ literatura encontram-se vários trabalhos que utilizam características de textura para caracterização de regiões de imagens médicas, como por exemplo, mama [Pereira-Jr._2007] [Felipe_2003], osso [Rubin_2003] e encéfalo [Balan_2005]. As 
características de textura tem demonstrado muita eficiência na caracterização de imagens não só no contexto médico, mas também na recuperação de imagens diversas [Huang_2003] [Çarkacioglu_2003]. Nos experimentos realizados no presente trabalho serão utilizadas a abordagem de textura descrita no parágrafo anterior, utilizando quatro dos descritores de Haralick, são eles: Homogeneidade, Energia, Contraste(Variância) e Correlação.

Outro método utilizado para caracterização de texturas de imagens é a extração utilizando-se Filtros de Gabor. Nessa abordagem, as funções utilizadas nos filtros de Gabor, senóides complexas e bidimensionais, têm como objetivo extrair atributos para caracterizar diferentes tipos de texturas presentes na imagem. Essas texturas são descritas pela freqüência e orientação das funções senoidais que compõem as respostas do conjunto de filtros aplicados à imagem. Esses filtros permitem a manipulação de parâmetros como frequiência, orientação, excentricidade e simetria que podem ser utilizados como características de representação de padrões de textura na imagem. Uma aplicação dessa técnica para caracterizar textura de imagens e utilizar as características na recuperação por conteúdo pode ser vista em [Park_2002].

\section{Forma}

Representar ou definir formas de objetos contidos em uma imagem é uma tarefa bastante difícil. Embora haja muitos métodos práticos de descrição de forma, não há uma metodologia aceita de maneira unânime. O que geralmente se faz em algoritmos de caracterização de forma é processar a imagem com um algoritmo de segmentação, isolando o objeto de interesse, fazendo em seguida a extração de características do contorno do objeto isolado [Costa_2001].

Outra maneira de se extrair características de forma é utilizando a Transformada Discreta de Fourier. Nessa abordagem, cada ponto pertencente ao contorno do objeto é transformado em um coeficiente (número complexo) no espaço da freqüência, esse conjunto de coeficientes (ou parte dele), também conhecido como descritores de Fourier do contorno, pode ser utilizado para representar o objeto original [Felipe_2005b]. Ainda na caracterização de forma, outra técnica bastante utilizada é a chamada Cadeia de Códigos, onde o contorno do objeto é aproximado por uma seqüência de segmentos de reta conectados, dos quais são conhecidos o comprimento e 
a direção. Nesse modelo a frequiência direcional e a curvatura são exemplos de métricas que podem ser utilizadas para representar a forma do objeto [Theodoridis_1999].

A utilização de Momentos Geométricos para representação de forma também tem se mostrado bastante eficiente. Um Momento Geométrico é definido da seguinte maneira:

$$
m_{p q}=\int_{-\infty}^{+\infty} \int_{-\infty}^{+\infty} x^{p} y^{q} I(x, y) d x d y
$$

Onde: $\mathrm{I}(\mathrm{x}, \mathrm{y})$ representa os valores de intensidade do pixel na posição $(\mathrm{x}, \mathrm{y})$ e os valores $p$ e $q$ somados definem a ordem do momento.

A partir de seus valores é possível se reconstruir a imagem original, isso porque cada coeficiente de momento agrega certa quantidade da informação da imagem. Eles apresentam uma ótima capacidade de representar formas complexas, compostas de várias regiões disjuntas. Alguns momentos importantes como Momentos Centrais, Momentos de $\mathrm{Hu}$ e Momentos de Zernike podem ser vistos com mais detalhes em [Kim_2000] [Sonka_1999]. Alguns dos descritores de forma citados acima e outros também utilizados em CBIR foram comparados entre si considerando-se parâmetros como robustez, complexidade computacional e, principalmente, a similaridade perceptual [Zhang_2001].

Vários trabalhos buscam melhores representações e caracterização de forma para otimização de sistemas CBIR [Felipe_2006a] [Felipe_2005b] [Traina_2004] [Torres_2003]. Nesse trabalho, embora haja muitos métodos práticos de descrição de forma, foi utilizado um algoritmo de segmentação, isolando o objeto de interesse (no caso o pulmão), fazendo em seguida a extração de características como: Área quantidade de pixels da região segmentada, Perímetro - quantidade de pixels da borda do objeto segmentado, Extensão - área do objeto segmentado dividida pela área do menor retângulo envolvente, Solidez - área do objeto segmentado dividida pela área do menor polígono envolvente, Excentricidade, Tamanho do Maior e do Menor eixo da elipse correspondente ao objeto, Diâmetro do circulo equivalente ao objeto segmentado (círculo de mesma área). Todas as quantidades de tamanho e área expressa em quantidade de pixels.

Um método de representação de características de cor, textura e forma pode ser encontrado em [Balan_2005]. Esse método utiliza a combinação do algoritmo EM (Expectation and Maximization) para realizar o ajuste de um Modelo de Misturas 
Gaussiano (Gaussian Mixture Model) no histograma da imagem com um classificador baseado nos Campos Aleatórios de Markov (Markov Randon Fields). Implementa uma variação do método EM/MPM, introduzindo uma aplicação da técnica Annealing, a qual realiza um aumento gradativo do valor do parâmetro de interação espacial do modelo de Markov durante o processo de segmentação. Essa segmentação é baseada na diferença de textura das classes que compõem a imagem. Após a segmentação, são computadas cinco medidas para representação de cada região, são elas: dimensão fractal, centro de massa ou centróide, massa (ou tamanho), nível de cinza médio e o coeficiente linear utilizado para estimar a dimensão fractal. Uma aplicação prática das características extraídas por esse método pode ser encontrada em [Balan_2007] utilizando imagens de RM de cérebro humano.

Como visto nos parágrafos anteriores, há na literatura uma grande diversidade de extratores de características utilizados para representar imagens médicas. Cada um deles é utilizado para descrever diferentes percepções visuais e apresentam diferentes desempenhos nos diferentes domínios de imagens.

\section{4 - Consultas por Similaridade}

Uma das mais novas direções de pesquisa para sistemas gerenciadores de base de dados é lidar com tipo de dados complexos, tais como imagens, sons em seus vários formatos, hipertextos, sequiências de proteínas e impressão digital, entre outros [Traina Jr._2002].

A maioria das características extraídas das imagens pode ser vista como pontos multidimensionais em um espaço $n$-dimensional, como é o caso dos histogramas, momentos invariantes, características de Fourier entre outras ([Traina_2002]). Embora existam métodos de acesso espaciais desenvolvidos para gerenciar dados de alta dimensão, é necessário destacar que em algumas ocasiões não é possível ter todos os vetores de características obtidos com o mesmo número de componentes (dimensões) e, portanto, não é adequado utilizar nenhum método de acesso espacial. Para tais situações foram desenvolvidos os Métodos de Acesso Métricos - MAMs, que organizam um grande conjunto de dados métricos permitindo inserções, exclusões e pesquisas, baseando-se somente nas distâncias entre itens de dados [Traina_2007].

Nos domínios métricos, as únicas informações disponíveis são os objetos e as 
distâncias entre eles. Estruturas de indexação de dados para espaços métricos (que englobam tanto dados espaciais com dimensão definida quanto dados adimensionais) foram propostas para suportar buscas por similaridade. Busca por similaridade é aquela em que se considera quão "próximo" (similares) dois dados são entre si. A similaridade entre os dados é definida através de uma função distância, ou função de "dissimilaridade" $d\left(O_{i}, O_{j}\right)$, que retorna zero se ambos os objetos $O_{i}$ e $O_{j}$ forem idênticos, e um valor positivo que aumenta quanto maior for a distância (ou dissimilaridade) entre os objetos. Uma função de distância métrica é a base na construção de MAMs [Traina_2002], que estão agora atingindo um grau de eficiência bom o bastante para serem utilizados em situações práticas, como é o caso da Slim-tree [Traina Jr._2002]. Os métodos de acesso métricos construídos sobre as características das imagens têm sido utilizados com sucesso para sua indexação e são adequados para responder consultas por similaridade, tais como as consultas k-nearest neighbor query (k-nn), que retornam os $k$ objetos mais próximos do objeto de busca, como por exemplo "encontre as 5 imagens mais semelhantes à imagem de busca dada, considerando seu histograma", e as consultas por abrangência (range-query), que retornam todos os objetos cuja distância ao centro do objeto de busca é menor ou igual ao raio fornecido. Por exemplo, "encontre todas as imagens que se encontram a uma distância de 10 unidades da imagem de busca dada".

A Slim-tree, estrutura utilizada na indexação das imagens desse trabalho, foi proposta por Traina et. al. em [Traina Jr._2000]. Ela é uma estrutura balanceada e dinâmica, que permite inserções posteriores à criação da árvore. Porém, quando comparada com a M-tree nas mesmas condições, sempre a sobrepujou, tanto em termos de número de acessos a disco quanto em termos de número de distâncias calculadas para responder a consultas por abrangência e, portanto, também em tempo total de execução [Traina Jr._2002]. A Slim-tree possui nós internos que são chamados de indexnodes e nós folha que são os leafnodes. A página que armazena cada nó é de tamanho fixo, e cada nó pode armazenar um número máximo de objetos $C$ (Capacidade). 


\section{5 - Funções de Distância}

Utilizando as características extraídas previamente da imagem, um MAM constrói a estrutura de índices calculando as distâncias entre elas, procedimento que deveria corresponder à comparação entre as imagens originais. No entanto, uma função de distância métrica é a base na construção de MAMs. Um sistema que efetue o armazenamento e a manipulação de imagens possui três componentes fundamentais, que atuam de forma integrada: um conjunto de extratores de características (descritores) de imagens, uma estrutura de indexação e uma função de distância (ou um conjunto delas) [Felipe_2005c].

Uma função de distância $d($ ) é chamada de distância métrica quando atende às seguintes propriedades:

1. Simetria: $d\left(O_{1}, O_{2}\right)=d\left(O_{2}, O_{1}\right)$;

2. Não negatividade: $0<d\left(O_{1}, O_{2}\right)<\infty, O_{1} \neq O_{2}$ e $d\left(O_{1}, O_{1}\right)=0$;

3. Desigualdade triangular: $d\left(\mathrm{O}_{1}, \mathrm{O}_{2}\right) \leq d\left(\mathrm{O}_{1}, \mathrm{O}_{3}\right)+d\left(\mathrm{O}_{3}, \mathrm{O}_{2}\right)$. onde, $O_{1} O_{2}$ e $O_{3}$ são objetos pertencentes ao espaço métrico.

Dependendo do domínio de aplicação ao qual pertencem as imagens a serem avaliadas, esse modelo métrico poderá ou não mostrar-se aceitável quanto à adequação dos resultados à expectativa dos especialistas do domínio. Essa adequação é discutida em [Smeulders_2000], onde os autores definem o gap semântico como sendo a ausência de coincidência entre a informação que pode ser extraída dos dados visuais e a interpretação que os mesmos dados recebem de um usuário em um determinado contexto.

Uma forma de buscar a redução do gap é analisar os modelos matemáticos utilizados para cálculos de dissimilaridade. A escolha eficiente da função de distância a ser utilizada para calcular a dissimilaridade entre os vetores de características é importante no desenvolvimento de ferramentas voltadas à recuperação de imagens médicas por consultas por similaridade. Alguns desses modelos matemáticos serão descritos a seguir:

\section{Família de Distâncias Minkowski}

Um conjunto de funções distância bastante utilizado são as funções $L_{p}$, definido como: 


$$
L_{p}\left(\left(a_{1, \ldots, a k}\right),\left(b_{1}, \ldots, b k\right)\right)=\sqrt[p]{\sum_{i=1}^{k}\left|a_{i}-b_{i}\right|^{p}}
$$

Nota-se que de acordo com o valor atribuído a $p$ obtém-se as variações da família Minkowski. A função de distância $L_{l}$, conhecida como City Block ou Manhattan, corresponde ao somatório do módulo das diferenças entre as coordenadas. Seu raio de abrangência, formado pelos pontos eqüidistantes a um dado ponto central, forma um losango com as diagonais paralelas aos eixos das coordenadas. A função de distância $L_{2}$, conhecida como Euclidiana, apresenta uma área de abrangência maior, comparada à $L_{1}$. Seu raio de abrangência forma uma circunferência centrada na coordenada de referência. Outra função conhecida, pertencente à família $L_{p}$, é a $L_{i n f}$, conhecida como Infinity ou Chebychev. Nessa última, o conjunto de pontos eqüidistantes forma um quadrado com os lados paralelos aos eixos das coordenadas, e sua área de abrangência engloba um espaço maior que as $L_{1}$ e $L_{2}$.

Ainda na família Minkowski também se é possível trabalhar com ponderação de atributos. Nessa abordagem, conhecida como Distância Minkowski Ponderada, um vetor de ponderação atribui diferentes pesos para cada atributo. Essa distância ponderada é muito utilizada quando há diferentes influências entre os atributos, considerando-se que determinados atributos podem exercer maior ou menor relevância em relação a outros. Essa função é definida como:

$$
d_{L p}(X, Y)=\sqrt[p]{\sum_{i=1}^{n} w_{i}\left(x_{i}-y_{i}\right)^{p}}
$$

onde $\mathrm{w}_{\mathrm{i}}$ é o vetor de ponderação $\mathrm{w}=\left(\mathrm{w}_{1}, \mathrm{w}_{2}, \ldots, \mathrm{w}_{\mathrm{n}}\right)$.

Além das funções da família Minkowski, bastante utilizadas em consultas por similaridade, existem outras comumente utilizadas, como apresentadas a seguir.

\section{Divergência de Jeffrey}

A Divergência de Jeffrey é uma função simétrica e estável com relação, por exemplo, à variação da divisão dos níveis de um histograma. Sua equação é 
derivada empiricamente de outra função, conhecida como Divergência de Kullback-Leibler. A idéia principal expressa nessa função é mensurar a ineficiência média de se codificar um determinado vetor de características a partir de outro vetor, o de referência. A divergência de Jeffrey é definida como:

$$
d_{J}(X, Y)=\sum_{i=1}^{n}\left(y_{i} \log \frac{y_{i}}{m_{i}}+x_{i} \log \frac{x_{i}}{m_{i}}\right)
$$

onde $\mathrm{m}_{\mathrm{i}}=\left(\mathrm{y}_{\mathrm{i}}+\mathrm{x}_{\mathrm{i}}\right) / 2$.

\section{Valor Estatístico $\chi^{2}$}

A função $\chi^{2}$ denotada por:

$$
d_{\chi^{2}}(X, Y)=\sum_{i=1}^{n} \frac{\left(y_{i}-m_{i}\right)^{2}}{m_{i}}
$$

onde $\mathrm{m}_{\mathrm{i}}=\left(\mathrm{y}_{\mathrm{i}}+\mathrm{x}_{\mathrm{i}}\right) / 2$, valoriza as elevadas discrepâncias existentes entre dois vetores de características e mede o quão improvável é a ocorrência da distribuição do vetor comparado em relação ao referência.

\section{Distância Canberra}

Nessa função de distância, a diferença absoluta dos valores das características de um vetor é dividida pela soma absoluta dos mesmos. Ela é uma função sensível a pequenas variações e tem sido empregada em áreas como bioinformática, para cálculo de diferenças entre sequências de DNA. Sua equação é escrita da seguinte maneira:

$$
d_{C}(X, Y)=\sum_{i=1}^{n} \frac{\left|x_{i}-y_{i}\right|}{\left|x_{i}\right|+\left|y_{i}\right|}
$$

As funções de distâncias apresentadas até aqui, bem como outras consolidadas (por exemplo a Divergência de Kullback-Leibler e Distância Quadrática) podem ser estudadas com maiores detalhes em [Bugatti_2008b]. Esse último trabalho citado traz, inclusive, uma análise da influência e comparação de desempenho entre essas diferentes funções no processamento de consultas por similaridade em recuperação de imagens baseada em conteúdo. 
Em outro trabalho, encontrado em [Vasconcelos_2000], é traçada uma análise das funções matemáticas mais representativas utilizadas para similaridade entre imagens. Nele é feita também uma correlação entre as funções, de acordo com a aplicação mais apropriada de cada uma. Porém, nessa análise hierárquica para escolha da função a ser utilizada, são consideradas apenas as características estatísticas do domínio de aplicação. Logo, essas funções não captam aspectos particulares das imagens em questão. Como se espera que os resultados de comparações entre imagens sejam apropriados e efetivos, deve-se também fazer uso de funções ajustadas às características mais específicas do domínio de aplicação, no nosso caso, as imagens médicas.

$\mathrm{Na}$ literatura encontramos outros trabalhos que desenvolvem funções de distância ajustadas a características específicas desejadas [Felipe_2006b] [Felipe_2006a] [Traina_2003]. Um trabalho interessante, apresentado em [Felipe_2005a], levanta a questão da necessidade de se considerar a percepção humana na interação entre atributos de um vetor. Nesse trabalho são propostas as funções de distância Warp Metric Distance (WMD) e Global Warp Distance (GWD). A WMD é uma adaptação da técnica de comparação de duas séries temporais que possuem desenvolvimentos semelhantes, porém deformadas em relação ao tempo, denominada Dynamic Time Warping (DTW). A GWD realiza o cálculo de coeficientes para características globais como simetria, curtose e picos utilizando a WMD ponderada com os respectivos coeficientes calculados. Ainda nesse trabalho, uma nova família de distâncias perceptuais, denominada AID (Attribute Interaction Distances), é proposta e discutida. A família de distâncias $A I D$ leva em consideração os efeitos da interação entre os vetores de características extraídos das respectivas imagens, trabalhando com o conceito de interação fraca ou forte entre dois atributos, sendo assim propostas duas funções de distância a Weak Attribute Interaction Distance (WAID) e a Strong Attribute Interaction Distances (SAID).

Pode-se assim ver que há na literatura uma variedade de funções de distância propostas.Porém, apesar dessa variedade de funções de distância propostas, nenhuma demonstra preocupação real com a integração de características e o mapeamento dessas com o perfil de cada usuário do sistema. 


\section{6 - Avaliação de Eficiência}

O propósito de sistemas CBIR é possibilitar a recuperação de imagens similares tendo uma imagem exemplo como centro da consulta. A eficiência desses sistemas deve ser medida considerando o quão realmente semelhante são as imagens retornadas pelo sistema. Essa avaliação é muito subjetiva, sendo altamente dependente do conceito de similaridade do observador que avalia o resultado. Porém, para conseguir uma aproximação na avaliação desses sistemas, normalmente se constroem bases de imagens classificadas de acordo com um determinado padrão de semelhança. Com essa base classificada em mãos, os métodos de avaliação de eficiência de sistemas CBIR tomam como semelhantes imagens que apresentam a mesma classificação. Por levar em consideração apenas um padrão de semelhança (o que o faz muito próximo de um método de avaliação de classificação), esse método não seria o melhor para avaliar eficiência em cálculos de similaridade. Porém, atualmente é o que mais se aproxima da realidade, sendo o mais utilizado entre os pesquisadores da área.

Assim como as curvas ROC (Receiver Operating Characteristic), que medem a sensibilidade e especificidade da classificação dos dados, são usadas para avaliar desempenho de sistemas de auxílio ao diagnóstico [Metz_2000], um dos métodos mais utilizados para a avaliação de eficiência de sistemas de busca é o gráfico de precisão e revocação [Alto_2005] [Müller_2004a].

Considere que para uma determinada consulta por similaridade exista um conjunto $\mathrm{R}$ de imagens relevantes. $\mathrm{O}$ sistema de busca utilizado processa a consulta e retorna um conjunto A de objetos (objetos recuperados). A intersecção dos dois conjuntos citados $(\mathrm{R} \cap \mathrm{A})$ compreende os elementos relevantes que foram recuperados com a consulta realizada. Tendo em mente a disposição desses conjuntos, como apresentados na Figura 6, as medidas de precisão e revocação são definidas da seguinte maneira:

- Revocação é a porção do conjunto de elementos relevantes (R) que foram recuperados na consulta dentre todos os relevantes recuperados $(\mathrm{R} \cap \mathrm{A})$ :

$$
\text { Revocação }=(\mathrm{R} \cap \mathrm{A}) / \mathrm{R}
$$

- Precisão é a porção do conjunto de elementos relevantes recuperados $(\mathrm{R} \cap \mathrm{A})$ dentre todos os que foram recuperados na consulta (A):

$$
\text { Precisão }=(\mathrm{R} \cap \mathrm{A}) / \mathrm{A}
$$




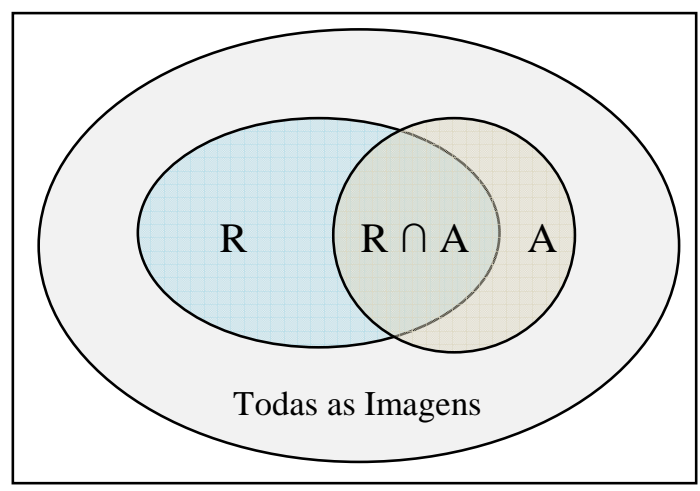

Figura 6: Representação dos Conjuntos de Imagens Relevantes (R) e Recuperadas (A) para definição de valores de precisão $((\mathrm{R} \cap \mathrm{A}) / \mathrm{A})$ e Revocação $((\mathrm{R} \cap \mathrm{A}) / \mathrm{R})$

Para uma avaliação confiável dos resultados obtidos por um determinado sistema de recuperação de imagens similares, deve-se estabelecer um conjunto de dados apropriado para avaliação e assim realizar diversas operações de consultas atribuindo a cada consulta, um elemento diferente da base como centro da consultas. Para isso, é preciso construir um gráfico de precisão vs. revocação, como apresentado na Figura 7, onde cada ponto do gráfico representa a média aritmética dos desempenhos das diversas consultas realizadas.

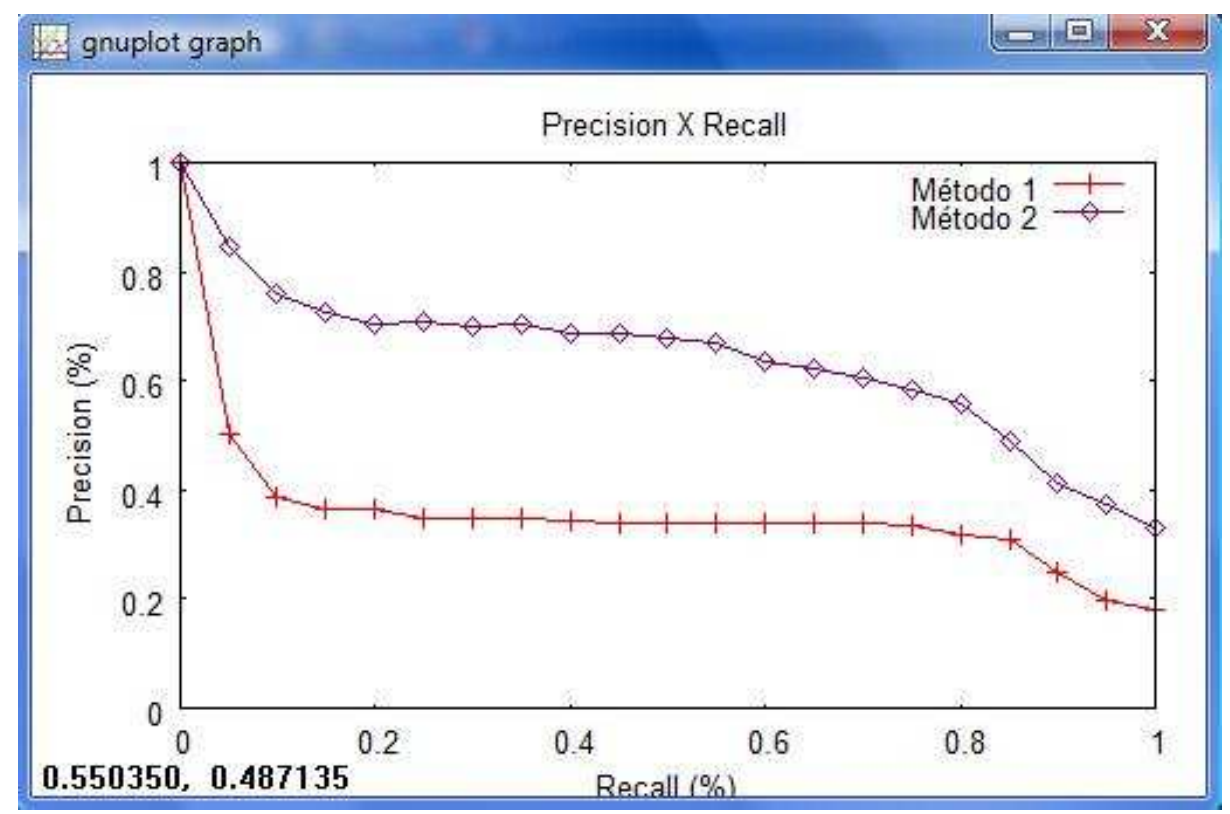

Figura 7 - Exemplo de Gráfico de Precisão vs. Revocação

Com o gráfico em mãos, a avaliação do desempenho do sistema passa a ser realizada de maneira prática, verificando-se o formato e altura da curva obtida. Assim, quanto mais próxima do topo do gráfico a curva estiver, melhor será o resultado da operação de busca. No exemplo apresentado na figura acima, o gráfico mostra com maior clareza o quanto o Método 2 apresentou melhor desempenho que o Método 1. 
Nesse trabalho foram utilizadas curvas de precisão vs. revocação para avaliar o desempenho das características extraídas considerando a percepção do médico nas consultas por similaridade. Assim, dada a base de imagens para teste, para cada uma das classes definidas, o gráfico foi construído baseado na média aritmética dos desempenhos obtidos pelo sistema nas várias consultas realizadas (utilizando todos os elementos da classe como centro de consulta).

\section{7 - CBIR em um Ambiente Real}

Em um ambiente médico de análise de imagens para o diagnóstico é comum que um grupo de radiologistas se reúna para discutir e avaliar casos em que a imagem de referência gera dúvidas no diagnóstico. A utilização de uma segunda opinião é importante para um diagnóstico mais preciso [Pereira-Jr._2007]. Nesses casos de análise de imagens, a percepção visual é o resultado da interação intrínseca entre as informações adquiridas pela visão, as informações baseadas no conhecimento previamente adquirido pelo médico e ainda nas informações de outros radiologistas como segunda opinião. É nesse último aspecto da formação da percepção visual que entraria a ferramenta CBIR, ou seja, na obtenção de outras informações sobre imagens semelhantes à de referência para serem utilizadas como auxílio à tomada de decisão.

A subjetividade no padrão de semelhança entre imagens têm tornado o ambiente de análise de imagens médicas um campo promissor para construção de ferramentas de auxílio ao diagnóstico. Atualmente, ferramentas de ajuda na detecção de estruturas anormais nas imagens e de extração de características numéricas já têm sido bastante adotadas nesse meio. As estações de trabalho ("workstations") têm sido equipadas de computadores e monitores adequadas à visualização de imagens médicas. Essas estações são interligadas ao RIS (Radiology Informations System) e ao Servidor DICOM do Sistema PACS (Picture Archiving and Communication System) permitindo assim o acesso a dados do paciente, à confecção de laudos eletrônicos e a utilização de ferramentas de auxílio ao diagnóstico. Na Figura 8 é ilustrado o fluxo de informações e imagens em um ambiente PACS contendo um sistema CBIR integrado e dispondo de dispositivos para aquisição de imagens, dispositivos de saída de imagens para impressão, distribuição e armazenamento de imagens digital, um servidor DICOM para manutenção das imagens e uma integração com os sistemas HIS (Hospital Informations 
System) e RIS para disponibilidade de informações textuais do paciente e dos pedidos de exames radiológicos. Essas facilidades tecnológicas e a necessidade dos médicos de uma ferramenta eficaz na recuperação eficiente de imagens armazenadas em grandes bases têm aberto caminho para construção de sistemas de recuperação baseados em conteúdo.

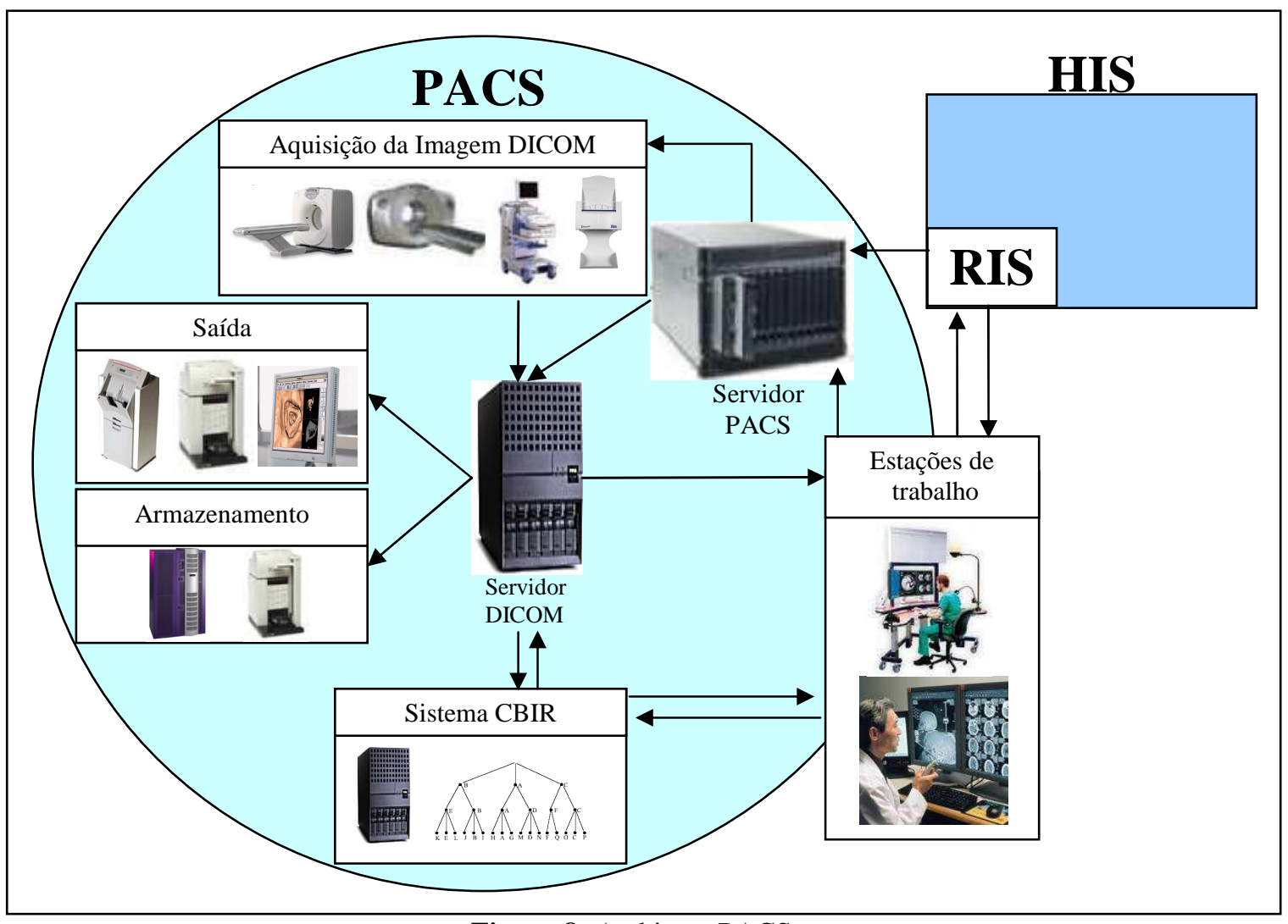

Figura 8: Ambiente PACS

Há na literatura muitos projetos conhecidos de construção de sistemas CBIR. Alguns desses explicam qual a metodologia para a extração de características e qual a métrica de comparação utilizada, outros citam somente superficialmente quais descritores foram utilizados e os benefícios que trouxeram. O SMIRE (Similar Medical Image Retrieval Engine), descrito em [Cheng_2005], apresentou ótimos resultados utilizando coeficientes wavelets e histogramas de níveis de cinza. Uma métrica própria de comparação entre as 322 características de cada imagem foi proposta como parte do método utilizado e a implementação de realimentação manual ajudou na obtenção de melhores resultados. Já o sistema FIRE (Flexible Image Retrieval Engine) [Deselaers_2006] utiliza características de textura e cor associadas, extraídas através de histogramas de coocorrência. A métrica utilizada para comparação é a distância Euclidiana e a Divergência de Jeffrey, permitindo também o uso de Realimentação de 
Relevância. Cada um dos sistemas foi testado com imagens específicas, de um domínio específico, o que dificulta a avaliação e comparação entre eles. Para possibilitar uma avaliação justa e comparações entre diferentes sistemas foi proposta a construção de um conjunto base de imagens referências para servirem como plataforma de testes de avaliação [Müller_2004b]. Também tem surgido na literatura conceitos genéricos para implementação de CBIR [Guld_2007] e novos parâmetros de comparação entre sistemas [Deserno_2007] na tentativa de padronizar e validar a construção de ferramentas e Sistemas CBIR.

Diversos trabalhos nessa linha de pesquisa têm sido desenvolvidos no sentido de agregar funcionalidades de CBIR aos PACS [Fischer_2008] [Tan_2006] [AzevedoMarques_2005b] [Morioka_2005]. Todos esses trabalhos de agregação têm por objetivo fazer com que os PACS dêem suporte a uma recuperação eficiente de imagens, de forma totalmente digital e automática. Porém, conseguir essa recuperação eficiente no domínio médico é um trabalho bastante árduo. Isso porque características importantes das imagens médicas encontram-se normalmente em regiões localizadas e não na imagem como um todo. Essa dificuldade tem feito com que os sistemas de consulta sejam voltados para áreas específicas, como por exemplo, técnicas de análise de nódulos em mamografias, e que também esses dependam de algum tipo de anotação ou interação com o usuário.

Em [Rosa_2002] é apresentado um sistema CBIR, denominado SRIS-HC (Sistema de Recuperação de Imagens Similares do Hospital das Clínicas). Nesse sistema duas técnicas de extração de características de imagens foram adotadas, são elas: o histograma tradicional e o histograma métrico, descrito com detalhes em [Traina_2003]. Com esses descritores, características da distribuição dos níveis de cinza (intensidade dos pixels) foram utilizadas como característica de comparação. A intersecção entre os histogramas foi utilizada como medida de dissimilaridade.

Outra proposta de integração de CBIR em PACS é apresentada em [Lehmann_2006, Lehmann_2003], onde o sistema IRMA (Image Retrieval in Medical Applications), aperfeiçoado recentemente [Lehmann_2006], traz também a possibilidade de se classificar imagens de acordo com a modalidade, orientação e região do corpo ou sistema biológico através de consultas aos vizinhos mais próximos. Em [Tan_2006] é apresentado um sistema CBIR integrado ao PACS e ao RIS. Nele são utilizadas características locais de textura em imagens de pulmão originadas de CT de 
alta-resolução. Aqui, estudos de casos armazenados no RIS são recuperados utilizando as imagens do PACS como objetos de consulta.

Todos esses trabalhos de integração de funcionalidade CBIR em sistemas PACS têm uma visão promissora no campo do diagnóstico auxiliado por computador, no incentivo à prática da medicina baseada em casos na radiologia e no próprio ensino e treinamento de novos médicos radiologistas [Datta_2008]. Essa visão de aproximar a tecnologia da informação ao ambiente de análise de imagens radiológicas sem causar grande impacto na rotina habitual do médico é o grande objetivo da construção de sistemas mais eficientes. A evolução dessas ferramentas CBIR em ambientes práticos vem crescendo fortemente nos últimos anos. A aproximação e interação das características visuais extraídas por esses sistemas de recuperação de imagens por conteúdo com a percepção do usuário médico, vista como essencial para a sua aceitação em ambientes reais [Jaimes_2006], vem se tornando aos pouco evidentes nos trabalhos de processamento de imagens médicas [Pietrzyk_2008] [Donovana_2008], bem como em estudos sobre a satisfação do usuário com os sistemas CBIR [Filardi_2008], demonstrando assim a forte tendência de aproximação do sistema ao usuário final, o médico radiologista.

\section{8 - Considerações Finais}

Nesse capítulo foram abordados os principais conceitos envolvidos no processo de recuperação de imagens baseada em conteúdo. Também foram apresentados alguns tipos de processamentos utilizados nesse projeto e o estado da arte no desenvolvimento de sistemas CBIR voltados ao ambiente real de diagnóstico por imagem.

A usabilidade de um sistema CBIR em ambiente de radiologia também foi discutida e tida como um ponto importante a ser considerado em projetos que desenvolvem essa tecnologia. Os médicos normalmente não possuem um conhecimento específico do conjunto de algoritmos de extração de características e funções de distâncias. Por isso, para que os profissionais médicos tenham uma maior aceitação dessa tecnologia, esses sistemas devem ser capazes de reconhecer parâmetros de uso habitual dos radiologistas. Assim, o uso do sistema passa a ser feito de forma transparente, sem exigir conhecimento de técnicas de processamento computacional de imagens. 
Foi visando essa aproximação com o médico radiologista que esse trabalho analisou e desenvolveu pares "extratores de características de imagens médicas e função de distância" que melhor representassem cada situação diagnóstica. Esses pares serão ligados a "parâmetros perceptuais" (de uso habitual dos médicos) envolvidos no processo médico de análise diagnóstica de imagens de modo a permitir a comparação entre imagens mantendo sua semântica natural. 


\section{Inclusão da Percepção do Especialista em Consultas por Similaridade}

\section{1 - Considerações Iniciais}

Nesse capítulo serão apresentados conceitos de percepção humana na comparação de imagens, suas aplicações na construção de sistemas CBIR para ambientes reais de diagnóstico por imagem e a consolidação da proposta deste trabalho de se incluir nas consultas por similaridade um terceiro elemento (parâmetro perceptual) capaz de conduzir o mecanismo de consultas por similaridade a resultados mais próximo do esperado pelo especialista médico.

\section{2 - Conceitos de Similaridades em Recuperação por Conteúdo}

Um conceito fundamental para a busca de imagens por similaridade é a definição do que significa "similaridade" ou semelhança. O ser humano é muito eficiente no reconhecimento de informação apresentada de maneira visual (gráfica), e, portanto, tem uma grande facilidade em interpretar imagens. A tecnologia disponível atualmente para a construção de sistemas computacionais que analisem imagens digitalizadas e delas recuperem alguma informação é ainda muito incipiente, quando comparada com essa capacidade do ser humano. Porém, modelos formais de similaridade procuram abstrair esse processo da determinação da similaridade realizado pelo ser humano [Wangenheim_2003]. As suposições assumidas nesses modelos seguem as seguintes propriedades: 
- Reflexividade: Um objeto é similar a ele mesmo.

- Simetria: Se um objeto A é similar a B, então o objeto B é similar a A.

- Transitividade: Se o objeto A é similar a B e o objeto B é similar a C, então A também é similar a C.

- Monotonicidade: A similaridade de dois objetos cresce monotonicamente com o aumento de correspondências e a redução de diferenças.

Porém, para situações reais de comparações e similaridade a Monotonicidade e a Transitividade são amplamente rejeitadas na literatura [Burkhard_2004]. Um exemplo é a seguinte afirmativa: "Um quadrado pequeno é similar a um quadrado grande. Um quadrado grande é similar a um círculo grande. Mas, um quadrado pequeno não é similar a um círculo grande". A transitividade nesse exemplo foi invalidada porque o critério de semelhança foi substituído (da forma para o tamanho dos objetos). Outro ponto a ser analisado é a monotonicidade. A variação de cada critério (forma e tamanho) não pode ser considerada monotônica em relação à similaridade. Isso porque a variação da forma em uma unidade não produz a mesma variação de dissimilaridade que a mesma variação no tamanho do objeto. Existem muitos exemplos em que julgamentos de similaridade não se comportam dessa forma, pois esse requisito é altamente dependente do critério final escolhido.

Esta discussão mostra que o critério de um determinado julgamento de similaridade tem um papel essencial na avaliação da similaridade, porém na literatura, a consideração desse critério como ponto crucial no processo de similaridade é pouco explorado na construção de sistemas de recuperação de imagens por conteúdo. Essa deficiência originou uma separação muito grande entre o que um indivíduo pode reconhecer em uma imagem, e o que pode ser esperado de um processo computacional que tente reproduzir esse reconhecimento. Essa separação origina o que se convencionou chamar de "descontinuidade semântica” (semantic gap) [Deserno_2008].

Uma solução para se contornar essa descontinuidade é definir critérios de similaridade para conjuntos de dados bem delimitados. Embora ainda não existam processos adequados para a identificação de classes para imagens em geral, ou seja, critérios genéricos para a definição de similaridade, já existem processos que permitem extrair dados significativos para a busca por similaridade em domínios de imagens 
restritos [Tao_2007] [Xue_2007]. Porém, para que o conceito de CBIR possa ser utilizado em situações clínicas reais, é necessário tornar possível a definição de critérios de similaridade em domínios menos específicos, e ao mesmo tempo preservar a capacidade de análise automatizada que não apresente uma descontinuidade semântica muito grande em relação à capacidade de análise dos usuários humanos [Pietrzyk_2008] [Jaimes_2006]. Uma maneira de fazer isso, citada em [Azevedo-Marques_2005a], é identificando, decompondo e descrevendo o próprio conceito de similaridade, de maneira a permitir suportá-lo em diferentes níveis de especificidade. Na Figura 9 são ilustrados os níveis de especificidade, desde o exame radiológico, a imagem, até as características numéricas (assinaturas) considerando, nesse nível, a definição de parâmetros de percepção (e não a definição de um domínio específico).

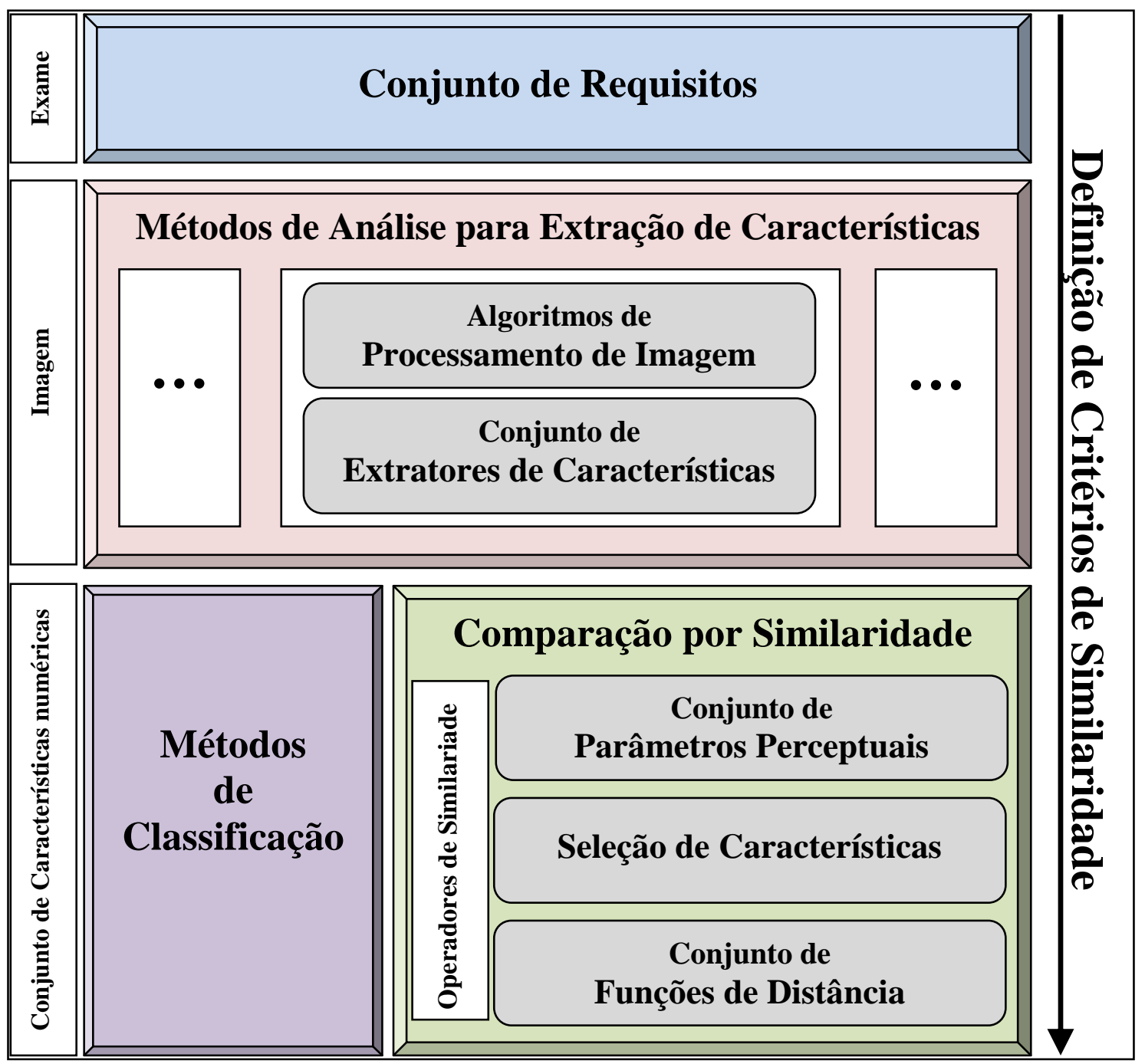

Figura 9: Níveis de Especificidade para Definição de Critérios de Similaridade 
Assim, considera-se que a identificação de similaridade é um processo hierárquico em múltiplos níveis, onde em cada nível o processo de análise segue sempre um mesmo padrão, e que pode ser descrito da seguinte maneira: uma imagem somente pode ser submetida a um processo de análise se atender a um conjunto de requisitos; atendidos os requisitos, a imagem é submetida a um conjunto de extratores de características, as quais são avaliadas tanto para comprovar que atendem a determinadas propriedades, quanto podem ser utilizadas para, por meio de uma função de distância adequada, realizar a comparação por similaridade baseada em conteúdo. Esse processo pode ser utilizado para a classificação de imagens, e dessa maneira, os critérios de classificação de um nível podem ser os requisitos do nível mais específico, criando-se a definição de uma hierarquia de similaridade e de um processo recursivo para tratá-la. Um critério de similaridade é, portanto, composto por: um conjunto de extratores de características com as respectivas características extraídas; a definição dos domínios aceitáveis de valores para as características extraídas, bem como de suas correlações; e a definição das classes que podem ser determinadas (ou que se procura determinar) a partir dessas características.

\section{3 - "Parâmetro Perceptual": Intuição e Definição}

Como visto na seção anterior, para que os recursos de CBIR possam ser utilizados em situações clínicas reais, é necessário tornar possível a definição de critérios de similaridade em domínios menos específicos, e ao mesmo tempo preservar a capacidade de análise automatizada que não apresente uma descontinuidade semântica muito grande em relação à capacidade de análise dos usuários humanos.

Definição "Parâmetro Perceptual": Indicador de maior relevância das características visuais de alto nível da imagem durante o processo de reconhecimento e comparação realizado pelo especialista. O parâmetro perceptual é utilizado como uma associação de palavras que expressam padrões ou características percebidas. 
Esse trabalho visa demonstrar que a definição de parâmetros perceptuais para melhorar o resultado de consultas por similaridade seja o passo inicial e fundamental para se diminuir tal descontinuidade semântica. Esse parâmetro é o responsável por determinar quais características visuais, quando alteradas, produzirão maior impacto na semelhança entre a imagem referência e as comparadas. Ou seja, na consulta onde o parâmetro de percepção é um, uma pequena alteração nesse parâmetro produzirá na comparação um efeito de dissimilaridade maior que a mesma alteração acontecida em outro parâmetro visual. A grande contribuição desse terceiro elemento é a abertura para que, em diferentes momentos, o médico possa utilizar um aspecto visual da imagem com maior relevância de similaridade que outros.

Para exemplificar a importância de se incluir na consulta por similaridade esse elemento chave - o parâmetro perceptual, pode-se utilizar uma base de imagens contendo fotografias do rosto de várias pessoas. Cada rosto apresenta características gerais semelhantes, ou seja, dois olhos, nariz e boca dispostos de maneira simétrica na face. Ao se fazer uma análise de semelhança nas imagens, uma pessoa pode comparálas evidenciando aspectos relacionados ao nariz e outra, ao realizar essa mesma comparação, pode evidenciar outro aspecto, como formato do olho ou boca. Esse nível de critério ainda não seria o que vemos como parâmetro de percepção, pois aqui caberia apenas especificar mais o contexto da consulta, o que não é o objetivo direto deste trabalho.

Nesse exemplo, mesmo especificando mais o contexto e solicitando-se para comparar apenas o nariz de cada rosto, o problema semântico ainda continuaria existindo (em menor grau, é claro). Isso porque uma pessoa poderia considerar o formato do nariz como sendo o parâmetro de maior relevância na similaridade e outra poderia tratar o tamanho do nariz como parâmetro de maior relevância. Nesse caso, construindo um extrator de "forma do nariz" iria satisfazer um conjunto de observadores, construindo um extrator de "tamanho de nariz" satisfaria outro conjunto, e utilizando-se os dois extratores, a interação entre eles dependeria de cada observador, porque essa interação pode não ser monotônica (de mesma intensidade).

Entende-se que o sistema humano de percepção visual não leva apenas um parâmetro em consideração, e sim uma combinação entre eles. Essas percepções diferem em função das características físicas do estímulo e são interpretadas em função das experiências anteriores a ele associado. Esses pesos (relevância) que o ser humano 
associa aos diferentes aspectos perceptuais é o que proporciona a diferença entre observadores [Alexandre_2007], que é tão evidente no ambiente médico.

Atualmente os trabalhos de CBIR utilizam a especificação do contexto como solução mais adequada para limitar diferentes percepções. No escopo do exemplo citado anteriormente ficaria: "Compare os rostos de acordo com a forma de cada nariz". Essa abordagem tem surtido bons resultados, mas força o observador a aceitar esse padrão de semelhança. Porém, em ambientes reais o contexto da comparação nem sempre está automaticamente disponível. Com isso percebe-se que especificar muito o contexto de análise das imagens pode, na prática, não ser muito aceito, porque o padrão intrínseco de cada observador pode não considerar aquela especificação como sendo a melhor naquele momento ou em determinados casos.

Portanto, uma possível forma de se tratar esse problema seria deixar cada observador especificar por si mesmo quais os parâmetros perceptuais possuem maior relevância em uma dada comparação, baseado em sua experiência ou em sua noção de similaridade. Assim, o resultado de similaridade poderia satisfazer o desejo específico de cada observador.

\section{4 - Parâmetros de Percepção em imagens de Tomografia Computadorizada de Pulmão}

O estudo para a definição do terceiro elemento da tríade (a percepção do usuário) na construção de um sistema CBIR teve como ponto de partida a investigação do campo de aplicação do sistema. Uma observação do ambiente em que os médicos analisam e laudam as imagens dos pacientes possibilitou uma aproximação do sistema CBIR com a realidade vivida no cotidiano do radiologista. Nessa experiência, relatada nessa seção, foram observadas a real necessidade do sistema no ambiente e os objetivos de sua utilização, assim como situações práticas onde o sistema seria requisitado.

Durante a análise do ambiente de imagens médicas, o primeiro dado observado foi o padrão de imagem digital utilizado na visualização dos exames. As imagens médicas digitais, geradas por aparelhos modernos de exames radiológicos, por exemplo, Tomografia Computadorizada (CT), Ressonância Magnética (RM) e RaioX (RX), são criadas no formato DICOM (Digital Imaging and Communication in Medicine). Para 
que o Sistema CBIR seja compatível com a rotina médica e integrado a um sistema PACS a comparação entre imagens deve levar em consideração o padrão gerado nos exames.

O padrão DICOM, ilustrado na Figura 10, armazena no início do arquivo da imagem (área chamada de cabeçalho DICOM) um conjunto de informações sobre o exame (como modalidade, tipo, data, etc.), o paciente (como nome, sexo, idade, etc.) e a própria imagem (resolução, bits por pixel, etc.). $\mathrm{Na}$ figura são listadas 40 tags de informação do cabeçalho (de um total de mais de 100 tags, onde nem todas precisam necessariamente serem preenchidas). Após esse cabeçalho, são armazenados os pixels da imagem propriamente dita. Atualmente, são alocados na memória 16 bits por pixel (apesar de apenas 12 bits serem utilizados para guardar seu valor de intensidade). Essa resolução gera imagens com 4096 níveis de cinza [Caritá_2004]. Transformar essas imagens em outros formatos como jpg, bmp ou gif exige uma re-quantização dos níveis de cinza (de 4096 para 256, por exemplo), o que pode representar uma perda muito grande no conteúdo intrínseco da imagem. Outro ponto negativo da transformação é que as informações contidas no cabeçalho DICOM não são contempladas em outros formatos e essas informações são potencialmente importantes para definições de critérios e parâmetros de comparação.

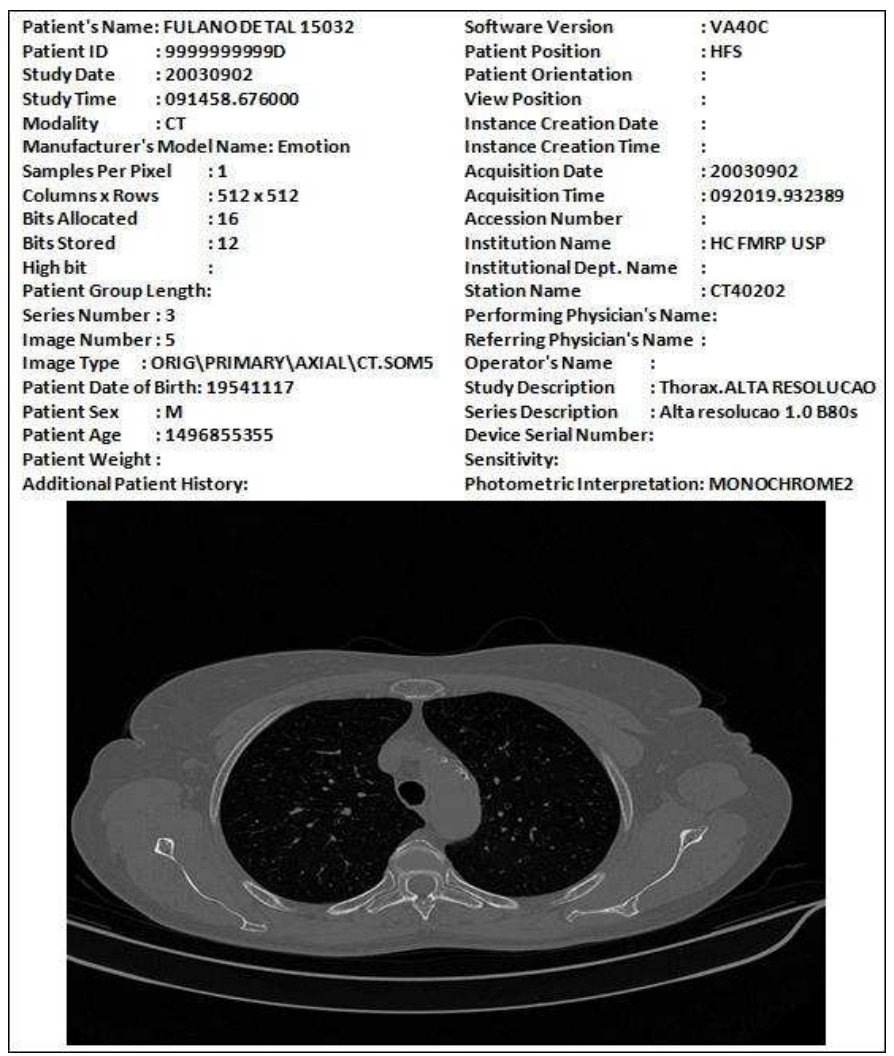

Figura 10: Padrão de imagem - DICOM 


\section{Definição da modalidade de imagem a ser trabalhada}

O próximo passo foi definir a modalidade de imagem a ser trabalhada. $\mathrm{Na}$ prática clínica do diagnóstico por imagem, os exames radiológicos mais comuns são: Raio X (RX), Tomografia Computadorizada (CT), Ressonância Magnética (RM) e Ultra-sonografia (US). Cada um desses exames gera imagens digitais no padrão DICOM, porém, os princípios físicos e computacionais de formação dessas imagens são muito distintos. Por exemplo, imagens de CT são geradas a partir da quantificação do poder de atenuação (absorção) do tecido frente a um feixe de fótons de Raio X. Já a imagens de RM são geradas a partir da quantificação do poder de resposta de cada tecido frente a um determinado estímulo magnético. Definições completas e mais detalhadas sobre o princípio físico de formação das imagens de CT e RM podem ser visto em [Webb_2002] [Abdala_2007]. O objetivo aqui é ressaltar que o princípio físico de formação das imagens médicas traz consigo uma semântica, uma informação sobre determinadas características de cada tecido analisado. Devido a essa diferença na semântica expressa pelos níveis de cinza das imagens, a comparação entre imagens de diferentes modalidades (para recuperação por conteúdo) passa a não fazer tanto sentido, a não ser que as diferenças sejam previamente levadas em consideração.

\section{Exemplo: Tomografia Computadorizada}

Mesmo dentro de uma mesma categoria de imagens, diferentes protocolos do exame podem gerar diferentes percepções na imagem resultante. Por exemplo, na formação de imagens de Tomografia Computadorizada, diferentes protocolos de geração de imagens podem ser utilizados. O objetivo do exame, o grau de detalhe das estruturas que se deseja visualizar nas imagens e a quantidade de $\mathrm{RX}$ incidente no paciente podem ser características determinantes na escolha do protocolo. Todas as informações que definem o protocolo utilizado são especificadas no cabeçalho DICOM (ver Figura 8). São exemplos de informações relevantes: a espessura do corte - Slice Thickness, a resolução - Columns/Rows, o algoritmo de Convolução - Convolution Kernel, entre outros. Como cada imagem em um exame de CT representa uma fatia do corpo do paciente, o parâmetro Espessura do Corte expressa em milímetros a espessura da fatia correspondente no corpo, representada na imagem 2D pela média das atenuações causadas pelos tecidos contidos naquela espessura. Por exemplo, um exame tido como de "Alta Resolução", é aquele onde essa espessura vale cerca de $1 \mathrm{~mm}$ no corpo [Webb_2002]. Outro parâmetro determinado na formação da imagem e que 
interfere nos parâmetros visuais gerados é o chamado Convolution Kernel. Esse diz respeito ao tipo de filtro utilizado na operação de convolução do processo de construção da imagem digital. Na Figura 11 são apresentadas duas fatias idênticas, do mesmo exame, construídas com filtros diferentes. Nesse caso, a utilização do filtro B80s (imagem da esquerda) gera uma imagem com maiores detalhes, porém com mais ruídos, já o filtro B20s (imagem da direita), gera uma imagem mais suavizada, com menos ruído.

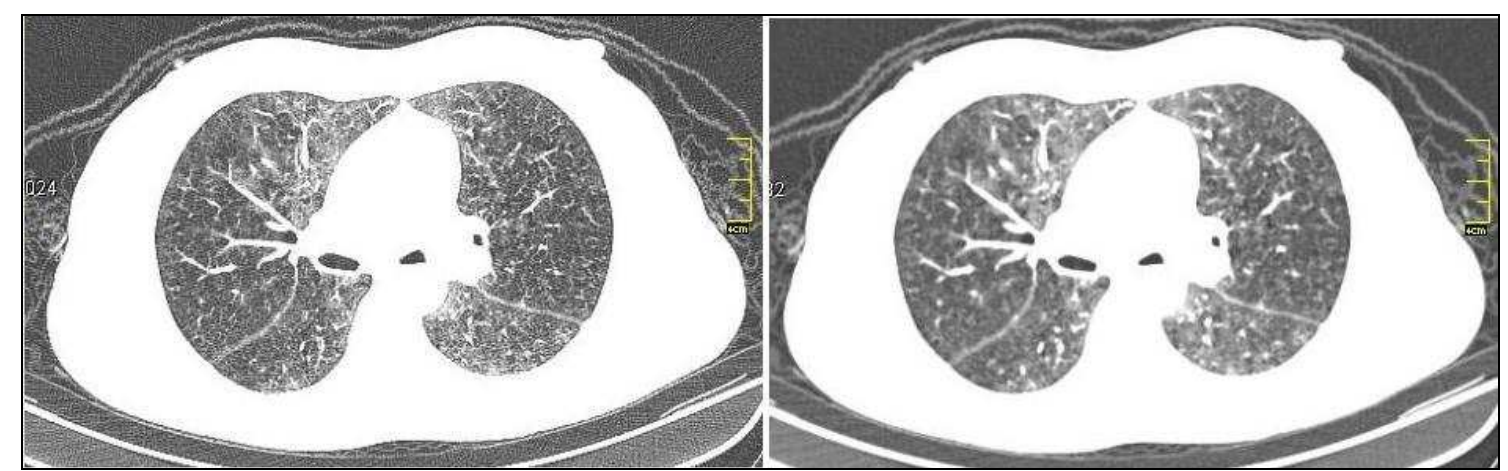

Figura 11: Efeito do Convolution Kernel: B80s na imagem da esquerda e B20s na imagem da direita

Todos esses parâmetros de geração das imagens médicas devem ser considerados no processo de comparação, o que não acontece nos trabalhos atuais da literatura. Isso não significa que imagens construídas por protocolos diferentes não possam ser comparadas, mas sim que devem ser tomadas medidas necessárias para não se quebrar a semântica contida em cada tipo de geração das imagens.

Nesse trabalho, todos os experimentos foram realizados sobre imagens de Tomografia Computadorizada, utilizando-se o protocolo de Alta Resolução (ou seja, imagens representando 01 (um) milímetro de espessura para cada fatia) para regiões do tórax. Nesse protocolo, dois tipos de Convolution Kernel são utilizados na geração das imagens, são eles: o B80s e o B20s. Porém, o foco do estudo será nas imagens geradas pelo filtro de convolução B80s, por serem os utilizados pelos médicos durante a análise do exame e também, apesar dos ruídos, apresentarem um nível maior de detalhes.

Foram vários os motivos que levaram a escolher esse tipo de imagem. Especialistas médicos e pesquisadores do Hospital das Clínicas de Ribeirão Preto (HCRP-USP), campo de estudo desse trabalho, demonstraram interesse em estudar padrões de lesões difusas de pulmão. Por esse motivo, o levantamento de uma base de imagens contendo esse tipo de lesão foi facilitado, bem como a liberação do uso das imagens pelo comitê de ética e pesquisa da instituição. Portanto, como o protocolo de 
CT de Alta Resolução é o protocolo utilizado quando há suspeita da existência de lesões difusas no pulmão, foi decidido trabalhar na mesma linha.

\section{Levantamento dos critérios de similaridade e Parâmetros Perceptuais}

Definido o tipo de imagem, o passo seguinte foi um levantamento dos principais critérios de comparação vinculados ao tipo de imagem escolhido. Nessa fase, a participação dos médicos radiologistas foi essencial para definir os critérios de similaridade e expressarem seus respectivos parâmetros perceptuais. Como definido na seção 3.3, o Parâmetro Perceptual do médico radiologista representa a característica visual de maior relevância perceptual em uma determinada situação diagnóstica.

Para se chegar nesse conhecimento, foram realizadas entrevistas com 04 médicos radiologistas e 03 residentes do Hospital das Clínicas de Ribeirão Preto. Questionamentos como:

- Quais os principais critérios de comparação utilizados para o determinado tipo de exame?

- Quais achados clínicos são freqüentemente visualizados nesses exames?

- Para cada achado listado, o que você (radiologista) enxerga de diferente na imagem que o ajuda a identificar esse achado?

ajudaram na identificação dos principais achados e seus respectivos parâmetros visuais.

Com base nas respostas dos radiologistas, foram levantados os principais critérios de comparação para o escopo de imagem escolhido. São eles:

- baseado em lesões pulmonares (cor/forma/textura do interior pulmonar)

- baseado em anormalidades no mediastino (cor/forma-tamanho/textura de estruturas do mediastino)

- baseado em lesões ósseas (cor/forma/tamanho do osso)

$\mathrm{Na}$ prática, um radiologista utiliza todos esses critérios ao laudar uma imagem. As ferramentas de visualização de imagens DICOM utilizadas nas estações de laudo são projetadas para auxiliar essa análise. Por exemplo, uma funcionalidade comum utilizada na visualização dessas imagens é o janelamento (descrito na seção 2.2). Como as imagens DICOM possuem resolução de 4096 níveis de cinza, fica impossível ao olho humano perceber a diferença de tantos tons de cinza. Essa funcionalidade permite ao médico ampliar uma faixa menor de níveis de cinza e com isso varrer todos os níveis da imagem. Desse modo, pode-se escolher as faixas de interesse de acordo com o que se 
deseja visualizar na imagem. A Figura 12 ilustra o efeito visual desse janelamento e suas respectivas aplicações.

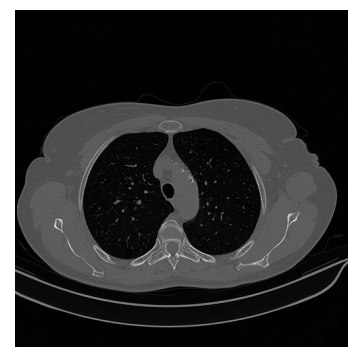

a)

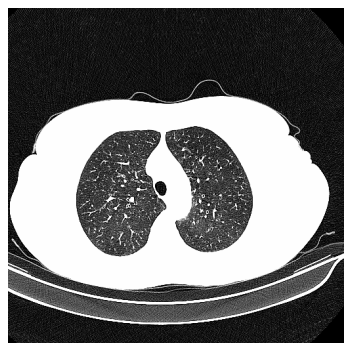

b)

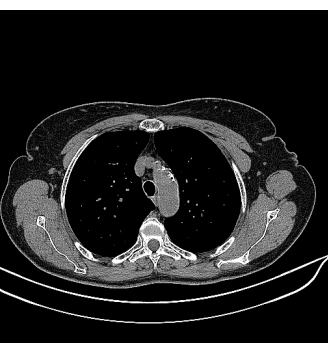

c)

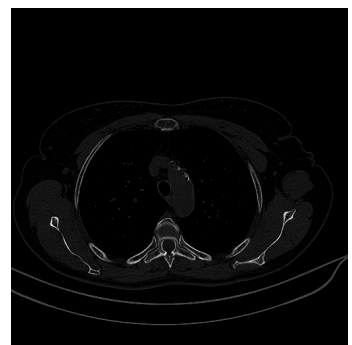

d)

Figura 12: a) Imagem Original b) Imagem Janelada em W1400/C-600 - ideal para visualizar pulmão c) Imagem janelada em W300/C50 - ideal para partes moles do mediastino d) Imagem janelada em W1800/C800 - ideal para visualizar osso

Apesar de utilizar todos os critérios ao observar e laudar uma imagem, foi levantado na pesquisa que alguns deles exigem um maior tempo de análise que outros. Esses, normalmente são os critérios que geram maiores dúvidas entre os radiologistas, talvez por apresentarem alterações visuais pouco perceptíveis ao analista humano. Esse levantamento também foi um ponto importante utilizado para se enfatizar a pesquisa em lesões pulmonares não nodulares. As lesões pulmonares apresentam alterações visuais menos óbvias, onde as possibilidades de dúvidas e as chances de erro na classificação são maiores. Por esses motivos nota-se que um sistema automatizado de recuperação de imagens por conteúdo ajudaria na tomada de decisão, recuperando casos clínicos similares que ajudam o radiologista chegar a uma conclusão melhor embasada. Na literatura são encontrados alguns estudos focados no reconhecimento e na classificação dessas lesões pulmonares [Depeursinge_2008] [Depeursinge_2007] [Abe_2004] [Uchiyama_2003].

Definido o critério de comparação para lesões pulmonares, foram levantados com os médicos os passos utilizados na análise das imagens para detecção visual dos achados encontrados nas mesmas. A resposta dos médicos a esse levantamento foi:

"Procuramos por":

- deslocamento da estrutura normal;

- aumento de tamanho relativo à estrutura normal;

- presença de densidades anormais

- destruição da estrutura normal ou bordas

Todas essas características levantadas se relacionam com características básicas como forma, tamanho, densidade, bordas e contornos de estruturas presentes na imagem. 
A próxima pergunta estava associada à relevância dessas características na comparação de imagens, ou seja, se todas elas tinham a mesma relevância quando se compara uma imagem referência a alguma outra de caso similar. A resposta unânime do especialistas foi que não, e a relevância dessas características dependem da história clínica do paciente, ou das evidências (como a Hipótese Diagnóstica - definida a seguir) que acompanharam o pedido de exame. No entanto, concluiu-se que em cada situação diagnóstica o radiologista considera, de modo subjetivo, algumas dessas características visuais com maior relevância que outras. Essa subjetividade está exatamente concentrada na formação e na experiência do médico.

Definição: "Hipótese Diagnóstica" - suspeita levantada por algumas evidências que desencadeia um processo analítico de uma doença ou de um quadro clínico, para se chegar a uma conclusão (Diagnóstico). Hipótese que motiva a investigação de determinados aspectos do paciente, por meio de perguntas, observações ou exames.

Diversas doenças pulmonares são caracterizadas pela presença de determinadas alterações comuns na estrutura normal do pulmão. Essas alterações são chamadas pelos médicos de "achados radiológicos".

Definição: “Achados Radiológicos” - Lesões, anormalidades ou alterações na estrutura normal de um tecido observado nas imagens médicas de exames radiológicos. Podem carregar consigo informações sobre manifestações de doenças, disfunções ou outra anormalidade que evidencie uma doença ou confirme uma Hipótese Diagnóstica.

Cada achado está diretamente relacionado a parâmetros visuais característicos. Ainda com a ajuda dos médicos radiologistas e residentes, alguns dos principais achados de pulmão foram levantados e para cada um deles foi especificado o que eles, os médicos, enxergam de diferente na imagem que os ajuda a identificar esse achado. Os achados levantados foram:

- Enfisema: Aumento permanente do espaço aéreo distal ao bronquíolo terminal, acompanhado de destruição das paredes alveolares. Região focal de baixa atenuação, usualmente sem paredes definidas. 
- Consolidação: É a substituição do ar alveolar por transudato, exudato ou tecido. Aumento homogêneo da atenuação do parênquima pulmonar.

- Espessamento do septo interlobular: Opacidade linear fina que corresponde ao septo interlobular. Aumento na espessura do septo interlobular, usualmente causado por edema, infiltração celular ou fibrose.

- faveolamento (favo de mel): Cistos pulmonares de destruição fibrosados, simbolizando perda completa da arquitetura acinar e bronquiolar. Espaços císticos agrupados, caracterizados por paredes bem definidas, geralmente espessas.

- opacidade em vidro fosco: Aumento da atenuação pulmonar, sem obscurecer as margens brônquicas e vasculares, causado por preenchimento parcial do espaço aéreo, espessamento intersticial ou colapso parcial alveolar (entre outros).

conforme descrições encontradas em [Souza-Jr_2002].

A resposta consenso das entrevistas, para cada achado estão listados na Tabela 2.

Tabela 2: Levantamento dos principais achados e seus parâmetros perceptuais

\begin{tabular}{|c|c|c|}
\hline Achado & Aspectos visuais da Imagem & Imagem \\
\hline 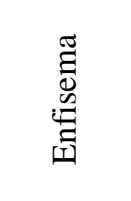 & $\begin{array}{l}\text { - região de baixa atenuação (mais } \\
\text { escura) } \\
\text { - usualmente sem paredes visíveis } \\
\text { - distribuição não-uniforme } \\
\text { - bolha separada por septo interlobular }\end{array}$ & \\
\hline 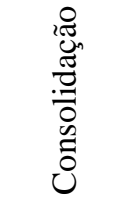 & $\begin{array}{l}\text { - aumento homogêneo da atenuação } \\
\text { (manchas mais claras) } \\
\text { - obscurece as margens dos vasos } \\
\text { - obscurece as paredes das vias aéreas }\end{array}$ & \\
\hline 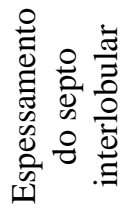 & $\begin{array}{l}\text { - aumento da espessura do septo } \\
\text { interlobular } \\
\text { - Opacidade linear fina } \\
\text { - Pode ser lisa, irregular ou nodular }\end{array}$ & \\
\hline
\end{tabular}




\begin{tabular}{|l|l|c|}
\hline - Espaços císticos agrupados \\
\hline - Usualmente com diâmetros \\
comparáveis, variando de $0,3 \mathrm{a} 1 \mathrm{~cm}$ \\
- Paredes bem definidas e geralmente \\
espessas \\
- Estrutura similar a um favo de mel
\end{tabular}

Posteriormente, em discussões com radiologistas e outros pesquisadores da área, os aspectos visuais da imagem, levantados anteriormente para cada achado foram sintetizados e sumarizados em um "Parâmetro Perceptual" que os define. A definição desse parâmetro levou em consideração a opinião dos médicos e os padrões visuais das lesões (também chamados de achados). Para facilitar posterior utilização desses parâmetros no processamento e análise das imagens médicas, os parâmetros perceptuais levantados foram divididos em dois grupos, de acordo com o comportamento dos achados que cada parâmetro apresenta em relação ao poder de atenuação do feixe de fótons incidentes. São eles:

Parâmetros de Alta Atenuação (achados que tornam a imagem mais clara por apresentar maior poder de atenuação sobre o feixe de elétrons que o atravessa). As imagens representativas são mostradas na Figura 13:

Parâmetro 1: Aumento Homogêneo da Atenuação

Achado Representativo: Imagens contendo Consolidação

Parâmetro 2: Aumento não Homogêneo (espalhado) da Atenuação

Achado Representativo: Imagens contendo Vidro Fosco

Parâmetro 3: Fissuras interlobular

Achado Representativo: Imagens contendo Espessamento

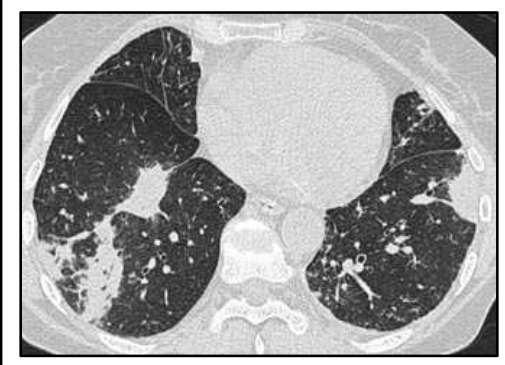

a) Consolidação

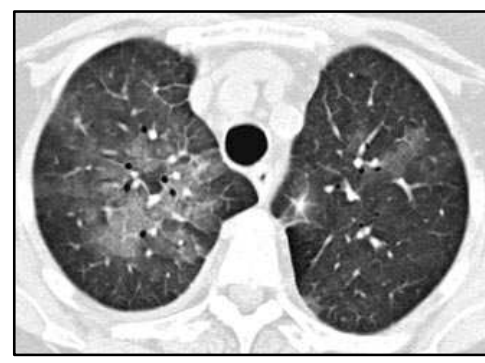

b) Vidro Fosco

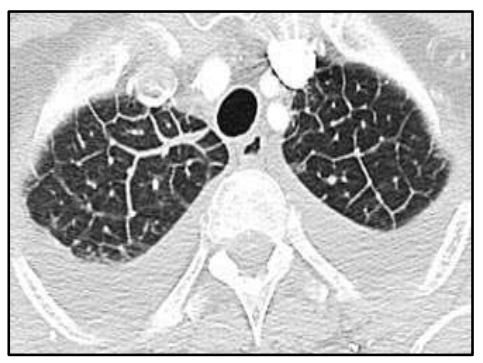

c) Espessamento

Figura 13: Imagens com achados de alta atenuação 
Parâmetros de Baixa Atenuação (achados que tornam a imagem mais escura por apresentar menor poder de atenuação sobre o feixe de elétrons que o atravessa), onde as imagens representativas são mostradas na Figura 14:

Parâmetro 4: Baixa atenuação com paredes bem definidas Achado Representativo: Imagens contendo padrão Favo de Mel Parâmetro 5: Baixa atenuação sem paredes bem definidas Achado Representativo: Imagens contendo Enfisema

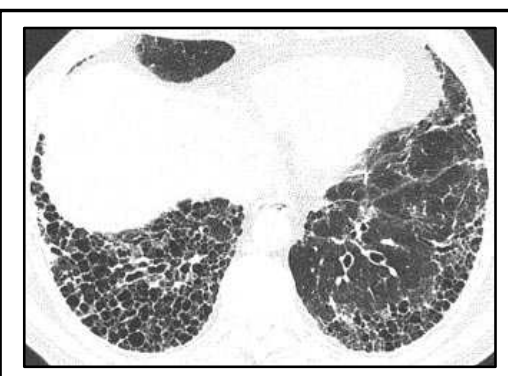

d) Favo de Mel

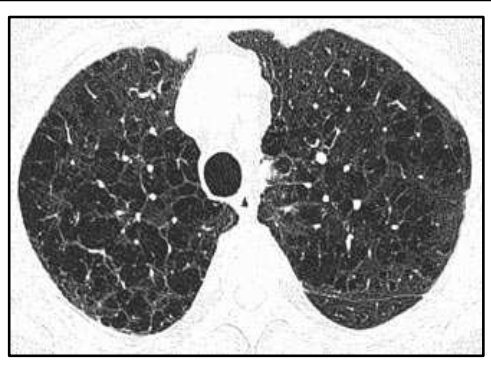

e) Enfisema

Figura 14: Imagens com achados de baixa atenuação

\section{5 - Considerações Finais}

Os conceitos de percepção apresentados nesse capítulo ajudaram no levantamento dos aspectos visuais relevantes das imagens de CT de pulmão. Os Parâmetros Perceptuais aqui definidos passam então a representar os aspectos visuais relevantes de cada um dos cinco achados considerados na pesquisa. A inclusão desses parâmetros nas consultas por similaridade é o próximo passo da pesquisa, onde cada parâmetro perceptual deverá ser associado a um binômio (extrator de características e função de distância) definido de modo a permitir, durante uma situação real, que o médico expresse qual parâmetro visual ele gostaria de considerar como relevante em determinada consulta por conteúdo no sistema CBIR.

Deve-se ressaltar que apesar da importância do histórico dos pacientes no processo diagnóstico, tal informação não está sendo utilizada neste trabalho, estando fora do escopo do mesmo. 


\section{Capítulo 4 \\ Métodos de Extração Baseados nos Parâmetros Perceptuais}

\section{1 - Considerações Iniciais}

Com o objetivo de melhorar os resultados de sistemas de recuperação de imagens médicas utilizando CBIR este trabalho propõe-se a incluir no processo de consulta por similaridade um elemento que permita ao médico especificar qual (ou quais) dos diversos parâmetros visuais existentes na imagem médica devem ser considerados como sendo o(s) parâmetro(s) relevante(s) em cada consulta. Esses parâmetros foram levantados junto aos médicos do HC-FMRP, conforme detalhado no Capítulo 3.

Para melhor compreensão da influência de se processar consultas por similaridade levando em consideração a percepção do usuário no momento da consulta foi decidido separar a abordagem de inclusão do parâmetro perceptual e medir sua influência em dois momentos distintos da extração de características. Como apresentado na seção 2.3 dessa dissertação, os métodos de extração para recuperação por conteúdo são compostos de alguns passos essenciais. Os principais são: o processamento da imagem e a análise e extração dos atributos. Na literatura encontramos com maior facilidade trabalhos que se preocupam com a inclusão do contexto das imagens e conhecimento médico na fase de extração dos atributos [Lam_2007] [Tao_2007] [Xue_2007]. Porém, nesse trabalho, será mostrada a influência dessa metodologia nas duas etapas: no pré-processamento e na análise para extração de atributos. 


\section{2 - Incluindo o Parâmetro Perceptual no pré-Processamento}

O padrão DICOM (detalhes na seção 3.4) de imagem aloca 16 bits para cada pixel da imagem, porém, atualmente, são utilizados 12 desses bits para representar o valor do pixel [Caritá_2004]. Essa resolução de imagem proporciona uma variação de até 4096 níveis de cinza em cada imagem, onde a escala numérica dos pixels varia de -1024 a 3096. Em boa parte dos algoritmos de CBIR que reconhecem imagens desse padrão, fazem uma transformação da imagem original (de 4096 níveis) para outros formatos que suportam apenas 256 níveis de cinza. O problema dessa abordagem é que nessa requantização, muita informação relevante é perdida. Por outro lado, conservar os 4096 níveis de cinza no processamento e análise de características tornaria a extração de características computacionalmente custosa.

Ao fazer uma análise da imagem o médico radiologista varre, por janelamento, grande parte dos 4096 níveis. Como o olho humano consegue diferenciar simultaneamente poucos níveis de cinza, as ferramentas de visualização de imagens DICOM permitem que o médico escolha quais "janelas" do histograma ele quer visualizar. Em imagens de CT essa técnica é de grande valia, pois para diferentes tipos de tecidos do corpo humano, diferentes tons de cinza serão atribuídos a ele na imagem. As variações de cor dentro de um mesmo órgão, por exemplo, podem ser imperceptíveis ao olho humano sem o auxílio dessa ferramenta.

Buscando imitar essa rotina humana na visualização das imagens, a abordagem proposta nesse trabalho foi utilizar os parâmetros de percepção levantados e préprocessar a imagem original de modo a ressaltar as características visuais desses parâmetros na imagem (e diminuir a influência de outros parâmetros), antes dessa imagem ser analisada pelo algoritmo de extração de características. O ponto chave dessa técnica foi definir quais seriam as informações que não poderiam ser perdidas ao se requantizar a imagem para análise de características. Para simplificar os experimentos dessa abordagem os parâmetros levantados foram divididos pelos médicos em dos grandes grupos: 
- parâmetros de ALTA atenuação: aqueles relacionados com estruturas de alta densidade, que impedem a passagem de RX para a formação da imagem, provocando um clareamento na imagem de CT,

- parâmetros de BAIXA atenuação: os relacionados à baixa densidade da estrutura, que permite uma passagem maior de elétrons para a formação da imagem, provocando um escurecimento maior na mesma.

Como os médicos normalmente analisam lesões de pulmão com um janelamento centrado no valor médio de intensidade de pixel igual a -600 (indicado de vermelho na Figura 15c), propõe-se aqui separar essa visualização em duas partes distintas, uma para cada grande grupo de parâmetros perceptuais: um com janelamento centrado no valor 800 (ponto médio da banda esquerda do janelamento utilizado pelo médico - indicado de verde na Figura 15d) para ressaltar estruturas de baixa atenuação e outro centrado no valor -400 (ponto médio da banda direita do janelamento utilizado pelo médico indicado de azul escuro na Figura 15e) para ressaltar estruturas de baixa atenuação presentes no pulmão.

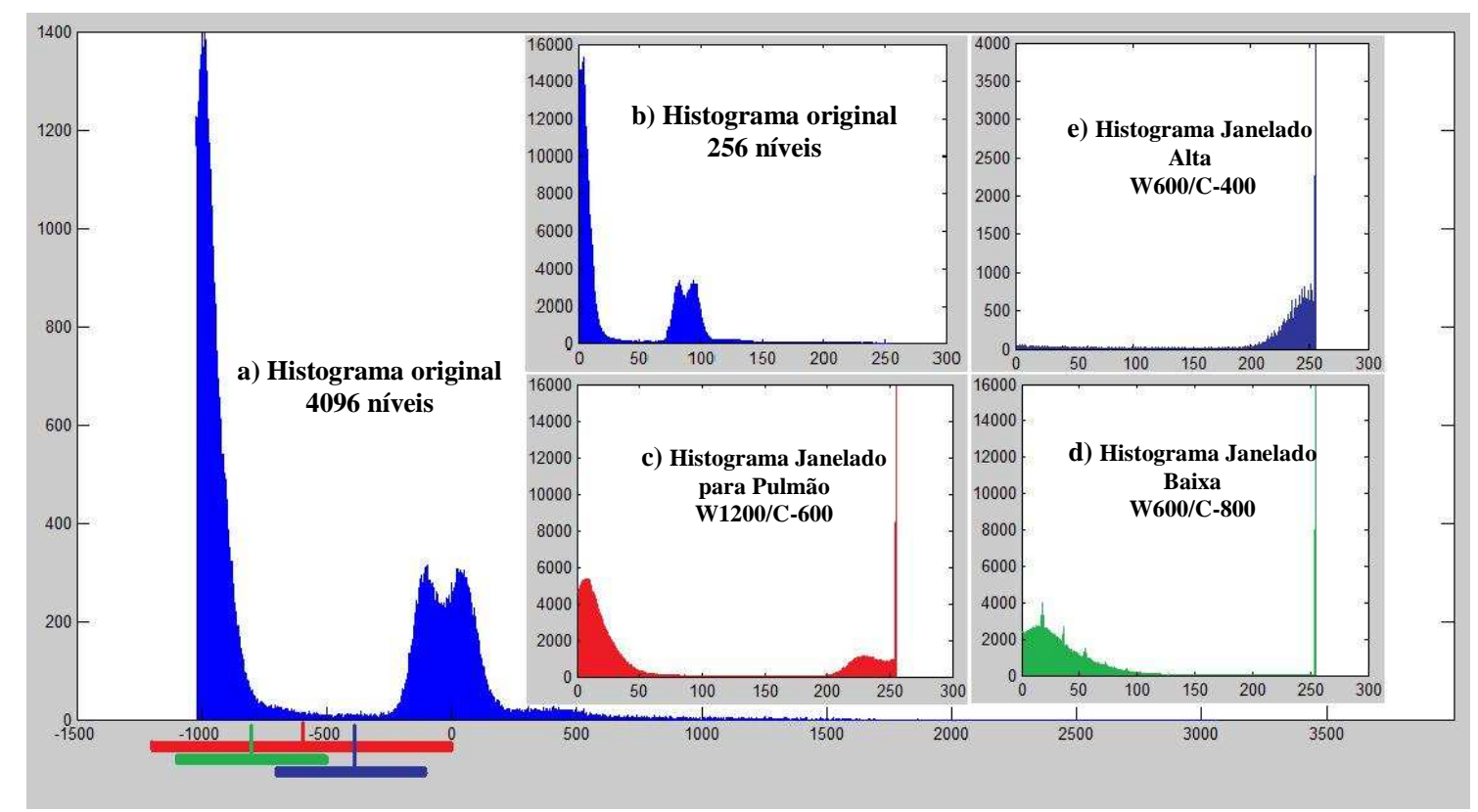

Figura 15 - Histogramas de Imagem DICOM. (a) Original. (b) Histograma de imagem requantizada em 256 níveis de intensidade. (c) Histograma com Janelamento W1200/600 (d) Histograma com Janelamento W600/C-800 (e) Histograma com Janelamento W600/C-400 
A figura 16 mostra a diferença visual das duas imagens processadas a partir da imagem original:

- Imagem Original: 4096 níveis de cinza normalizados para 256 níveis

- Imagem Janelada Alta: janela de 600 pixels, centrados no valor de intensidade de cinza igual a -400 , normalizados para 256 níveis de cinza.

- Imagem Janelada Baixa: janela de 600 pixels, centrados no valor de pixel -800, normalizados para 256 níveis de cinza.

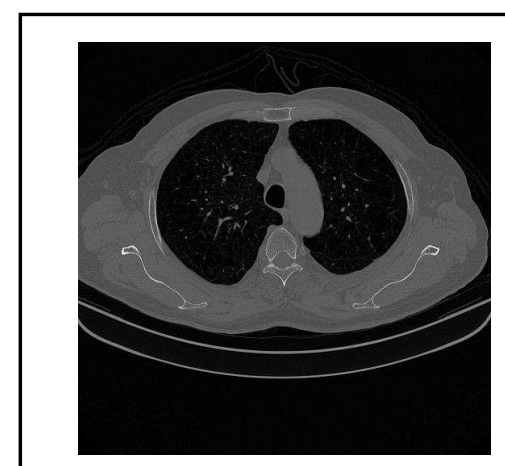

(a)

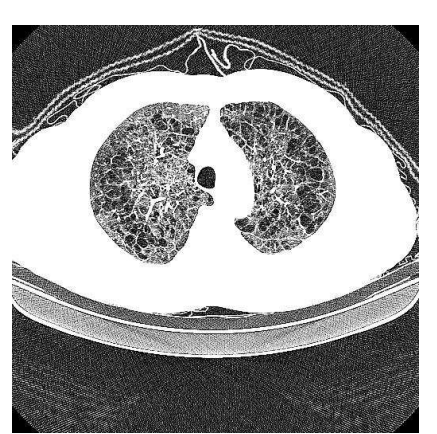

(b)

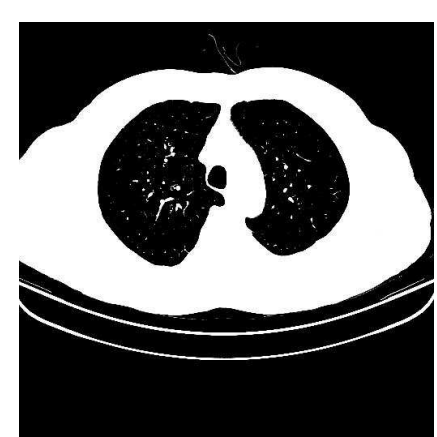

(c)

Figura 16 - (a) Imagem Original, (b) Imagem Janelada W600/C-800, (c) Imagem Janelada W600/C-400

No próximo capítulo dessa dissertação, nos experimentos 1 e 2, serão apresentados o desempenho dos extratores tradicionais para cada classe de lesão pulmonar do conjunto de imagens, utilizando-se atributos de cor e textura das três imagens apresentadas: imagem original, a imagem ressaltada para alta atenuação e a imagem ressaltada para baixa atenuação. Nesse caso, vale ressaltar que apesar dessas três imagens serem provenientes de uma mesma imagem DICOM, elas são, devido ao janelamento, visualmente diferentes entre si, tanto na textura quanto na distribuição de níveis de cinza das estruturas. 


\section{3 - Construindo Extratores de Características Específicos para o Contexto}

De uma maneira bem simplificada, pode-se definir o pulmão como sendo um órgão composto por alvéolos (sacos que contém ar), envolto de capilares pulmonares responsáveis pelas trocas gasosas, veias e artérias para irrigação sanguínea, brônquios e bronquíolos para condução do ar e espaços conhecidos como espaço intersticial, com estruturas que separam o meio externo (contato como ar) do meio interno (capilares pulmonares) e que são finas o suficiente para permitir a troca gasosa. A grande quantidade de ar dentro do pulmão dá um aspecto esponjoso ao órgão.

$\mathrm{Na}$ imagem de CT, as estruturas têm seu brilho quantificado na imagem de acordo com seu poder de atenuação do RX incidente. O ar, por exemplo, é bem menos denso que a água, utilizada como parâmetro para medir a atenuação do feixe de elétrons, e por isso apresenta um valor muito menor de brilho na imagem. Uma escala de cinza foi criada especialmente para a tomografia computadorizada e sua unidade foi chamada de Unidade Hounsfield (HU), em homenagem ao cientista que desenvolveu a tomografia computadorizada. Nesta escala podemos identificar diferentes tecidos, dependendo de seu poder de atenuação [Webb_2002]. Por exemplo:

- Água $0 \mathrm{HU}$ (Unidades Hounsfield)

- $\mathrm{Ar}-1000 \mathrm{HU}$

- $\quad$ Osso de 300 a $350 \mathrm{HU}$

- Gordura de -120 a $-80 \mathrm{HU}$

- Músculo de 50 a 55 HU

Desse modo, tomamos para esse estudo valores entre $-900 \mathrm{HU}$ e $-250 \mathrm{HU}$ para representar o interstício do pulmão, composto por membranas e capilares com pequena quantidade de células. Valores acima de $-250 \mathrm{HU}$ dentro do pulmão para corresponder a estruturas um pouco mais densas, como vasos sanguíneos, paredes de brônquios ou concentrações maiores de células estranhas ou fibrose. Com essas definições, foram construídos algoritmos que extraíssem informações relevantes do pulmão e que representassem bem o contexto das lesões intersticiais. 


\subsection{1 - Extrator Geral do Pulmão}

O extrator, aqui chamado de "Extrator Geral" é um algoritmo que extrai características peculiares ao pulmão referentes à distribuição de níveis de cinza do mesmo. Recebe como entrada uma imagem DICOM original e possui como único processamento antes da extração a segmentação dos pulmões. Ele faz uma varredura nos pixels dos pulmões e extrai 16 características baseadas em histograma de níveis de cinza. As características extraídas são as seguintes:

- Proporção de ar - Entende-se por proporção de ar nos pulmões a contagem de pixels no interior do pulmão que possui valor menor que 900 HU dividido pelo tamanho total do pulmão.

- Proporção de estruturas densas - Entende-se por proporção de estruturas densas a contagem de pixels que possuem valor maior que 250 HU dividido pelo tamanho total do pulmão.

- Distribuição do interstício pulmonar (ou estrutura pulmonar) - São 14 características que representam as estruturas que compõem o pulmão, sem o ar e as estruturas densas. Dos 650 níveis de cinza dispostos entre os valores -900HU e -250HU, faz-se uma equalização para 14 níveis de cinza, extraindo assim um histograma simples de 14 bins.

Com a utilização desse extrator, pretendemos caracterizar o pulmão das imagens de maneira simples, utilizando um vetor de apenas 16 dimensões para representar características básicas do contexto estabelecido.

\subsection{2 - Extrator Completo do Pulmão}

Esse extrator é composto pela junção das características dos outros extratores citados até agora nesse capítulo, tanto os tradicionais (histograma e textura por Haralick - utilizando as imagens DICOM pré-processadas ressaltando alta e baixa atenuação como descrito na seção 4.2), quanto o extrator específico citado na seção 4.3.1. É importante ressaltar que nesse extrator, o histograma utilizado para fazer parte do vetor de características foi equalizado em 32 níveis de cinza. Esse extrator será usado nos experimentos para avaliar o comportamento dos parâmetros perceptuais (representados por 5 classes de lesões pulmonares) com extratores específicos do contexto e comparálos a resultados obtidos apenas com extratores tradicionais. As características extraídas são as seguintes: 
- Histograma de Baixa Atenuação - Histograma Tradicional com 32 níveis de cinza da imagem DICOM pré-processada focando-se a janela de 600 níveis de intensidade centrados no valor de -800 HU (representando estruturas de baixa atenuação contidas no pulmão)

- Histograma de Alta Atenuação - Histograma Tradicional com 32 níveis de cinza da imagem DICOM pré-processada focando-se a janela de 600 níveis de intensidade pixels centrados no valor de $-400 \mathrm{HU}$ (representando estruturas de média atenuação contidas no pulmão)

- Textura - 32 características (sendo 16 de cada pulmão segmentado) de textura extraídas por matriz de co-ocorrência (descritores de Haralick: Homogeneidade, Energia, Contraste e Correlação), da imagem DICOM.

- Características Gerais do pulmão - 16 características que representam a Proporção de Ar e de Estruturas Densas no pulmão e a distribuição do interstício pulmonar, como descrito na seção 4.3.1.

- Forma do pulmão - extraindo 8 características de forma de cada um dos pulmões da imagem, baseadas na segmentação realizada para este trabalho (Ver seção 4.4). São as características:

- Área - quantidade de pixels do pulmão,

- Perímetro - quantidade de pixels da borda do pulmão,

- Extensão - área do pulmão dividida pela área do menor retângulo envolvente do pulmão,

- Solidez - área do pulmão dividida pela área do menor polígono envolvente do pulmão,

- Tamanho do Maior eixo - quantidade expressa em pixels,

- Tamanho do Menor eixo - quantidade expressa em pixels,

- Excentricidade da elipse correspondente ao pulmão - quantidade expressa em pixels,

- Diâmetro do circulo equivalente ao pulmão (círculo de mesma área) - - quantidade expressa em pixels.

Unindo todas as características acima, esse extrator gera um vetor de características contendo 120 posições, representando características de cor, forma e textura no mesmo vetor. 


\section{4 - Análise do Pulmão}

Como o foco de aplicação escolhido para validação da abordagem principal desse trabalho foi uma análise de imagens de CT de pulmão e os parâmetros perceptuais levantados são relativos às lesões pulmonares, todas as imagens foram pré-processadas por um algoritmo de segmentação do pulmão. Essa foi uma etapa importante, visto que nesse contexto de comparação, as características que nos interessam, extraídas pelos extratores já descritos na seção anterior, estão contidas nos pulmões.

Durante o estudo bibliográfico foram encontrados vários algoritmos sofisticados para segmentação de pulmão em imagens de CT de alta resolução [Prasad_2008] [Wang_2006] [Silva_2005] [Armato-III_2003], porém, como um estudo detalhado sobre segmentação não era o foco do trabalho, um algoritmo de segmentação eficiente para esse contexto foi implementado, conforme será descrito a seguir.

O algoritmo se aproveita da alta resolução da imagem DICOM, da técnica de window/center (janelamento) utilizada por radiologistas na visualização e análise do pulmão e de características anatômicas peculiares ao pulmão para realizar a segmentação. No processo de segmentação são utilizados conceitos de threshold, morfologia matemática e seleção de objetos para discriminar e separar o pulmão das demais estruturas da imagem. Na Figura 17 é apresentada, de maneira gráfica, o algoritmo utilizado para segmentação.

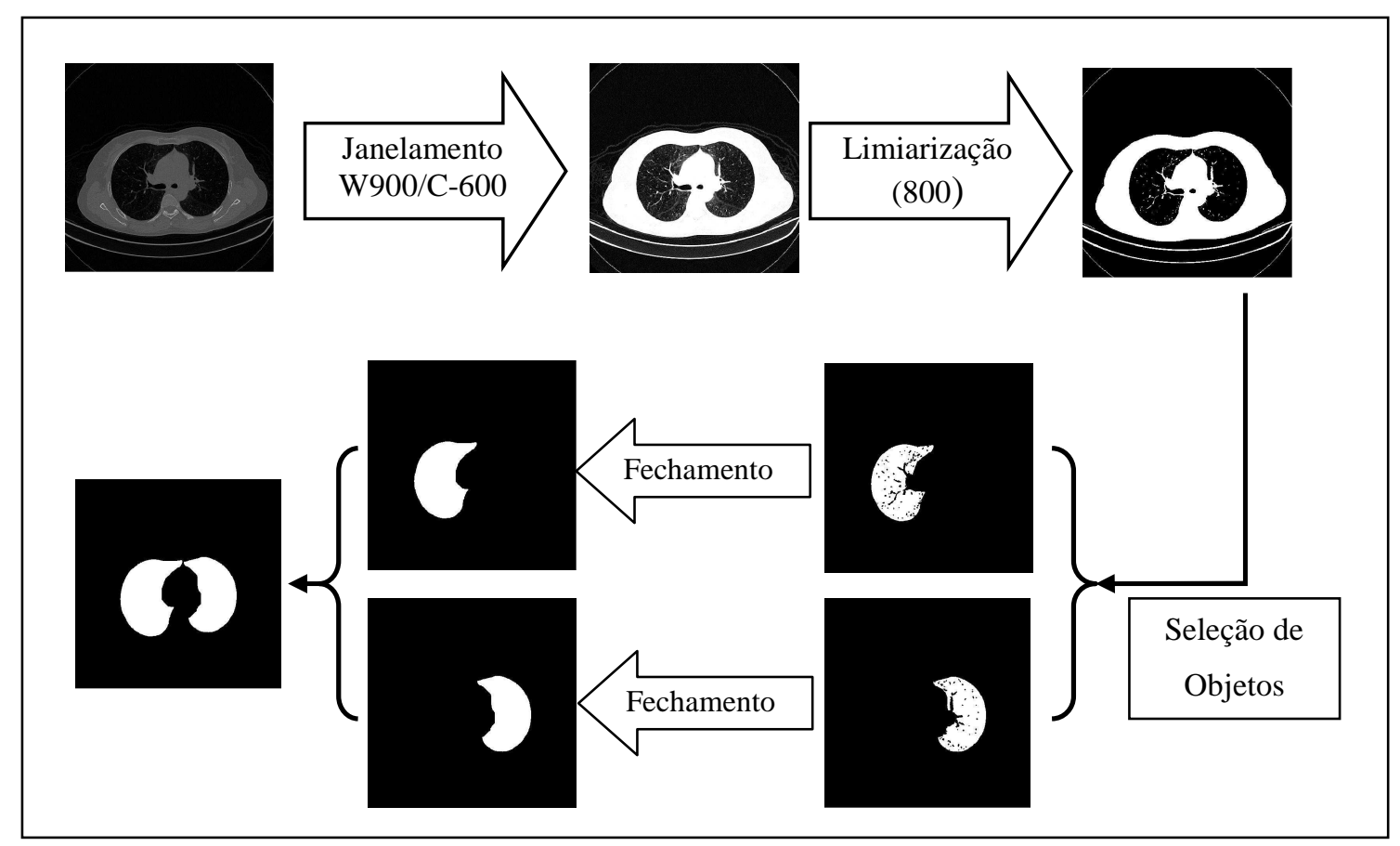

Figura 17 - Ilustração do Algoritmo de Segmentação do Pulmão 
A partir da imagem DICOM, o algoritmo faz um janelamento na imagem com janela de 900 níveis de intensidade centrados no valor de -600 , relativo à média de valores encontrados no pulmão (dados extraídos do conhecimento dos radiologistas ao manipular ferramentas de visualização das imagens DICOM nas estações de laudos). O janelamento produziu uma separação razoável do pulmão das outras estruturas de mesma intensidade de pixel na imagem. A imagem resultante é então binarizada utilizando um threshold no valor 800 de nível de cinza (valor empírico). O passo seguinte consistiu em selecionar os objetos de interesse, baseado em características anatômicas do pulmão (também coletadas do conhecimento dos radiologistas), como posição do pulmão na imagem e seu tamanho mínimo e máximo. A imagem binarizada de cada pulmão passa por operações de morfologia matemática (fechamento) para anular os "buracos" da limiarização causados por estruturas mais densas (normais ou não) contidas dentro do pulmão (Ex: vasos sanguíneos, traquéia, ou tecidos anormais). A etapa final do processo une em uma só imagem os dois pulmões, formando uma imagem binária só com os pulmões para ser utilizada como máscara da imagem original.

\section{5 - Considerações Finais}

Nesse capítulo foram descritos os métodos de processamento e extração específicos utilizados neste trabalho e como o conhecimento médico, levantado através dos parâmetros perceptuais dos radiologistas, foi introduzido em cada um deles. O propósito de se considerar a percepção no pré-processamento e na extração é demonstrar que o conhecimento do contexto pode ser inserido em todas as etapas dos métodos de representação das imagens por características numéricas e que, em cada etapa, diferentes resultados podem ser obtidos. 


\section{1 - Considerações Iniciais}

Nesse capítulo serão descritos os experimentos realizados nesse trabalho. Será apresentada uma análise dos resultados obtidos em cada experimento. Os resultados serão comparados entre si ressaltando a diferença dos experimentos e a influência de cada método na descrição de semelhança dos parâmetros perceptuais representados por 06 diferentes classes de imagens. Por fim serão descritas sugestões para a formação de tríades de otimização de consultas por similaridade em imagens de CT de pulmão nos ambientes reais de diagnóstico por imagens.

Para a realização dos experimentos foram utilizadas imagens de Tomografia Computadorizada de Alta Resolução de exames torácicos focados em pulmão. A base de testes é composta por 247 imagens coletadas de 108 exames distintos e reais de pacientes atendidos no HCFMRP. Os exames foram separados de acordo com a descrição do laudo e cada imagem dos exames foi classificada pelos residentes do referido hospital, divididas em seis (06) classes distintas (média de 40 imagens por classe), de acordo com o "achado" radiológico contido em cada uma das imagens. São as classes: Consolidação, Enfisema, Vidro Fosco, Favo de Mel, Espessamento e Normal. Um exemplo de cada uma das classes e seus respectivos parâmetros de visualização é apresentado com maiores detalhes na seção 3.4 dessa dissertação.

Nos experimentos aqui apresentados, cada classe foi analisada separadamente, permitindo um estudo individual do comportamento de cada parâmetro (representado por sua classe de imagens) e da interferência dos diferentes métodos de extração nesses parâmetros perceptuais. A análise de desempenho dos extratores de características e das funções de distância foi baseada em curvas de Precisão e Revocação. Esse método de avaliação de desempenho, descrito na seção 2.6, realiza várias (próximo de 40 para cada classe) consultas por similaridade, utilizando como centro de consulta as imagens da base pertencentes à classe sendo avaliada. Assim, para avaliação do desempenho da 
tríade, primeiramente foram realizados experimentos que definissem, para cada extrator e contexto (classe), qual a função de distância apresentava melhor desempenho. As funções de distância utilizadas foram: a L1 (Manhattam), L2 (Euclidiana), Linf (Infinity), Divergência de Jeffrey, Valor Estatístico X2 e distância Canberra (todas descritas em detalhes em [Bugatti_2008b]). Dando continuidade ao trabalho, o próximo passo foi a avaliação do desempenho do binômio de comparação (extrator de característica e função de distância), para cada parâmetro perceptual levantado no trabalho. Foram realizadas consultas por similaridade utilizando como centro de consulta as imagens da base cuja classe representa o parâmetro de percepção que estava sendo analisado. Ao final de todas as consultas, uma média das precisões de cada consulta foi calculada e plotada no gráfico de precisão vs. revocação. O valor obtido pela precisão média nos primeiros $25 \%$ de revocação será a principal medida de desempenho da dupla (extrator e função de distância) para cada parâmetro perceptual. Nessa análise de desempenho, foi decidido ater-se a resultados de precisão obtidos com até $25 \%$ da revocação porque, esse intervalo representa uma precisão obtida com no mínimo 20 imagens similares retornadas por consulta, número considerado pelos médicos entrevistados como compatível para comparação de imagens em ambiente reais. Visto que na prática eles não utilizariam um número maior de imagens similares para comparação de casos.

A inclusão do conhecimento médico para otimização das consultas por similaridade foi realizada em duas etapas do processo de extração de características: no pré-processamento e na análise para extração de atributos.

\section{2 - Parâmetros Perceptuais no Pré- Processamento}

Para avaliar o desempenho de se evidenciar os parâmetros de percepção do médico na imagem antes de submetê-la à extração de características, selecionamos dois extratores bem conhecidos e aceitos na literatura. São eles: Histograma da imagem, com 256 intensidades de níveis de cinza; e características de textura extraídas por análise da matriz de co-ocorrência, utilizando quatro características descritas por Haralick: Homogeneidade, Energia, Contraste (Variância) e Correlação. Cada um desses dois 
extratores foi submetido a testes com as imagens originais da base e com as mesmas imagens, porém pré-processadas (por janelamento) de forma a evidenciar padrões de Alta e Baixa Atenuação. Os resultados dos experimentos realizados com cada um dos extratores são descritos abaixo. Vale ressaltar que os valores de centro e tamanho da janela utilizada no algoritmo de janelamento foram escolhidos de acordo com valores que os médicos utilizam durante a visualização das imagens no ambiente de laudo.

\subsection{1 - Experimento 1: Histograma com 256 níveis de cinza}

Esse experimento visa comparar o desempenho de três testes realizados com a base de imagens de pulmão.

- O primeiro, chamado de "Histograma Tradicional", utiliza a imagem original DICOM equalizada para 256 níveis de cinza como entrada para extração de características.

- O segundo, chamado "Histograma Alta", utiliza a imagem DICOM janelada em W600/C-400, posteriormente equalizada para 256 níveis de cinza. Essa operação de janelamento aumenta o contraste de características visuais de alta atenuação e suprime características visuais de baixa atenuação.

- O terceiro, chamado "Histograma Baixa", utiliza a imagem DICOM janelada em W600/C-800 equalizada para 256 níveis de cinza. Essa operação aumenta o contraste de características visuais de baixa atenuação e suprime características visuais de alta atenuação.

Primeiramente, uma avaliação de qual a função de distância apresenta melhor desempenho no contexto dos dados extraídos por cada extrator foi essencial para determinar quais binômios (dupla: extrator e função de distância) seriam avaliados como melhores para cada parâmetro perceptual. Em uma visão geral, as funções de distância apresentaram pouca variação entre si, porém, para a etapa de avaliação seguinte, foi considerado para avaliação cada extrator atrelado à função de distância que apresentou melhor desempenho na média das consultas utilizando-se todas as imagens como centro de consulta. No Gráfico 1 é percebido que a função de distância Linf (infinity) apresentou melhor resultado ao distinguir as classes a partir de dados extraídos pelo "Histograma Tradicional". Em determinados momentos de revocação ela chegou a 
apresentar um desempenho 50\% maior que a média das outras funções, que apresentaram desempenho muito semelhante.

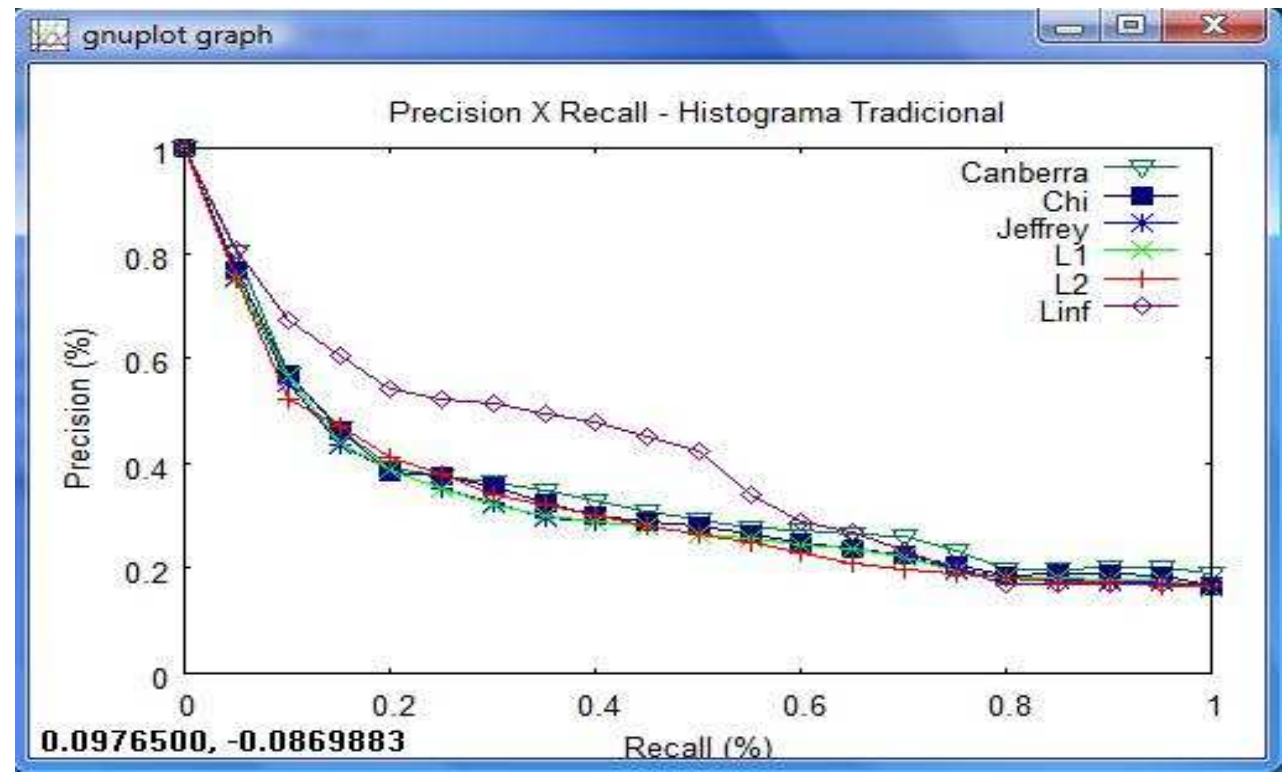

Gráfico 1 - Precisão e Revocação - "Histograma Tradicional"

No caso dos dados extraídos por "Histograma Baixa" e por "Histograma Alta" (Gráfico 2 e Gráfico 3 respectivamente), as funções de distância apresentam comportamentos semelhantes, onde a função de distância L2 (Euclidiana) e a L1 (Manhattan) apresentaram desempenho um pouco melhor que as outras e a função distância Canberra a que obteve o pior desempenho em ambas.

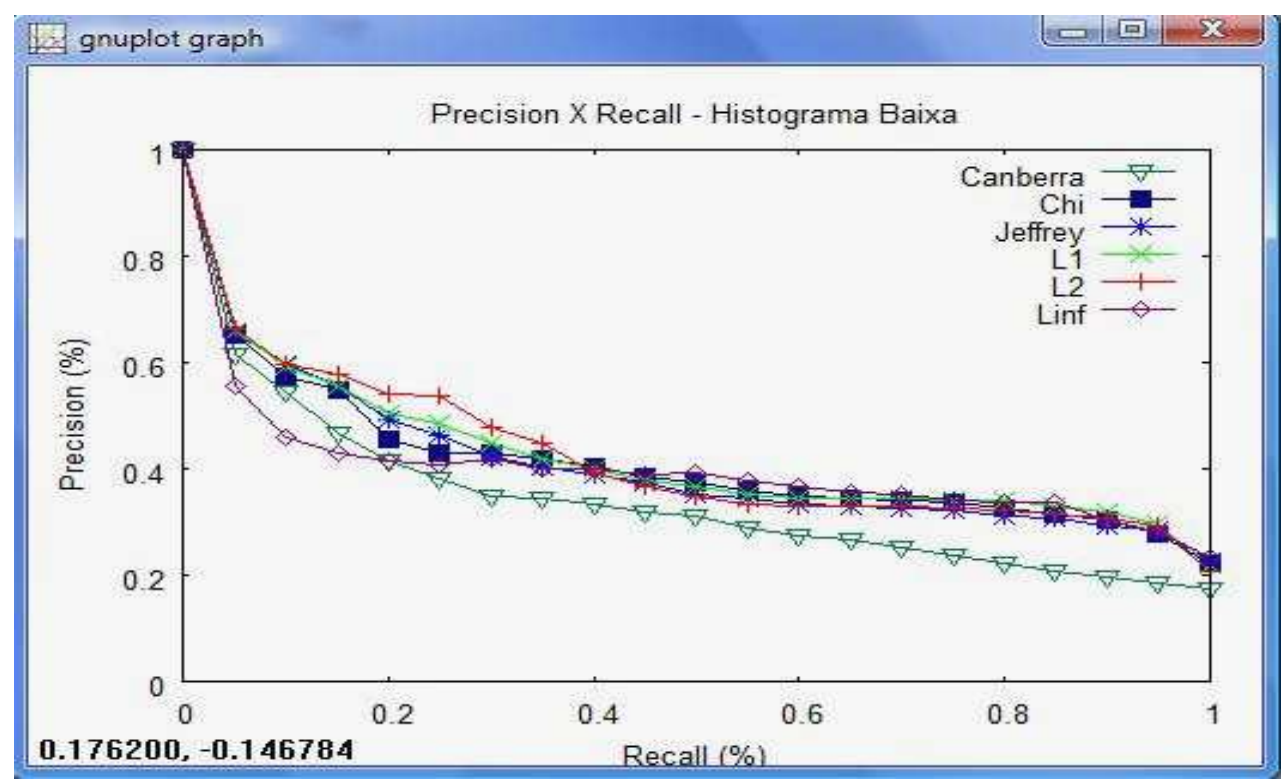

Gráfico 2 - Precisão e Revocação - "Histograma Baixa" 


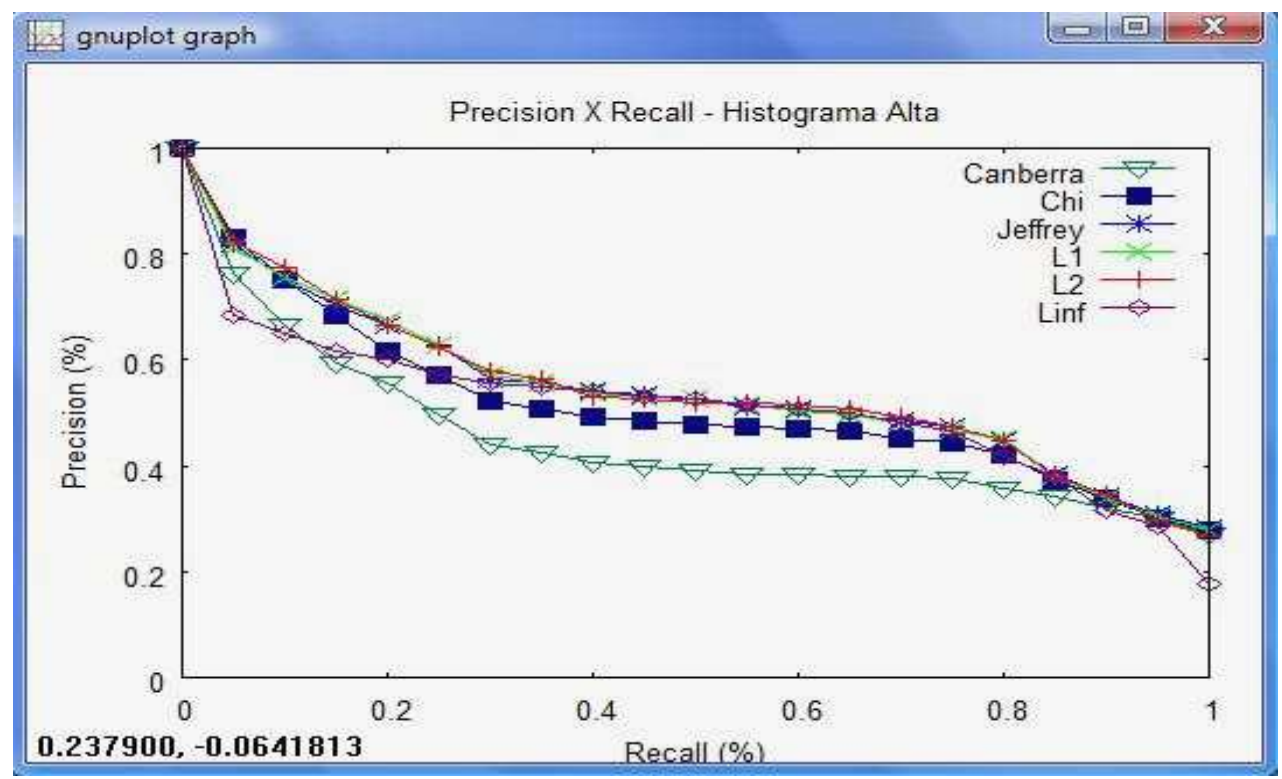

Gráfico 3 - Precisão e Revocação para o extrator "Histograma Alta"

Com os resultados apresentados acima, foram definidas as duplas (extrator função de distância) para a avaliação seguinte, são elas: "Histograma Tradicional Linf”,"Histograma Baixa - L2" e "Histograma Alta - L2". O experimento foi então repetido considerando agora o desempenho da dupla "Extrator - Função de Distância" em consultas por similaridade, usando como centro de consulta imagens de cada uma das classes (que representam os parâmetros perceptuais).

Observando os Gráficos 4, 5 e 6, o desempenho dos parâmetros de percepção "Clareamento Homogêneo", "Clareamento não Homogêneo" e "Escurecimento com fissuras", representados respectivamente pelas classes de imagens com Consolidação, Vidro Fosco e Favo de Mel, apresentaram o mesmo comportamento geral considerando os três métodos de extração comparados. Foi percebido que, nesses casos, aumentar o contraste da imagem nos níveis de cinza de baixa atenuação melhorou o desempenho médio do extrator histograma de $71 \%$ (precisão média nos primeiros $25 \%$ de recall) para $78 \%$ no primeiro parâmetro, de $60 \%$ para $65 \%$ no segundo e $54 \%$ para $58 \%$ no terceiro, todos comparados ao desempenho no procedimento tradicional. Isso significa um aumento médio de quase $10 \%$ na precisão das consultas.

O comportamento semelhante desses três parâmetros perceptuais pode ser explicado pelo fato de eles conterem partes mais claras na imagem. Os dois primeiros parâmetros envolvem "clareamento" da estrutura normal (pode ser percebido pelo nome) e o terceiro parâmetro ("Escurecimento com fissuras"), apesar de citar um escurecimento em sua definição, não deixa de ter partes claras, pois as bolhas escurecidas são envoltas por paredes (bordas, fissuras) claras e espessas. Todo esse 
efeito de clareamento nos três parâmetros determinou a igualdade de comportamento entre eles, visto que nesse aspecto visual, se diferenciam apenas na maneira como esse clareamento é distribuído no pulmão, característica não captada por um histograma de cor. Nos três casos, o melhor desempenho alcançado foi obtido utilizando a extração "Histograma Baixa" com a função de distância L2 e o "Histograma Alto", que aumenta o contraste da imagem nos níveis de pixels de alta atenuação, piorou o desempenho das consultas nos três casos.

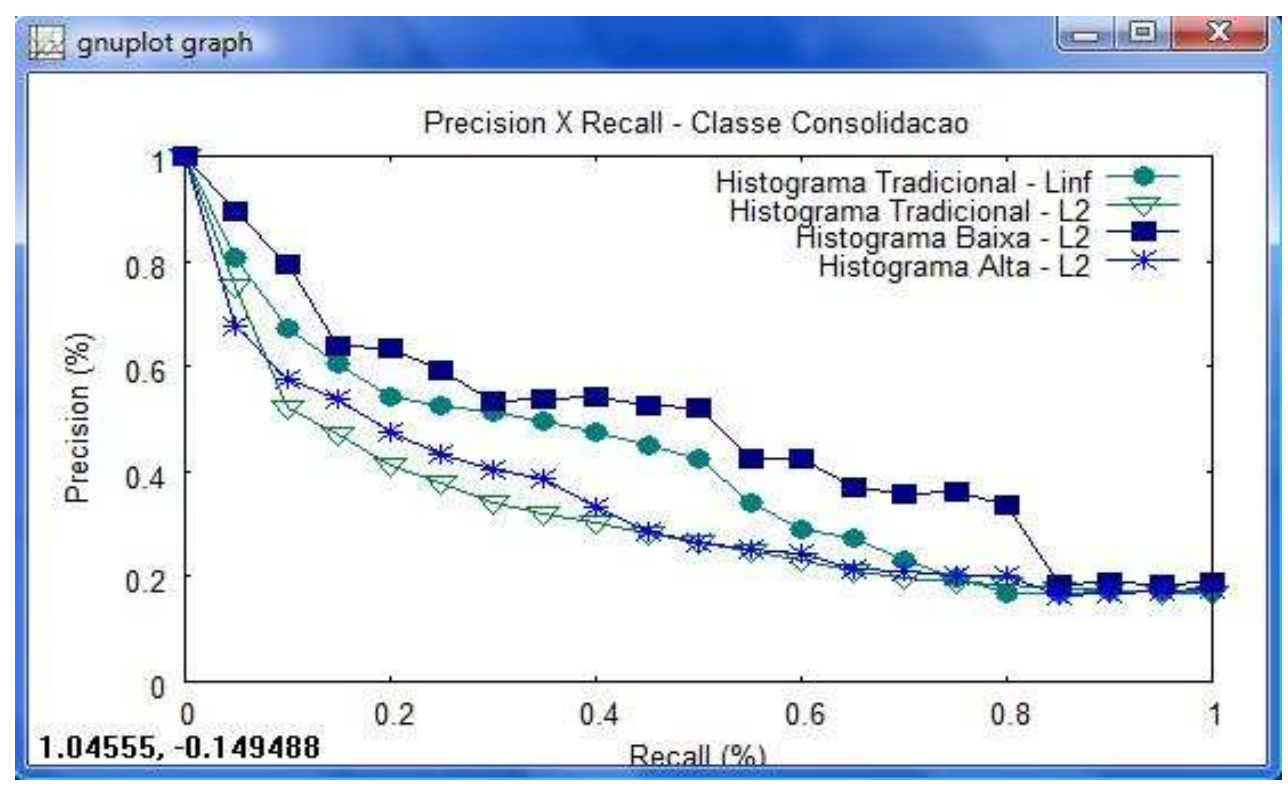

Gráfico 4: Precisão e Revocação para a classe Consolidação considerando a "dupla" extrator (histograma) e função de distância em sua melhor configuração

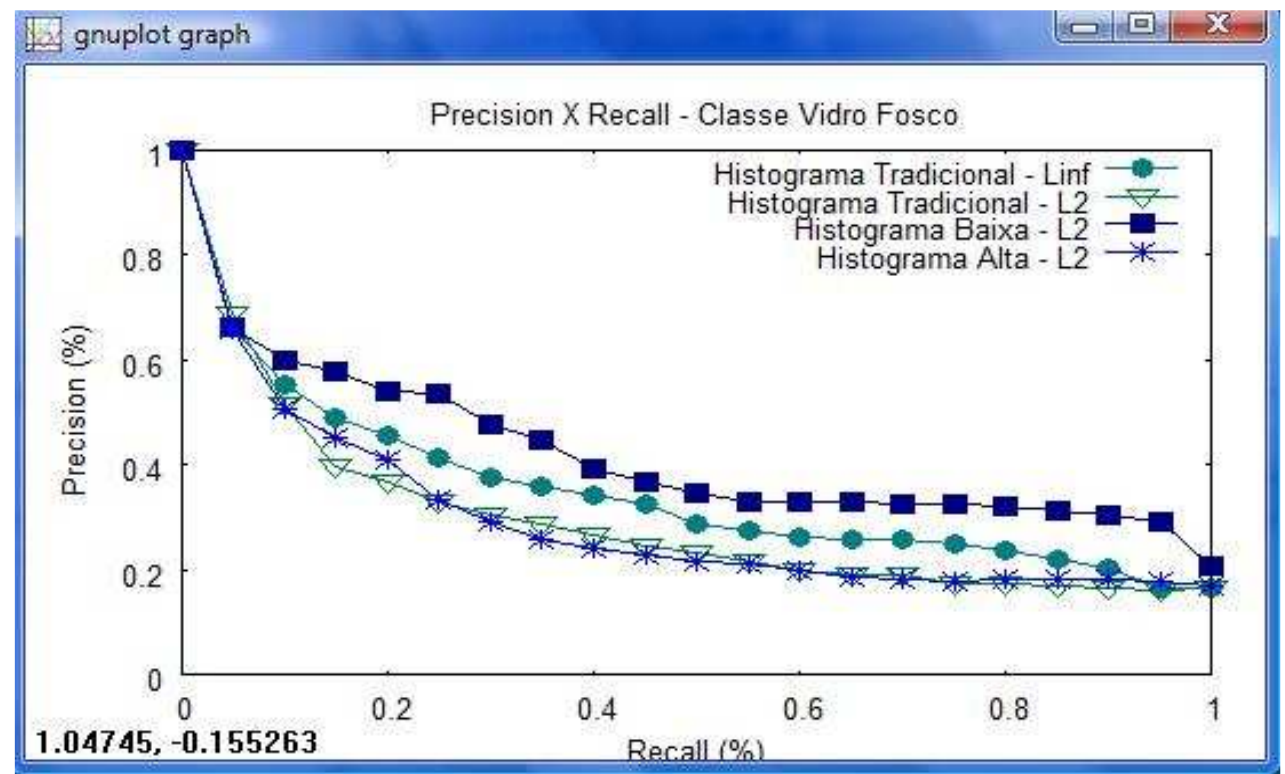

Gráfico 5: Precisão e Revocação para a classe Vidro Fosco considerando a "dupla" extrator (histograma) e função de distância em sua melhor configuração 


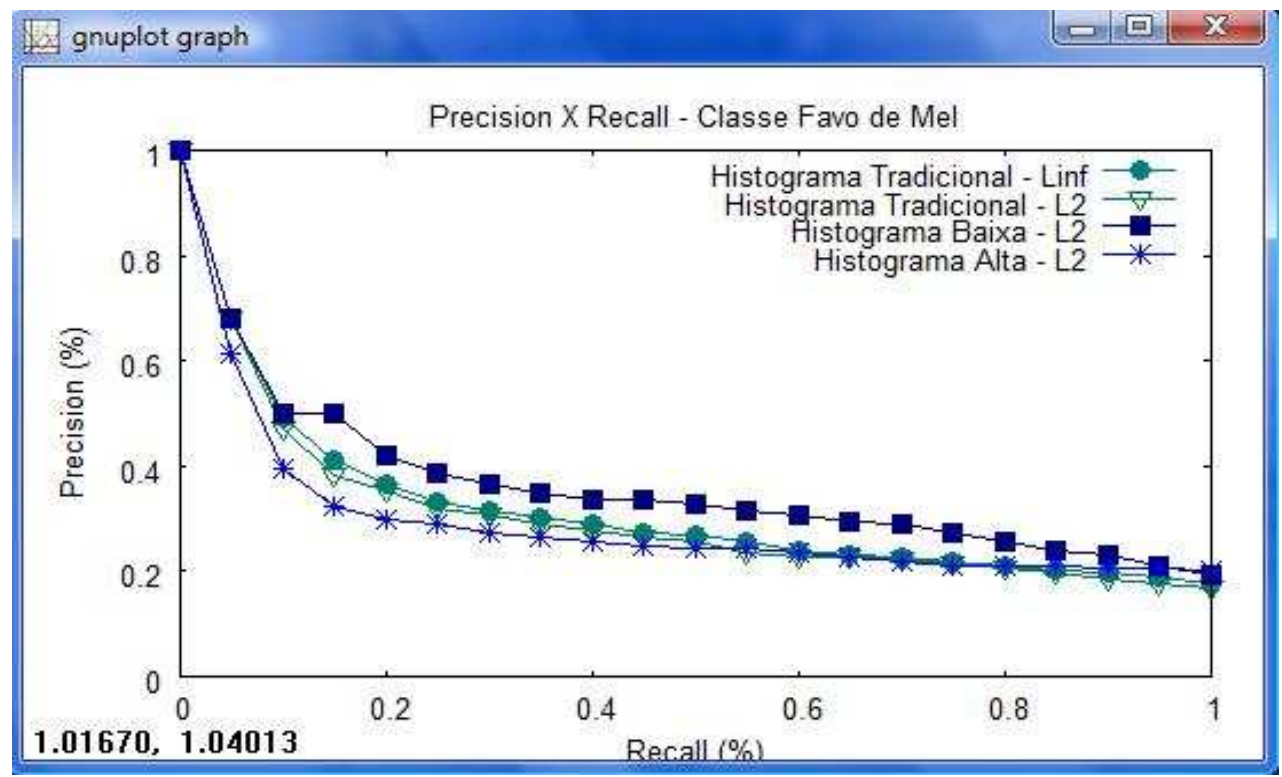

Gráfico 6: Precisão e Revocação para a classe Favo de Mel considerando a "dupla" extrator (histograma) e função de distância em sua melhor configuração

Para os parâmetros perceptuais que não envolvem clareamento da imagem, os comportamentos dos métodos de comparação apresentaram desempenhos contrários. No Gráfico 7 é mostrado o desempenho do parâmetro de percepção "Escurecimento sem fissuras", representado pela classe Enfisema. Para essa classe, aumentar o contraste da imagem nos níveis de cinza de baixa atenuação piorou o desempenho médio do extrator histograma comparado ao desempenho no procedimento tradicional. Esse parâmetro perceptual, que envolve apenas um "escurecimento" na imagem, determinou esse comportamento. Utilizando a dupla "Histograma Alto" (que aumenta o contraste da imagem nos níveis de pixels de alta atenuação) e a função de Distância L2, a consideração dos parâmetros de percepção resultou em uma melhora de $71 \%$ para $78 \%$ na precisão média nos primeiro $25 \%$ de recall (novamente um aumento de quase $10 \%$ de precisão nas consultas por similaridade). 


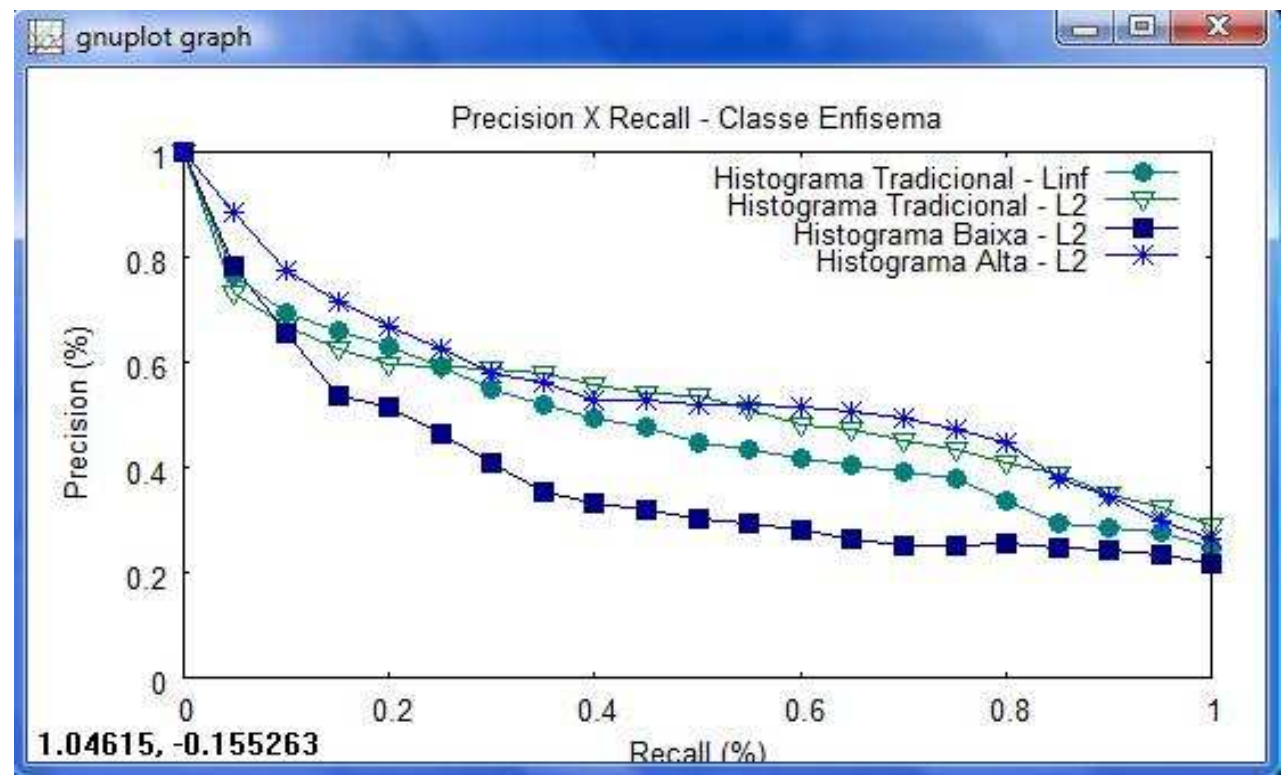

Gráfico 7: Precisão e Revocação para a classe Enfisema considerando a "dupla” extrator (histograma) e função de distância em sua melhor configuração

Outro resultado interessante nesse experimento foi o comportamento observado no desempenho das consultas cujas imagens exemplos foram imagens normais da base (imagens sem nenhum achado clínico visível, portanto, com nenhum parâmetro de percepção associado). Nesse caso, apresentado no Gráfico 8, o "Histograma Tradicional" apresentou o melhor desempenho, mostrando que os dois préprocessamentos executados para evidenciar os parâmetros perceptuais pioraram o desempenho das consultas nas imagens normais. Essa piora é justificada pelo fato de que imagens normais não apresentam alteração da estrutura normal. Como o objetivo do pré-processamento é evidenciar as características visuais dos parâmetros de percepção, a ausência desses parâmetros na imagem faz com que nenhuma característica visual seja evidenciada com o pré-processamento, ocorrendo apenas a perda de informação normal. Essa perda de informação no pré-processamento das imagens classificadas como normais aproxima as suas características extraídas das características extraídas de imagens que, por decorrência de algumas lesões, também perderam essas informações durante o processo de formação das imagens. É essa aproximação nas características intrínsecas extraídas das imagens que piorou o desempenho das consultas por similaridade em imagens normais. 


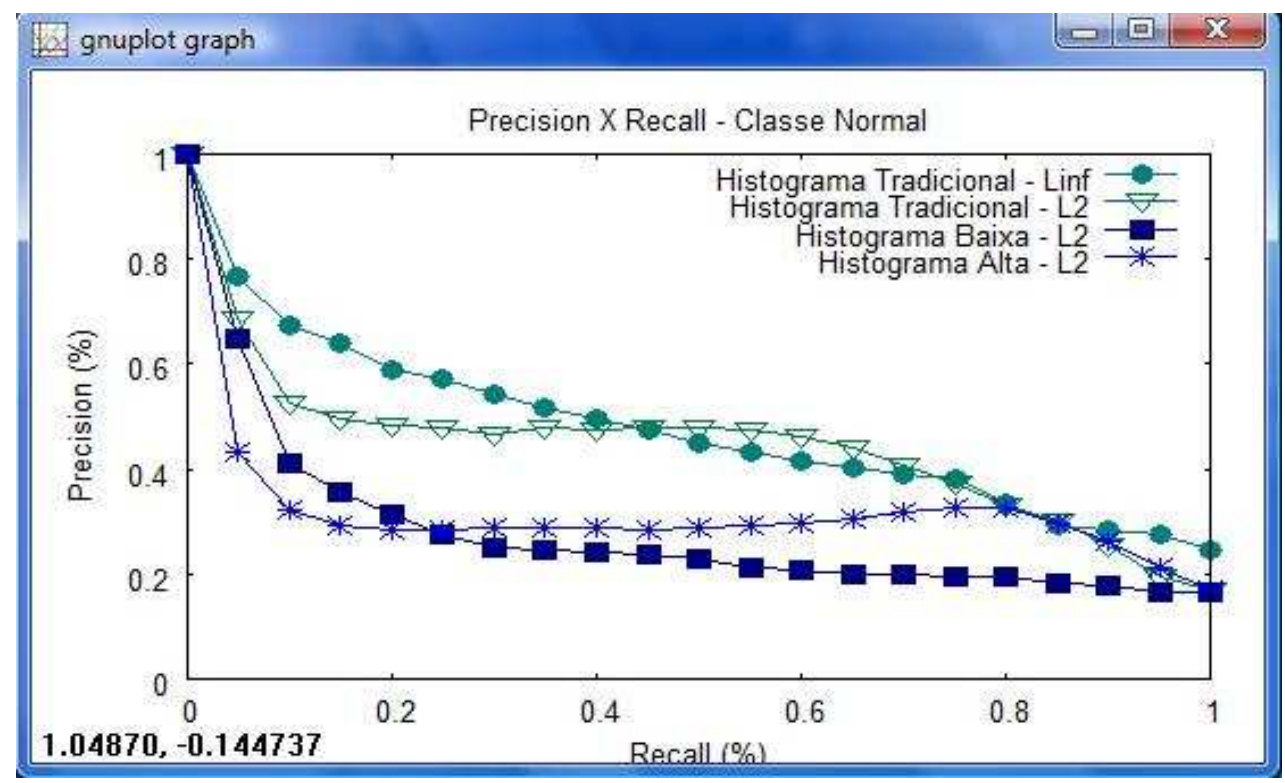

Gráfico 8: Precisão e Revocação para a classe Normal considerando a "dupla” extrator (histograma) e função de distância em sua melhor configuração

\subsection{2 - Experimento 2: Textura por Haralick}

Este experimento é similar ao anterior, porém utilizando um extrator de textura global no lugar do histograma. As montagens das matrizes consideraram quatro direções de vizinhança $\left(0^{\circ}, 45^{\circ}, 90^{\circ}, 135^{\circ}\right)$ com uma distância de 01,05 e 10 pixels. As medidas extraídas das matrizes de Co-ocorrência foram: Homogeneidade, Energia, Contraste e Correlação, para cada um dos pulmões, gerando assim, para cada imagem, um vetor contendo 32 atributos de textura (os 16 primeiros equivalem ao pulmão esquerdo e os 16 seguintes ao pulmão direito).

- O primeiro teste, chamado "Textura Tradicional", foi realizado utilizando-se a imagem DICOM original equalizada para 16 níveis de cinza.

- No segundo teste, chamado "Textura Alta", utilizou-se a imagem DICOM janelada em W600/C-400 equalizada para 16 níveis de cinza.

- No terceiro, chamado "Textura Baixa”, foi utilizada a imagem DICOM janelada em W600/C-800 equalizada em 16 níveis de cinza.

A busca experimental pela função de distância de melhor desempenho para cada um dos extratores de textura mostrou certa fragilidade das características extraídas por eles ao representarem o contexto especificado (lesões pulmonares). Como apresentado no Gráfico 9, que mostra o desempenho das funções de distância para o extrator "Textura Tradicional”, o comportamento das diferentes funções foi o mesmo. Esse fato 
se repetiu em todos os três extratores. Esse resultado levantou a suspeita de que os dados extraídos pelos extratores de textura aqui especificados não são tão representativos ao contexto apresentado. Porém, para dar continuidade aos experimentos, a distância L1 (Manhattan) foi escolhida para integrar o binômio com os extratores de textura. Essa escolha se deu por ela apresentar menor complexidade no cálculo.

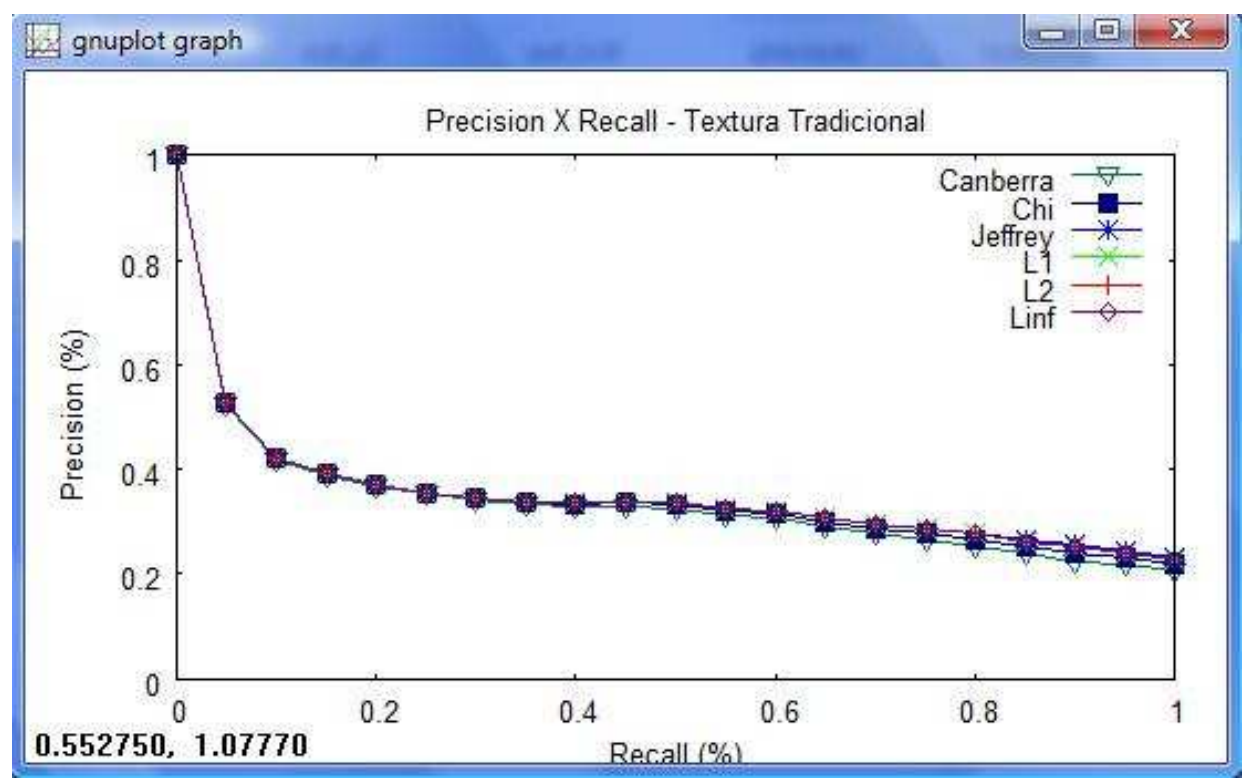

Gráfico 9: Precisão e Revocação - Textura Tradicional

A metodologia utilizada para extração de características de textura utilizou toda a extensão pulmonar e comparou pulmão esquerdo com pulmão esquerdo, pulmão direito com pulmão direito. Essa metodologia pode ter sido também responsável pela má atuação das características de textura no contexto das lesões pulmonares, visto que características globais (que consideram toda a extensão do pulmão) podem minimizar os efeitos das características locais (que ocorrem em pequenas regiões de interesse). $\mathrm{O}$ resultado apresentado no Gráfico 10 confirma essa hipótese. Nele percebe-se que o extrator de textura gerou bons atributos apenas para o parâmetro perceptual "Escurecimento sem fissura". Isso se deve ao fato de que o achado característico desse parâmetro perceptual (o Enfisema) é o único dos 5 que, na maioria das imagens, ocorre em uma extensão considerável do pulmão (e em ambos os pulmões de uma mesma imagem), o que provavelmente facilitou a determinação de textura específica. Os outros achados ocorrem, na maioria dos casos da base, em regiões pequenas do pulmão, ou na periferia, como no caso do padrão Favo de Mel, ou em regiões finas, como o espessamento, ou acumulados em regiões internas homogêneas, como no caso 
Consolidação. Ao contrário do enfisema, na maioria das vezes, esses outros achados ocorrem em apenas um pulmão. No entanto, ao longo dos experimentos, outras observações interessantes detalhadas a seguir, puderam ser deduzidas a partir dos resultados obtidos.

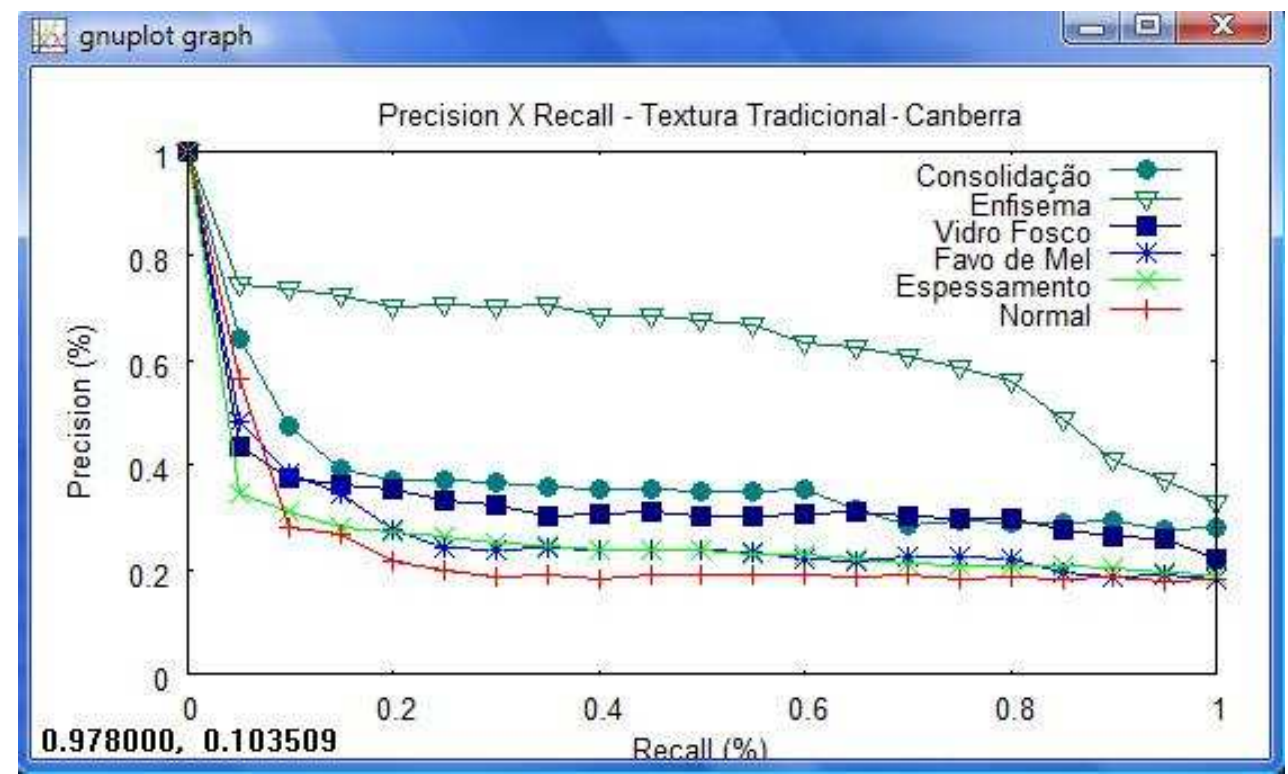

Gráfico 10: Precisão e Revocação - Dupla: Textura Tradicional - Canberra

Os experimentos de textura mostraram que as informações relevantes extraídas do pulmão por esse extrator encontram-se concentradas na região compreendida pelo janelamento de baixa densidade (W600/C-800). Essa conclusão foi levantada devido a duas observações: a primeira foi pelo fato do desempenho do extrator "Textura Baixa" ter sido o mesmo do extrator "Textura Tradicional"; a segunda, pelo fato de que o extrator "Textura Alta" fez com que o desempenho piorasse em todos os casos observados. Esse último extrator ("Textura Alta") aumenta o contraste na região de alta densidade do pulmão e diminui (quase que igualando os níveis de cinza) o contraste na região de baixa densidade. Essa perda de informação em regiões de baixa densidade foi a responsável pelo desempenho fraco desse extrator em todos os casos. Esse comportamento, apresentado nos Gráficos 11 e 12, mostra também que o aumento de contraste realizado pelo janelamento na região de baixa atenuação não alterou a relação de textura entre as imagens das diferentes classes, pois seu desempenho foi muito semelhante ao extrator tradicional, ou seja, sem o aumento de contraste. Essas duas observações apresentadas deram evidências de que as informações relevantes de textura estão concentradas nessas regiões de baixa atenuação. 


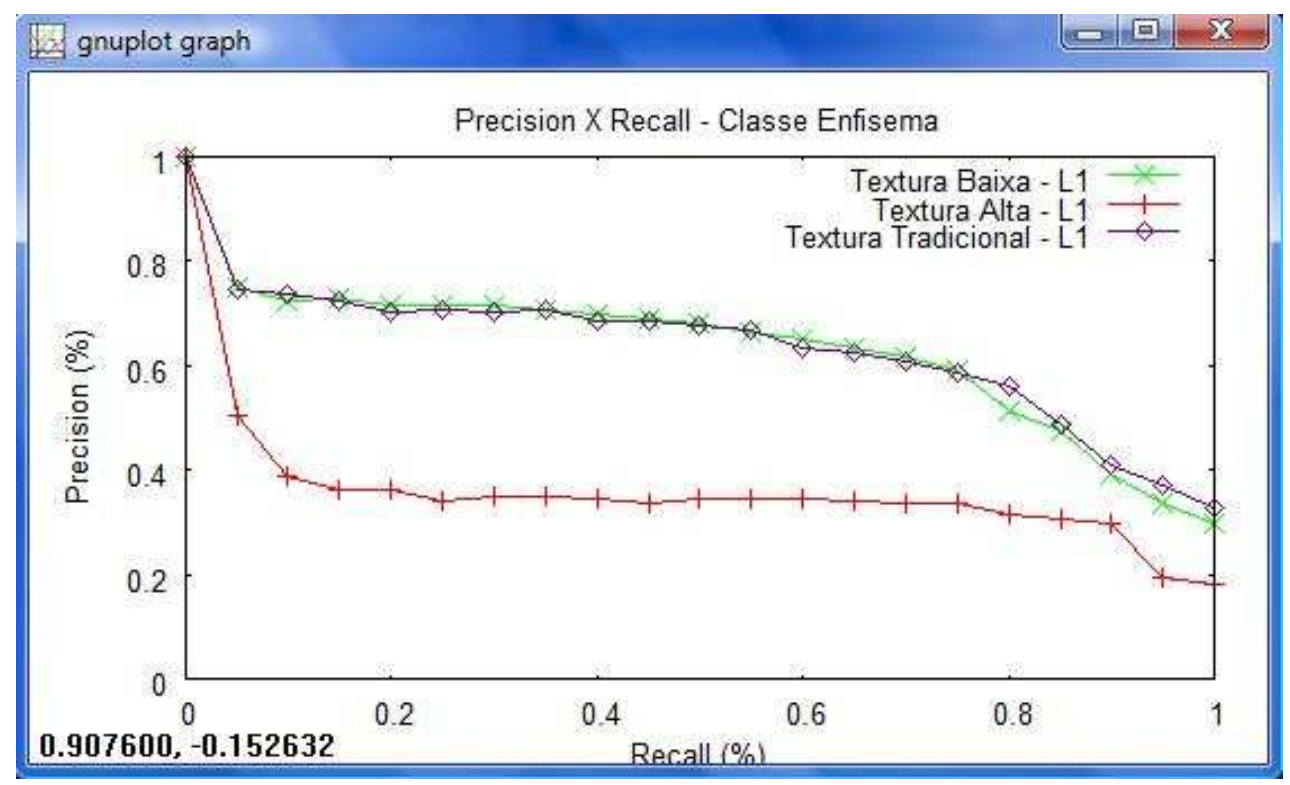

Gráfico 11: Precisão e Revocação - Enfisema

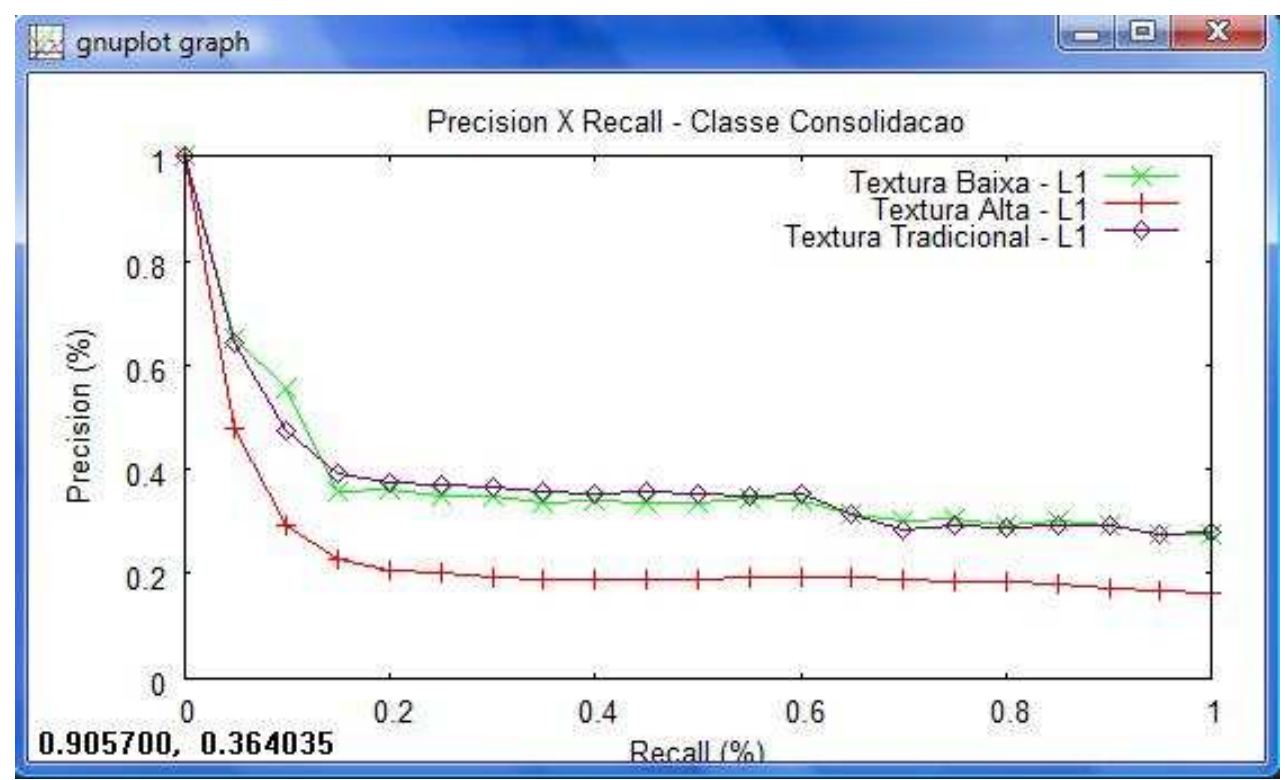

Gráfico 12: Precisão e Revocação - Consolidação

Uma avaliação geral do comportamento dos parâmetros de percepção mostrou que características globais de textura captam bem os achados que têm por característica estarem presentes em boa parte do pulmão, como no caso do Enfisema. Para se melhorar o desempenho das outras classes, será necessário outro tipo de préprocessamento, que ressalte características (parâmetros de percepção) individuais de cada classe e considerem a questão da localização específica de cada achado (regiões de interesse). 


\subsection{3 - Conclusões Parciais}

Os resultados dos experimentos 1 e 2 buscaram avaliar a influência de se considerar (evidenciar) os parâmetros de percepção no pré-processamento da imagem, analisando o comportamento dos binômios (extrator de características e funções de distância) para cada parâmetro perceptual.

Com esses resultados, concluiu-se que:

- Considerar (evidenciar) os parâmetros de percepção no préprocessamento melhora o desempenho das características extraídas por extratores tradicionais. No caso do histograma, essa melhora foi de $10 \%$ em todos os casos. No caso da textura, essa melhora não foi alcançada porque a operação de janelamento (aumento de contraste em região específica) manteve a relação original entre os pixels da imagem (característica captada pela matriz de co-ocorrência).

- As características relevantes de textura em imagens de pulmão encontram-se concentradas em regiões de baixa atenuação. Esse fato foi evidenciado em todas as classes ao se analisar que o extrator "Textura Baixa" (que buscava evidenciar a região de baixa atenuação) manteve o desempenho do extrator tradicional e que, em contrapartida, o extrator "Textura Alta" (que considerou a região de alta atenuação) piorou o resultado em todas elas.

Com os resultados desses experimentos foi possível reforçar a idéia de que diferentes parâmetros perceptuais das imagens (representados por suas respectivas classes) apresentam diferentes desempenhos com os mesmos extratores. Esse resultado confirma a hipótese de que a ferramenta CBIR que mapear para cada parâmetro uma dupla (extrator, função de distância) que melhor o represente, estará um passo à frente de se conseguir melhores resultados nas buscas por similaridade. 


\section{3 -Extração de Características Específicas ao Contexto}

A construção de extratores específicos ao contexto é o método utilizado na maioria dos trabalhos envolvendo Recuperação de Imagens Médicas por conteúdo para auxílio ao diagnóstico. Esse método busca incluir na representação das imagens a semântica do contexto. Utiliza características da imagem original diretamente ligada à percepção visual do contexto especificado, diferente da abordagem utilizada nos experimentos anteriores, que utilizaram extratores tradicionais (independentes do contexto), porém com uma tentativa de inclusão da semântica durante a fase de pré-processamento das imagens.

\subsection{1 - Experimento 3: Extrator Geral do Pulmão}

Nesse experimento analisamos principalmente a eficiência das características globais específicas do pulmão extraídas da descrição de similaridade dos diferentes parâmetros perceptuais. No Gráfico 13, que mostra o desempenho do "Extrator Geral" com a função L2 (euclidiana), pode-se perceber que, mesmo para um extrator específico ao contexto, cada classe de imagens apresentou diferentes desempenhos nas consultas por similaridade. Essa variação de desempenho entre as classes chegou a ser de $56 \%$ de precisão média para Espessamento e $80 \%$ para Consolidação nos primeiros $25 \%$ de revocação.

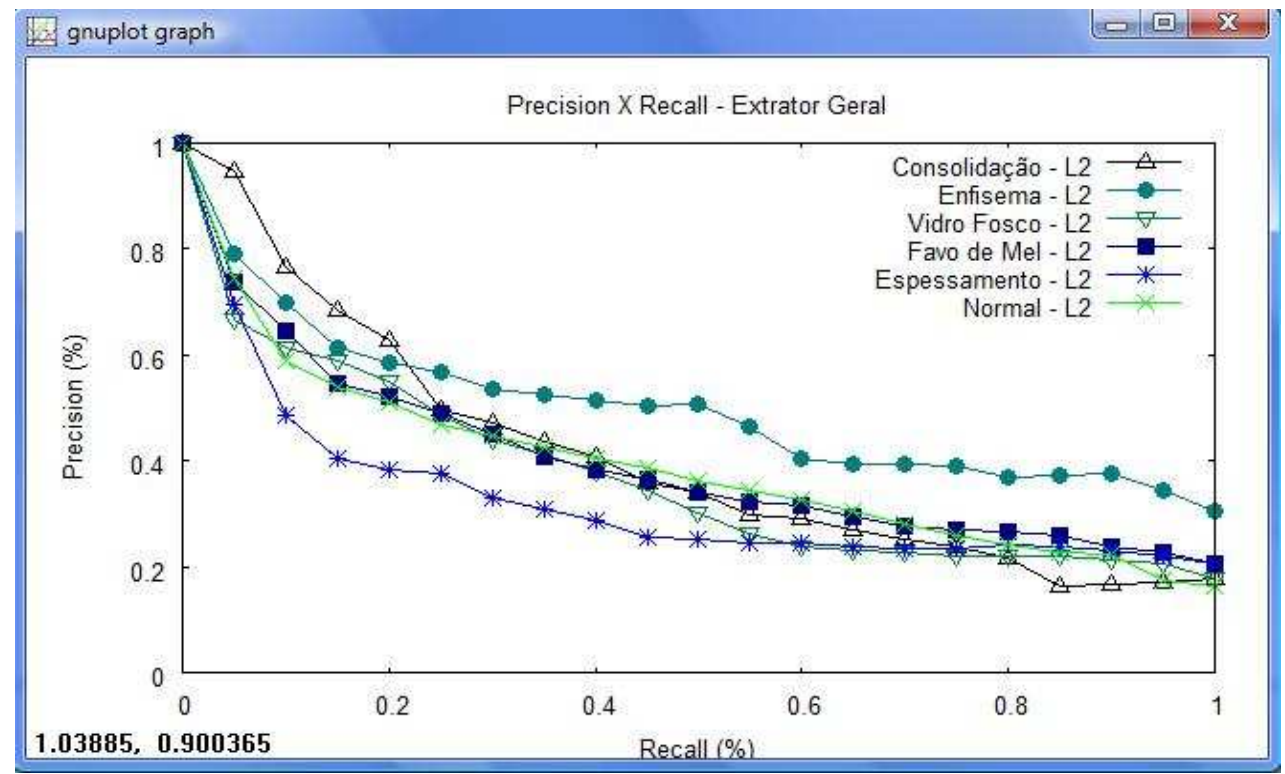

Gráfico 13: Precisão e Revocação - Extrator Geral 
Os desempenhos das funções de distância utilizando o "Extrator Geral" apresentaram pouca variação entre si. A função de distância que apresentou melhor desempenho na média das consultas, utilizando-se todas as imagens da base como centro de consulta, foi a L1 (Manhattan). Como apresentado no Gráfico 14, ela não ficou isolada na liderança de desempenho, porém manteve-se entre as melhores durante a primeira metade da linha da revocação, ao passo que as outras tiveram pequenas perdas de precisão nesse intervalo.

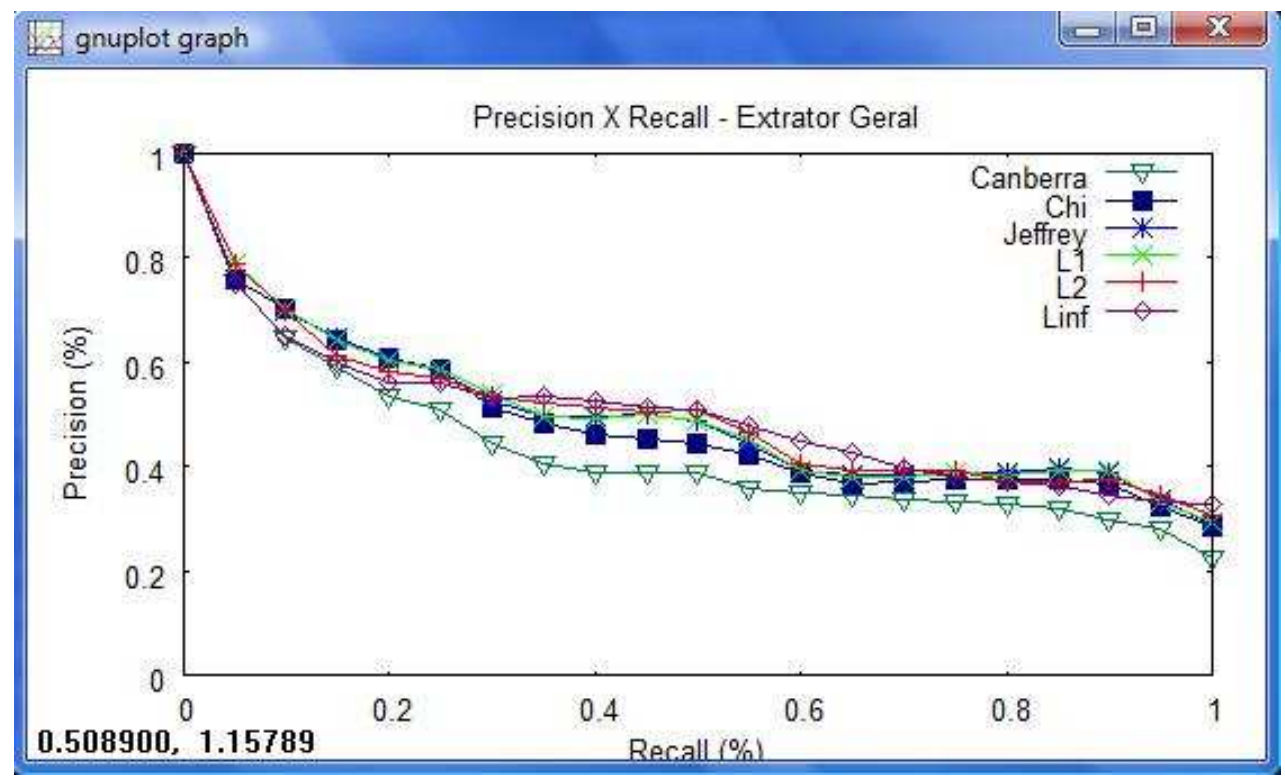

Gráfico 14: Precisão e Revocação - Extrator Geral

No Gráfico 15 é mostrada uma comparação do desempenho do Extrator Geral com os outros métodos de extração utilizados até o momento. Nessa comparação fica evidente a eficiência das características específicas, principalmente porque está sendo comparado o desempenho de 16 atributos específicos contra 256 atributos de cor e 32 atributos de textura. Nesse experimento, as precisões médias para o "Extrator Geral", o "Histograma Tradicional" e o "Textura Tradicional" foram, respectivamente, 70\%, 54\% e $46 \%$, ou seja, de um ganho médio de $28 \%$ de precisão no resultado das consultas. 


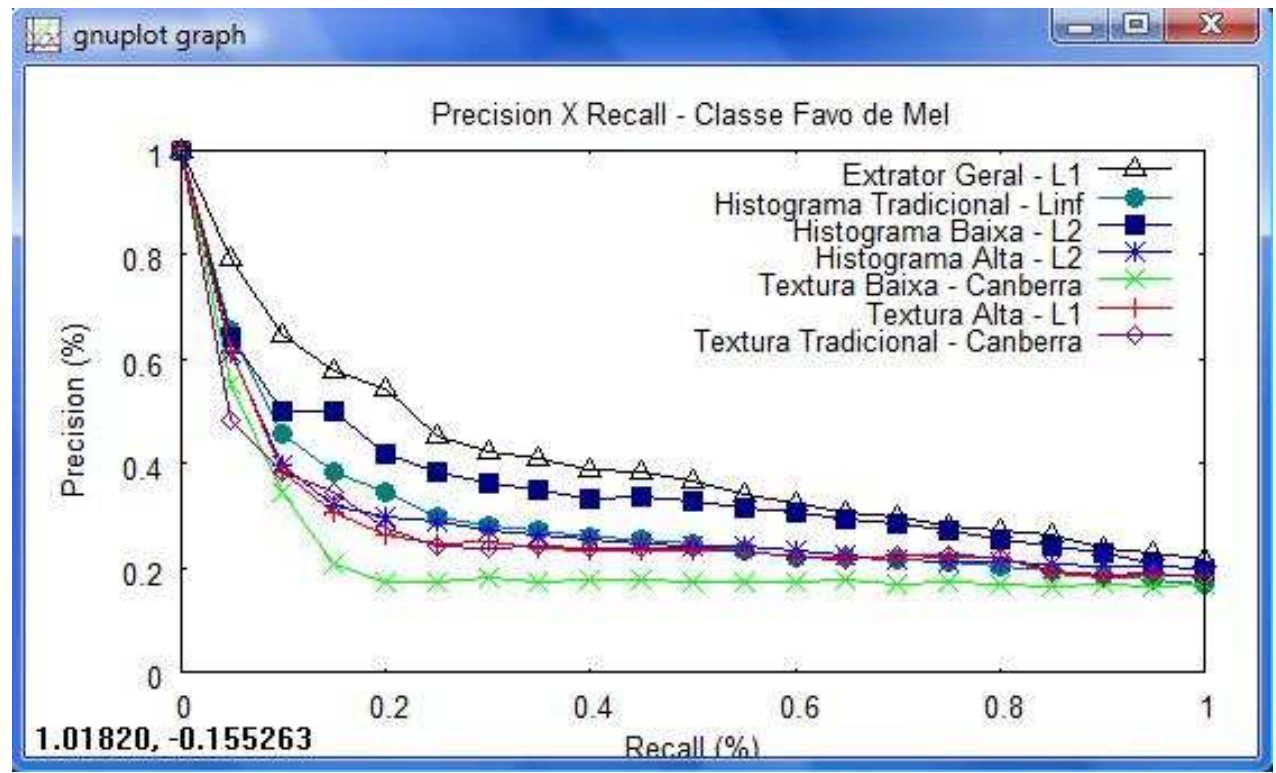

Gráfico 15: Precisão e Revocação para a classe Favo de Mel considerando a dupla extrator e função de distância em sua melhor configuração.

O Gráfico 15 representa o comportamento dos extratores para o parâmetro "Escurecimento com fissura (borda)", representado pela classe Favo de Mel, porém, esse comportamento se repetiu na maioria dos parâmetros perceptuais, com exceção apenas do "Escurecimento sem fissura", representado pela classe Enfisema (Gráfico 16), onde o "Histograma Alta" e a "Textura Baixa" sobrepuseram o desempenho do "Extrator Geral". O bom desempenho desses extratores mostra que em alguns casos um pré-processamento bem feito, evidenciando-se as características certas, o desempenho de um extrator tradicional geral (como histograma ou textura) pode conseguir ser melhor que um extrator específico do contexto.

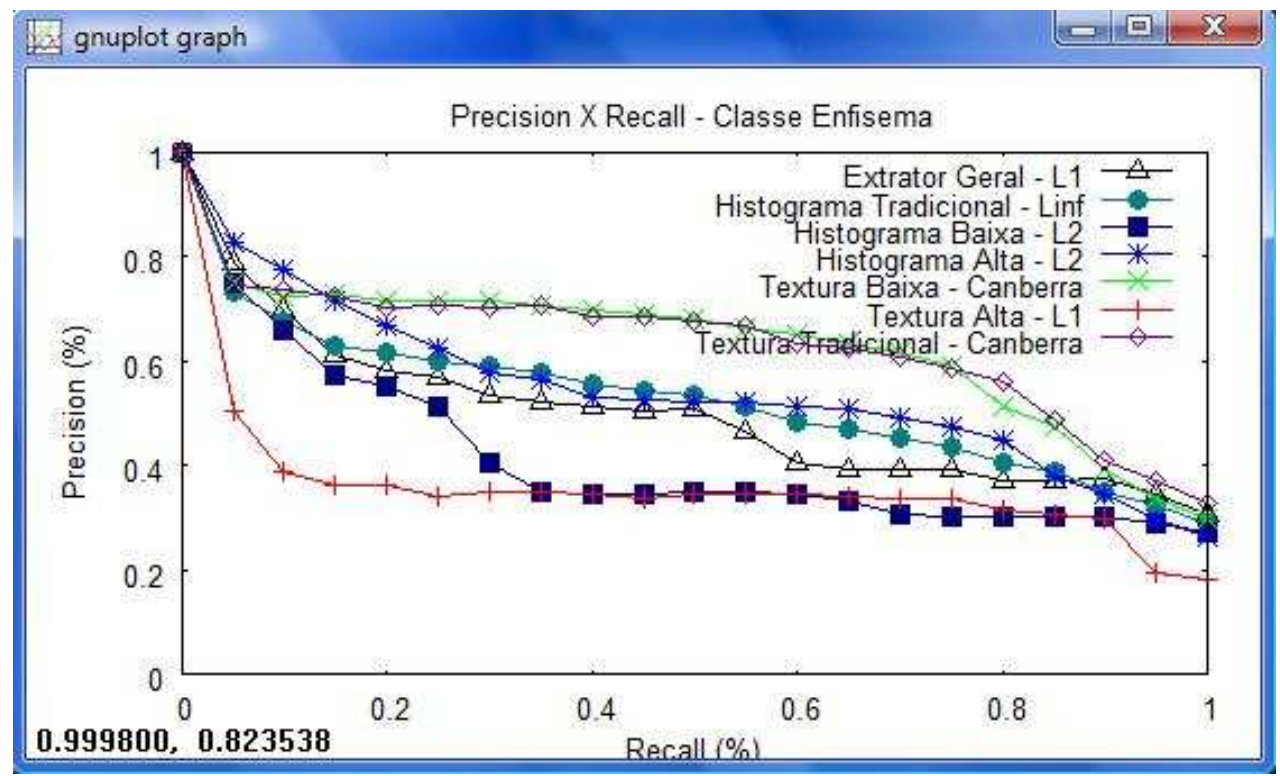

Gráfico 16: Precisão e Revocação para a classe Enfisema considerando a dupla extrator e função de distância em sua melhor configuração. 


\subsection{2 - Experimento 4: Extrator Completo}

Com o intuito de se avaliar o desempenho de todas as características (cor, textura, forma e características específicas) reunidas em uma única assinatura, foi implementado um extrator doravante denominado "Extrator Completo" que engloba "Todas as Características" visuais, com 120 características descritas com detalhes na seção 4.3.2. No Gráfico 17 é apresentado o desempenho dessas características em consultas por similaridade nas seis classes do conjunto de imagens. Ao se comparar o resultado obtido nesse experimento com o "Extrator Geral" (Gráfico 13), percebe-se que o comportamento das curvas de precisão vs. revocação para as classes é muito semelhante, porém, com um certo ganho na precisão geral. Isso mostra que 16 características específicas do contexto obtiveram um desempenho quase tão bom quanto o de 120 características gerais.

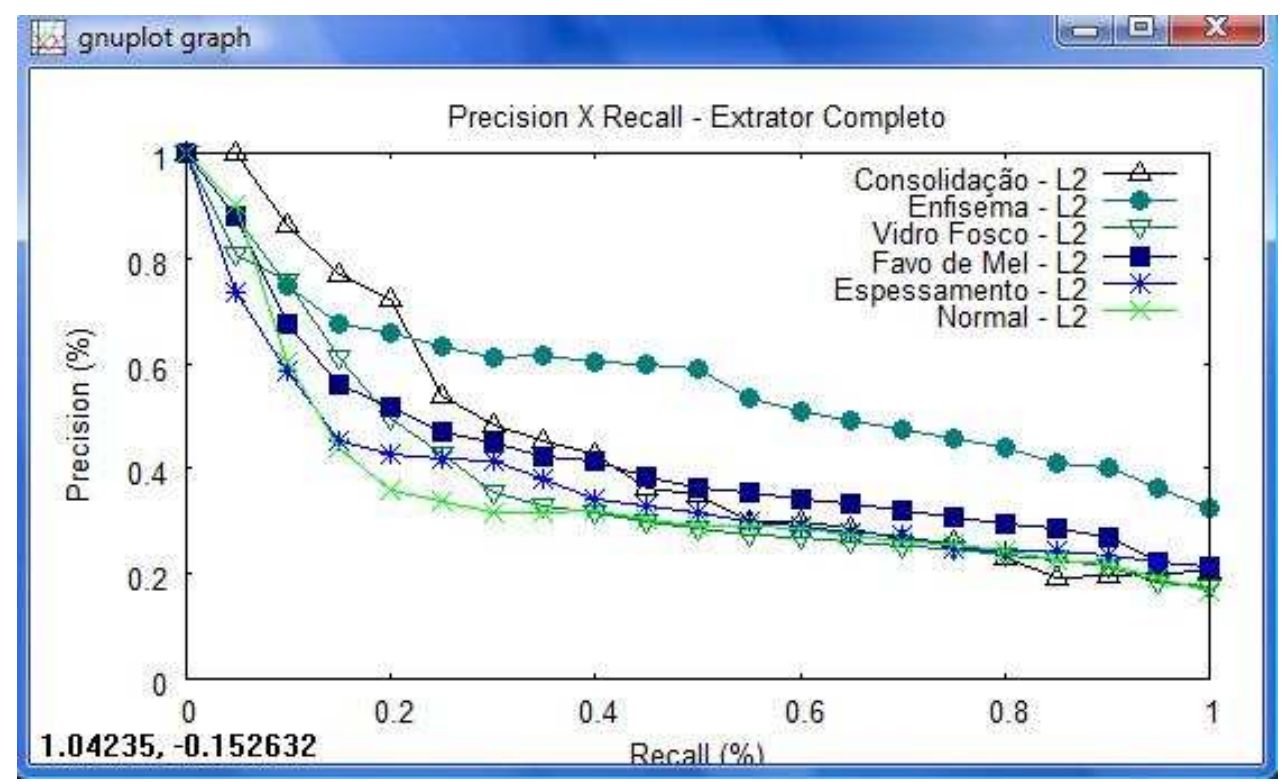

Grafico 17: Precisão e Revocação das classes utilizando o "Extrator Completo"

A análise dos desempenhos das funções de distância utilizando o "Extrator Completo" apresentou a função de distância Canberra como aquela que obteve o melhor desempenho na média das consultas, utilizando-se todas as imagens da base como centro de consulta. Como apresentado no Gráfico 18, ela obteve uma pequena vantagem, com uma média de precisão $6 \%$ melhor comparada às demais funções. 


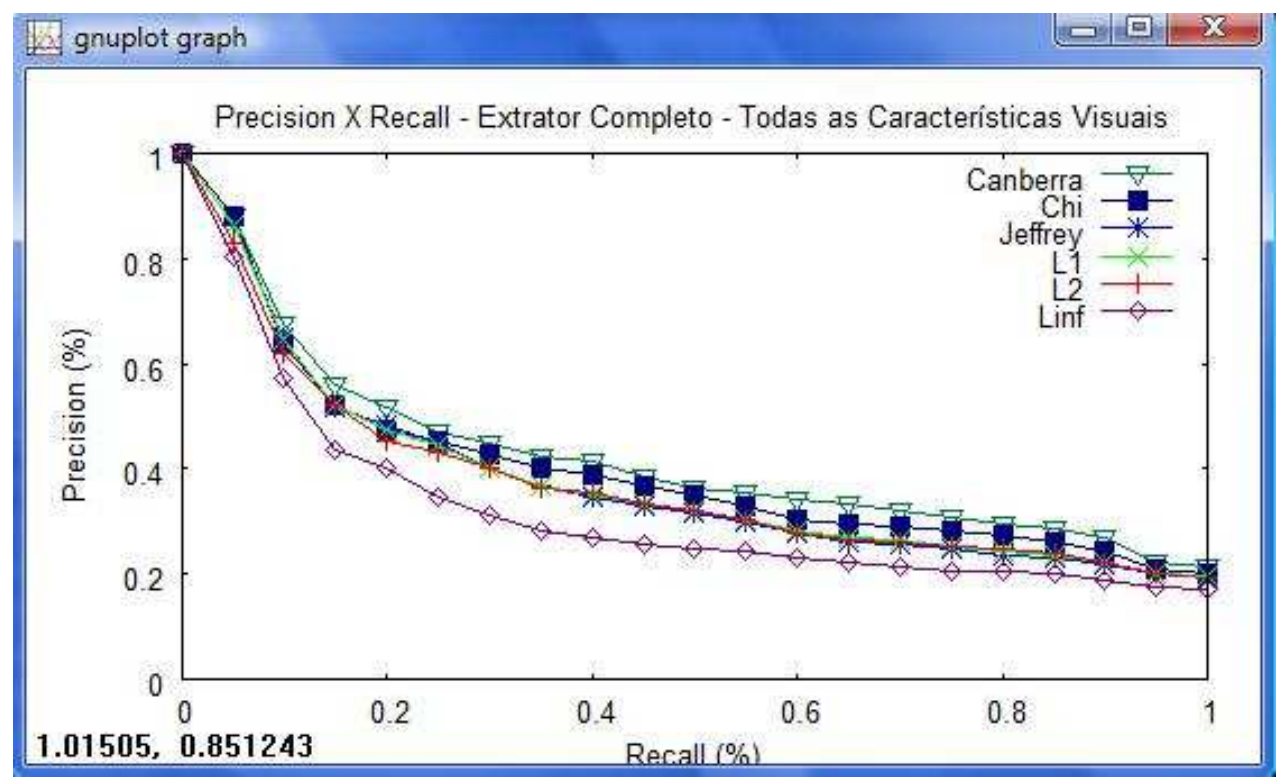

Gráfico 18: Precisão e Revocação da base de imagens utilizando o "Extrator Completo"

No Gráfico 19 compara-se o desempenho do Extrator Completo com os demais métodos para o parâmetro perceptual "Clareamento Homogêneo", representado pela classe Consolidação. Seu desempenho sobrepõe o desempenho de todos os demais, nos primeiros $25 \%$ de revocação. A Precisão média, nesse caso, é de $87 \%$ para o "Extrator Completo", enquanto a do "Extrator Geral" é de 80\%, a do "Histograma Tradicional" é de $71 \%$ e a da "Textura Tradicional" é de $54 \%$.

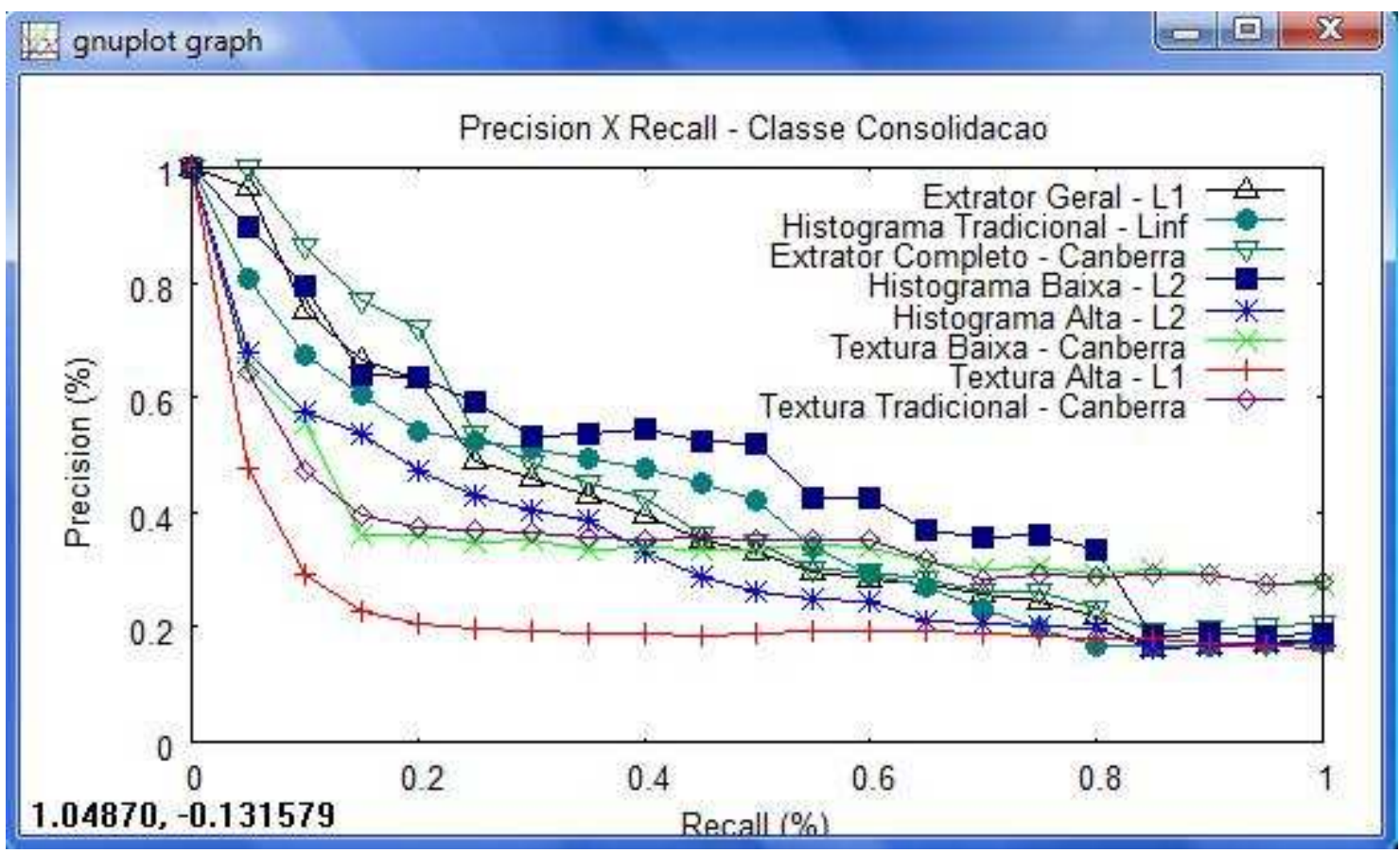

Gráfico 19: Precisão e Revocação para a classe Consolidação, considerando a dupla extrator e função de distância em sua melhor configuração.

Ao se observar o gráfico acima, percebe-se também que o extrator "Histograma Baixa" apresentou um bom desempenho (79\% de precisão média) nos primeiros $25 \%$ de 
revocação, sendo que, após esse valor de revocação ele se mantém como melhor extrator. Apesar de o "Histograma Baixa" conseguir esse resultado considerando 256 características, seu bom desempenho deixa uma margem para considerarmos que em alguns casos um pré-processamento bem feito, evidenciando-se as características certas, o desempenho de um extrator tradicional geral (como histograma) pode conseguir se aproximar de um extrator específico do contexto.

\subsection{3 - Conclusões Parciais}

Os resultados dos experimentos acima buscaram avaliar a influência de se considerar parâmetros de percepção específicos do contexto da imagem na construção de extratores de características.

Com esses resultados concluiu-se que:

Cada extrator, específico ao contexto ou não, demonstrou uma capacidade diferente de discriminar cada um dos parâmetros perceptuais (representados por suas respectivas classes de imagens).

$\mathrm{Na}$ maioria dos casos, um extrator específico consegue melhor desempenho de precisão comparada a um extrator tradicional, porém, em alguns casos, quando há um pré-processamento evidenciando características dos parâmetros de percepção, os extratores tradicionais podem obter uma precisão tão boa quanto, ou melhor que os extratores específicos.

\section{4 - Formações das Tríades}

Em resumo, os experimentos 3 e 4 mostraram que cada uma das classes da base de imagens apresenta características visuais distintas, que podem ser representadas por parâmetros perceptuais e evidenciadas por processamento e atributos específicos. Foi demonstrado também que esses processamentos e atributos específicos melhoram o desempenho no cálculo de semelhança da classe que contém o parâmetro de percepção evidenciado como parâmetro relevante, porém diminuindo a noção de semelhança das outras classes. Com isso, foi mostrado que a eficiência nas consultas por similaridade pode ser melhorada ao dar ao usuário a opção de escolher quais as características visuais devem ser consideradas como relevantes na comparação. 
Na seção 3.4 dessa dissertação foi descrito o levantamento de alguns parâmetros de percepção que mapeiam essas características visuais. Com esse levantamento tornouse possível construir o que foi denominado de tríade, ou seja, operadores que mapearão automaticamente quais os extratores e funções de distância melhor representam cada conjunto de características visuais. Na prática esses operadores funcionariam da seguinte maneira: Ao se realizar uma consulta por similaridade no ambiente de diagnóstico por imagem, o médico, por não dominar a área computacional, não saberia discernir quais dos extratores e funções de distância ele poderia utilizar para otimizar a consulta que deseja realizar, porém ele saberia informar com facilidade quais os parâmetros visuais da imagem de consulta ele gostaria que fossem considerados como parâmetros relevantes para a comparação. É nesse momento que o "Parâmetro Perceptual" é incluído na consulta por similaridade. Ele aproxima o médico da operação computacional de cálculo de similaridade tornando possível uma interação médicosistema que virtualmente aprimora o resultado da consulta. O papel principal desse terceiro elemento (o "parâmetro perceptual"), como mostrado na Figura 18 seria o de mapear, através dos operadores (tríades), quais os melhores métodos de extração e cálculo de similaridade otimizariam a resposta da consulta. 


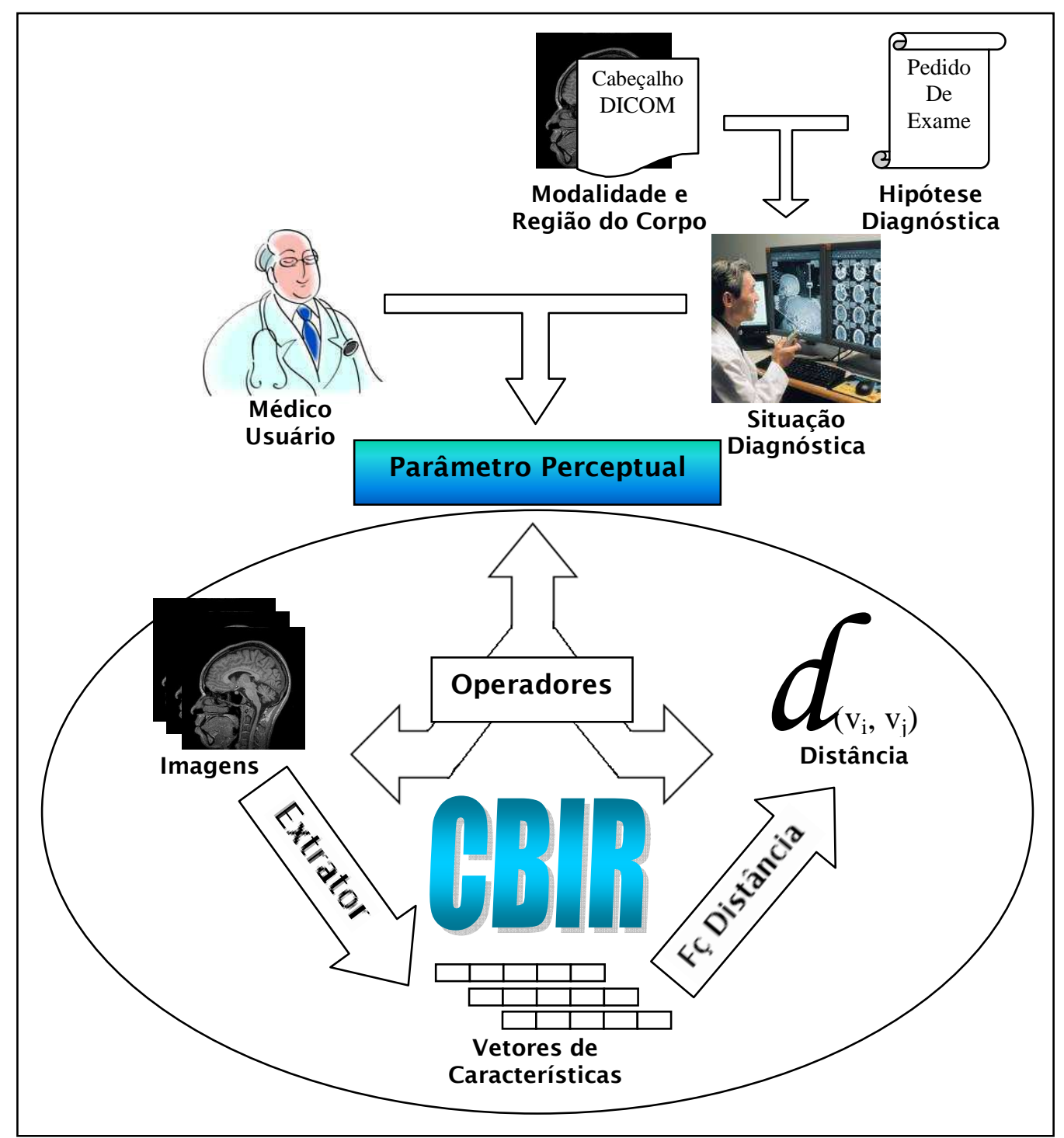

Figura 18: Integração do "trinômio" para CBIR

Para o caso estudado nesse trabalho, as sugestões de formação desses operadores seguem listadas na Tabela 3, onde foi colocada a classe das imagens utilizadas nos testes, o parâmetro perceptual representando uma idéia das características visuais dos "achados" nas imagens, os métodos de comparação por similaridade que apresentaram os melhores desempenhos e, nas duas últimas colunas, ganho médio na precisão obtida por esses métodos comparados aos métodos tradicionais de cor (histograma) e textura (haralick). 
Tabela 3: Formação das tríades, operadores de similaridade para as 6 classes de achados discutidos nesta dissertação.

\begin{tabular}{|c|c|c|c|c|}
\hline \multirow{2}{*}{$\begin{array}{l}\text { Achado } \\
\text { (Classe) }\end{array}$} & \multirow{2}{*}{$\begin{array}{l}\text { Parâmetro } \\
\text { Perceptual }\end{array}$} & \multirow{2}{*}{$\begin{array}{c}\text { Métodos de } \\
\text { Melhores Desempenhos }\end{array}$} & \multicolumn{2}{|c|}{ Ganho de Precisão } \\
\hline & & & $\begin{array}{c}\text { Cor - } \\
\text { histograma }\end{array}$ & $\begin{array}{l}\text { Textura - } \\
\text { Haralick }\end{array}$ \\
\hline \multirow{3}{*}{ Consolidação } & \multirow{3}{*}{$\begin{array}{l}\text { Clareamento } \\
\text { Homogêneo }\end{array}$} & $\begin{array}{l}\text { Extrator Completo } \\
\text { Canberra }\end{array}$ & $16,00 \%$ & $32,00 \%$ \\
\hline & & Extrator Geral - L1 & $8,00 \%$ & $24,00 \%$ \\
\hline & & Histograma Baixa - L2 & $7,00 \%$ & $23,00 \%$ \\
\hline \multirow{3}{*}{ Vidro Fosco } & \multirow{3}{*}{$\begin{array}{l}\text { Clareamento não } \\
\text { Homogêneo }\end{array}$} & $\begin{array}{l}\text { Extrator Completo - } \\
\text { Canberra }\end{array}$ & $13,00 \%$ & $27,00 \%$ \\
\hline & & Extrator Geral - L1 & $6,00 \%$ & $20,00 \%$ \\
\hline & & Histograma Baixa - L2 & $5,00 \%$ & $19,00 \%$ \\
\hline \multirow{3}{*}{ Espessamento } & \multirow{3}{*}{$\begin{array}{l}\text { Presença de } \\
\text { Fissuras }\end{array}$} & $\begin{array}{l}\text { Extrator Completo - } \\
\text { Canberra }\end{array}$ & $10,00 \%$ & $23,00 \%$ \\
\hline & & Extrator Geral - L1 & $4,00 \%$ & $17,00 \%$ \\
\hline & & $\begin{array}{l}\text { Histograma Alta - } \\
\text { Canberra }\end{array}$ & $1,00 \%$ & $14,00 \%$ \\
\hline \multirow{3}{*}{ Favo de Mel } & \multirow{3}{*}{$\begin{array}{l}\text { Escurecimento } \\
\text { com fissuras } \\
\text { (bordas) }\end{array}$} & $\begin{array}{l}\text { Extrator Completo - } \\
\text { Canberra }\end{array}$ & $17,00 \%$ & $25,00 \%$ \\
\hline & & Extrator Geral - L1 & $15,00 \%$ & $23,00 \%$ \\
\hline & & Histograma Baixa - L2 & $4,00 \%$ & $12,00 \%$ \\
\hline \multirow{3}{*}{ Enfisema } & \multirow{3}{*}{$\begin{array}{l}\text { Escurecimento } \\
\text { sem fissuras } \\
\text { (bordas) }\end{array}$} & Histograma Alta - L2 & $8,00 \%$ & $3,00 \%$ \\
\hline & & $\begin{array}{l}\text { Extrator Completo - } \\
\text { Canberra }\end{array}$ & $7,00 \%$ & $2,00 \%$ \\
\hline & & Textura Baixa - Canberra & $5,00 \%$ & $0,00 \%$ \\
\hline \multirow{3}{*}{ Normal } & \multirow{3}{*}{---- } & Extrator Geral - L1 & $6,00 \%$ & $23,00 \%$ \\
\hline & & $\begin{array}{l}\text { Extrator Completo - } \\
\text { Canberra }\end{array}$ & $5,00 \%$ & $22,00 \%$ \\
\hline & & $\begin{array}{l}\text { Histograma Tradicional - } \\
\text { Linf }\end{array}$ & $0,00 \%$ & $17,00 \%$ \\
\hline
\end{tabular}

No Gráfico 20 é apresentado o desempenho médio de consultas realizadas considerando os diferentes extratores de características já apresentados comparados ao desempenho das mesmas consultas utilizando-se os operadores de otimização de consulta. Na construção do gráfico, foram utilizadas todas as imagens da base como centro de consulta (independente da classe). A utilização de operadores (tríades) resultou em um ganho médio de $8 \%$ sobre o "Extrator Completo", $16 \%$ sobre o "Extrator Geral", 33\% sobre o "Histograma Tradicional", 43\% sobre o "Histograma Alta", 27\% sobre o "Histograma Baixa". 


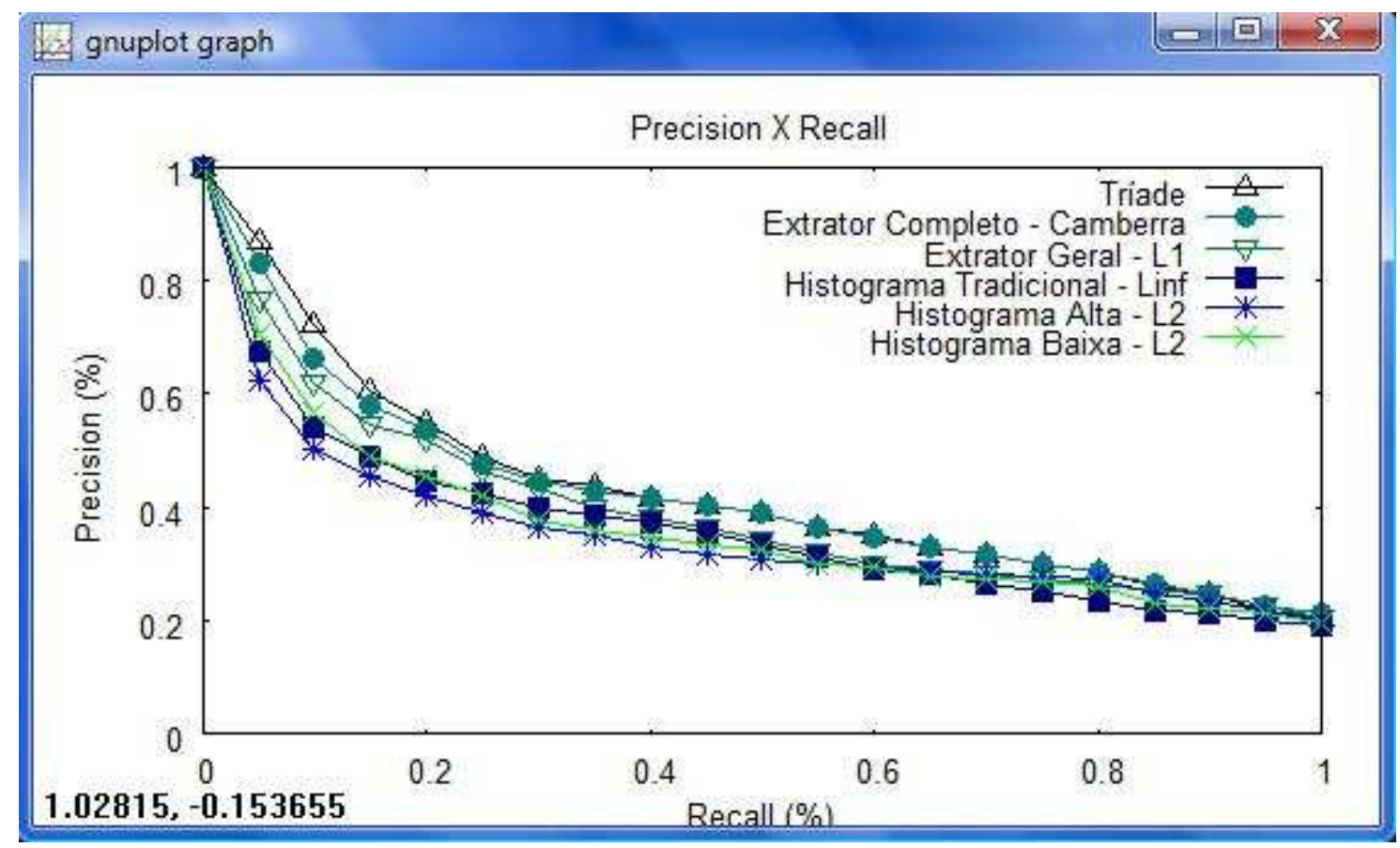

Gráfico 20: Precisão e Revocação dos extratores e do método com a Tríade (operadores) considerando todas as imagens da base como centro de consulta

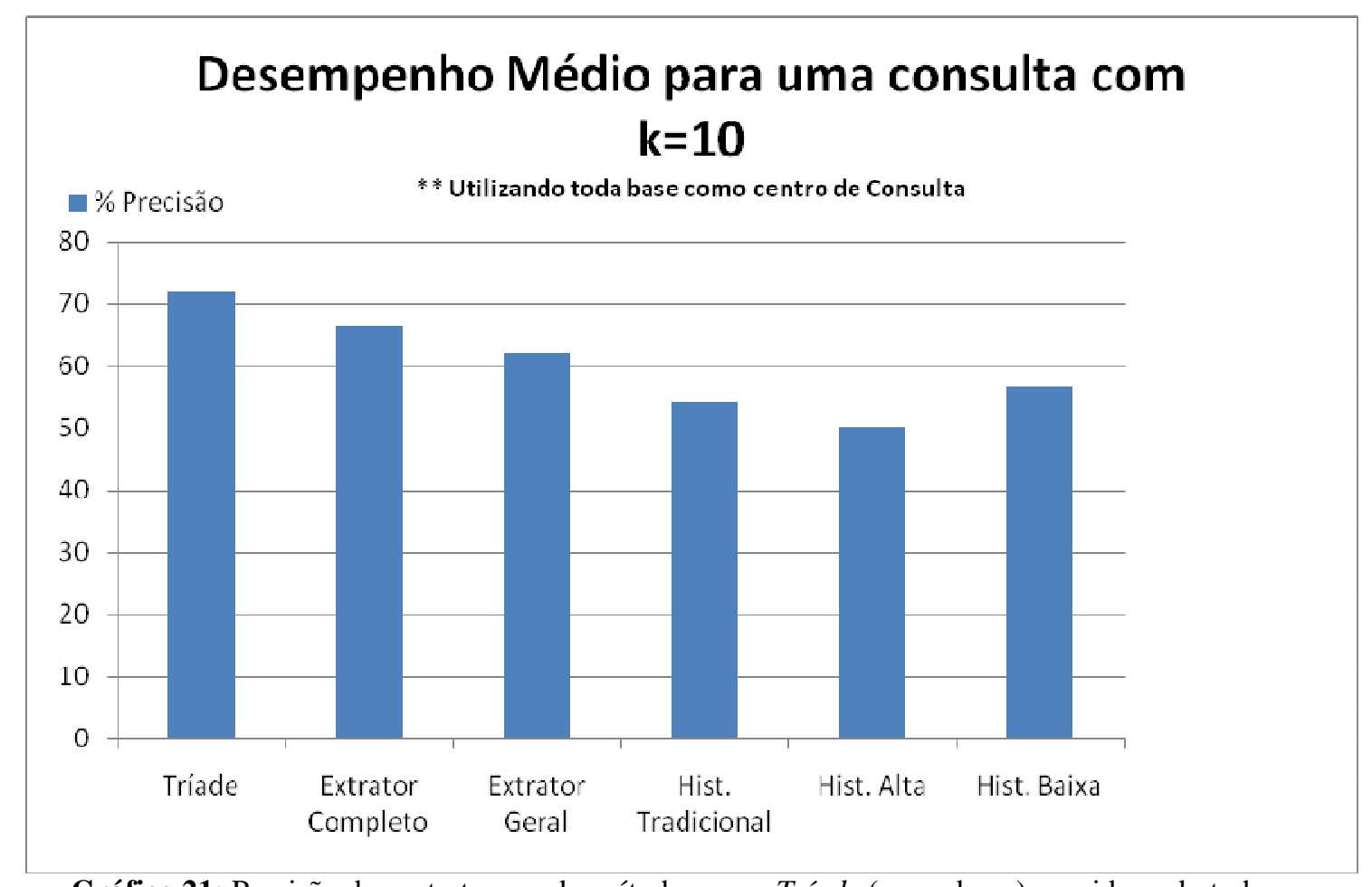

Gráfico 21: Precisão dos extratores e do método com a Tríade (operadores) considerando todas as imagens da base como centro de consulta com um $\mathrm{K}=10$ 


\section{Conclusões}

\section{1 - Considerações Iniciais}

O principal objetivo do trabalho foi propor uma metodologia de processamento de consultas por similaridade que permitissem a recuperação perceptual de imagens médicas guiada pelo próprio usuário radiologista. Foi proposta a criação de um terceiro elemento nas consultas por similaridade que permitisse ao médico expressar quais características visuais das imagens deveriam ser consideradas relevantes durante o processo de comparação e busca por imagens similares. Junto aos parâmetros perceptuais levantados em um ambiente real de análise e diagnóstico por imagens, foram também analisados e aprimorados extratores de características e funções de distâncias específicas e essenciais à comparação entre imagens. Todo o processo de estudo integrado desses três elementos (parâmetros de percepção, extratores de características e funções de distância) foi realizado buscando-se alcançar uma semântica natural nas comparações automáticas de imagens médicas. Com base em todo conhecimento obtido, foi proposta também a construção de operadores de similaridade que tornassem possível responder consultas utilizando-se diferentes características e funções de distância, de modo a retornar o que é mais próximo do esperado pelo humano, sem que o usuário precise determinar o que deve ser utilizado. É importante ressaltar que o especialista médico não deve/precisa deter conhecimentos específicos de computação para conseguir resultados às consultas por similaridade que atendam a sua percepção de semelhança. 


\section{2 - Principais Contribuições}

Os resultados desse trabalho mostraram a influência de se considerar (evidenciar) os parâmetros de percepção no pré-processamento da imagem e no processo de extração de características específicas ao contexto. Ao analisar o comportamento dos binômios (extrator de características e funções de distância) para cada parâmetro perceptual levantado, foi possível perceber que diferentes extratores apresentaram diferentes desempenhos para os mesmos parâmetros perceptuais das imagens (representados por suas respectivas classes). Esse resultado confirmou a hipótese de que a ferramenta CBIR que usar tal relacionamento para mapear cada parâmetro de percepção numa dupla (extrator, função de distância) que melhor o represente, estará um passo à frente de conseguir melhores resultados nas buscas por similaridade. Foi mostrado experimentalmente também que é possível se evidenciar/ressaltar características de interesse durante o pré-processamento das imagens. Ao se ressaltar essas características, até mesmo extratores tradicionais, como histograma, passam a apresentar melhor desempenho na discriminação de imagens similares. Foi constatado também que, na maioria dos casos, um extrator específico ao contexto consegue melhor desempenho de precisão comparada a um extrator tradicional, como foi o caso do "Extrator Geral", que com apenas 16 atributos mostrou-se melhor que o histograma tradicional. Porém, em alguns casos, quando há um bom pré-processamento evidenciando-se as características visuais discriminadas pelos parâmetros de percepção, os extratores tradicionais podem obter uma precisão tão boa quanto ou até melhor que os extratores específicos.

A seguir serão apresentadas, de forma resumida, as principais contribuições do presente trabalho para a área de Recuperação de Imagens Médicas Baseada em Conteúdo em ambientes reais de diagnóstico por imagem.

- Estudo do ambiente real de análise de imagens médicas e levantamento de aspectos importantes na formação da imagem médica, bem como na percepção de aspectos visuais das imagens durante análise dos radiologistas. Esse levantamento possibilitou a definição de "parâmetros perceptuais" e viabilizou sua utilização no processo de extração e comparação de imagens como uma nova metodologia de construção de sistema CBIR guiados pelo usuário.

- Análise do desempenho de extratores de características tradicionais, como histograma de cor e textura por matriz de co-ocorrência, incluindo-se no pré- 
processamento da imagem, algoritmos que evidenciam aspectos visuais ditados pelos parâmetros de percepção listados pelos médicos.

- Criação de um novo método de extração de características de imagens de pulmão baseado nos conhecimentos adquiridos durante levantamento de características visuais percebidas pelos médicos no momento da análise das imagens e confecção dos laudos dos exames. Os resultados mostraram que esses extratores específicos ao contexto apresentam melhor desempenho na comparação das imagens que a utilização de extratores genéricos.

- Análise do inter-relacionamento entre os parâmetros de percepção dos médicos e as características extraídas das imagens médicas, bem como o levantamento das funções de distância adequadas às comparações entre as imagens. Integração desse trinômio (parâmetro perceptual, extrator de característica e função de distância).

- Elaboração de operadores (funções de distância, extratores de características e parâmetros perceptuais) que viabilizam a busca por conteúdo onde o usuário médico passa a especificar apenas o "parâmetro perceptual" (já de seu conhecimento habitual) como entrada, junto à imagem de consulta, para o sistema CBIR. Os resultados dos experimentos realizados mostraram que essa é uma forma eficiente de representar diretamente o sentimento do analista humano ao comparar as imagens em questão, ressaltando-se na comparação de características desejadas e especificadas pelos médicos.

\section{3 - Trabalhos Futuros}

O desenvolvimento deste trabalho possibilitou uma abertura de possíveis aplicações em pesquisa sobre recuperação por conteúdo para ambientes reais de diagnóstico por imagens. Algumas sugestões de tópicos a serem abordados em trabalhos futuros são listados a seguir:

- Levantamento automático de parâmetros de percepção e regiões de interesse (ROIs), baseados em informações textuais contidas no pedido de exame e no cabeçalho DICOM de cada imagem.

- A utilização de "Realimentação por Relevância" para otimizar os operadores de similaridade (as tríades propostas nesse trabalho), como forma de aproximar 
ainda mais a consulta por similaridade da percepção humana na comparação de imagens.

- Continuação do trabalho para outros tipos de exames radiológicos como Mamografias e imagens de Ressonância Magnética, ou seja, análise do desempenho dos parâmetros de percepção em diferentes tipos de imagens médicas.

- Avaliação de uma gama ainda maior de extratores de características e funções de distância, analisando a precisão obtida pelo trinômio com relação à busca por similaridade em imagens médicas. E a construção de operadores mais abrangentes e menos específicos ao contexto.

- Proposta e desenvolvimento de novos extratores de características que permitam a comparação entre imagens médicas mantendo a semântica natural contida no princípio físico de formação das imagens, bem como na semântica clínica atribuída pelo médico a cada tipo de achado das imagens. 


\section{Referências}

[Abdala_2007] Nitamar Abdala „Jacob Szejnfeld, Ressonância Magnética: Indicações, Preparo, Técnica e Cuidados: LMP Editora, 2007.

[Abe_2004] H. Abe, K. Ashizawa, F. Li, N. Matsuyama, A. Fukushima, J. Shiraishi, H. MacMahon, K Doi, “Artificial neural networks (ANNs) for differential diagnosis of interstitial lung disease: results of a simulation test with actual clinical cases," in Academic Radiology, vol. 11, 2004, pp. 29-37.

[Alexandre_2007] Dulclerci Sternadt Alexandre ,João Manuel R. S. Tavares, “Factores da Percepção Visual Humana na Visualização de Dados," Proceedings of CMNE/CILAMCE, Porto, Portugal, 2007.

[Alto_2005] H. Alto, R. M. Rangayyan, J. E. L. Desautels, “Content-based retrieval and analysis of mammographic masses," Journal of Electronic Imaging, vol. 14,2005, pp. 1-17.

[Armato-III_2003] S. G. Armato-III ,H. MacMahon, “Automated lung segmentation and computer-aided diagnosis for thoracic CT scans," Proceedings of International Congress Series, 2003.

[Aslandogan_1999] Y. Alp Aslandogan ,Clement T. Yu, “Techniques and Systems for Image and Video Retrieval," IEEE Transactions on Knowledge and Data Engineering (TKDE), vol. 11,Jan/Feb 1999, pp. 56-63.

[Azevedo-Marques_2005a] Paulo Mazzoncini de Azevedo-Marques, "Generalização do Conceito de Diagnóstico Auxiliado por Computador no Ambiente Hospitalar através da Integração de Função de Recuperação por Conteúdo no Sistema de Gerenciamento de Imagens", Tese de Livre-Docência, Faculdade de Medicina de Ribeirão Preto, Universidade de São Paulo, Ribeirão Preto, pp. 115, 2005a

[Azevedo-Marques_2005b] Paulo Mazzoncini de Azevedo-Marques, Edilson Carlos Caritá, Alexander Antonio Benedicto, Pablo Rodrigo Sanches, "Integração 
RIS/PACS no Hospital das Clínicas de Ribeirão Preto: uma solução baseada em "web"," Radiologia Brasileira, vol. 38,Jan./Feb. 2005, pp. 37-43.

[Azevedo-Marques_2000] Paulo Mazzoncini de Azevedo-Marques, Antônio Carlos dos Santos, J. E. Júnior, W. M. Goes, C. R. Castro, “Implantação de um Sistema de Informação em Radiologia em Hospital Univeristário," Radiologia Brasileira, vol. 33,2000, pp. 155-160.

[Balan_2007] André Guilherme Ribeiro Balan, Agma Juci Machado Traina, Marcela Xavier Ribeiro, Paulo Mazzoncini de Azevedo Marques, Caetano Traina, Jr., "HEAD: the Human Encephalon Automatic Delimiter," Proceedings of 20th IEEE Intl Symposium on Computer-Based Medical Systems (CBMS 2007), Maribor, Slovenia, 2007.

[Balan_2005] André Guilherme Ribeiro Balan, Agma Juci Machado Traina, Caetano Traina, Jr., Paulo Mazzoncini de Azevedo Marques, "Fractal Analysis of Image Textures for Indexing and Retrieval by Content," Proceedings of 18th IEEE Intl Symposium on Computer-Based Medical Systems - CBMS, Dublin, Ireland, 2005.

[Brandão_2006] Paulo Brandão ,Ana Mafalda Reis, "Erro Médico em Imagiologia Performance e Sistemas de Detecção Computadorizada," in Qualidade e Saúde - Acta Med Port, vol. 19, pp. 235-238.

[Bueno_2002] Josiane Maria Bueno, "Suporte à Recuperação de Imagens Médicas baseada em Conteúdo através de Histogramas Métricos", Tese de doutorado, Departamento de Ciências de Computação, Universidade de São Paulo, São Carlos, SP, pp. 146, 2002

[Bugatti_2008a] H. Pedro Bugatti, Agma Juci Machado Traina, Caetano Traina, Jr., " $A$ New Method to Efficiently Reducing Histogram Dimensionality," Proceedings of Symposium on Medical Imaging (SPIE-2008), Computer-Aided Diagnosis track, San Diego - CA, 2008a.

[Bugatti_2008b] Pedro Henrique Bugatti, "Análise da influência de funções de distância para o processamento de consultas por similaridade em recuperação de imagens por conteúdo", Mestrado, Departamento de Ciências da Computação, Universidade de São Paulo, São Carlos, pp. 111, 2008b 
[Burkhard_2004] Hans-Dieter Burkhard, "Case Competion and Similarity in CaseBased Reasoning," Computer Science and Information Systems, vol. 1,November, 2004, pp. 27-55.

[Caritá_2004] Edilson Carlos Caritá, André Luiz Mendes Matos, Paulo Mazzoncini de Azevedo-Marques, "Image viewing tools used in a medical school," Radiologia Brasileira, vol. 37,Dec 2004, pp. 437-440.

[Çarkacioglu_2003] Abdurrahman Çarkacioglu ,Fatos Yarman-Vural, “SASI: a generic texture descriptor for image retrieval," Pattern Recognition Letters, vol. 36,November 2003, pp. 2615-2633.

[Cheng_2005] Pei-Cheng Cheng, Been-Chian Chien, Hao-Ren Ke, Wei-Pang Yang, "SMIRE: Similar Medical Image Retrieval Engine," in Lecture Notes In Computer Science, vol. 3491, 2005.

[Costa_2001] Luciano Fontoura da Costa ,Roberto Marcondes Cesar Jr., Shape Analysis and Classification - Theory and Practice. Boca Raton, CA: CRC Press, 2001.

[Datta_2008] Ritendra Datta, Dhiraj Joshi, Jia Li, James Z. Wang, "Image Retrieval: Ideas, influences and trends of the new age," ACM Comput Surv, vol. 40-2,April 2008, pp. 60.

[Depeursinge_2008] A. Depeursinge, J. Iavindrasana, G. Cohen, A. Platon, P. -A. Poletti, Henning Müller, "Lung Tissue Classification in HRCT data Integrating the Clinical Context," Proceedings of 21st IEEE International Symposium on Computer-Based Medical Systems, 2008.

[Depeursinge_2007] A. Depeursinge, D. Sage, A. Hidki, A. Platon, P. -A. Poletti, M. Unser, Henning Müller, “Lung tissue classification using Wavelet frames. In Engineering in Medicine and Biology Society," Proceedings of Engineering in Medicine and Biology Society, Lyon, France, 2007.

[Deselaers_2006] T. Deselaers, T. Weyand, D. Keysers, W. Macherey, H. Ney, "FIRE in ImageCLEF 2005: Combining Content-Based Image Retrieval with Textual Information Retrieval," in Lecture Notes in Computer Science, vol. 4022, 2006.

[Deserno_2007] Thomas M. Deserno, Sameer Antani, Rodney Long, “Gaps in ContentBased Image Retrieval," Proceedings of Medical Imaging 2007: PACS and Imaging Informatics, 2007. 
[Deserno_2008] Thomas M. Deserno, Sameer Antani, Rodney Long, “Ontology of Gaps in Content-Based Image Retrieval," Jornal of Digital Imaging,2008, pp. 114.

[Doi_2005] K Doi, “Current status and future potential of computer-aided diagnosis in medical imaging," Br J Radiol, vol. 78,January 1, 2005, pp. S3(19).

[Doi_2006] K Doi, "Diagnostic Imaging over the last 50 years: research and development in medical imaging science and technology," Phys Med Biol, vol. 51, pp. 5-27.

[Donovana_2008] T. Donovana, David J. Manning, T. Crawford, "Performance changes in lung nodule detection following perceptual feedback of eye movements," Proceedings of Medical Imaging 2008: Image Perception, Observer Performance, and Technology Assessment, 2008.

[Felipe_2003] Joaquim Cezar Felipe, Agma Juci Machado Traina, Caetano Traina Jr.,

"Retrieval by Content of Medical Images Using Texture for Tissue Identification," Proceedings of 16th IEEE Symposium on Computer-based Medical Systems, New York, 2003.

[Felipe_2005a] Joaquim Cezar Felipe, "Desenvolvimento de métodos para extração, comparação e análise de características intrínsecas de imagens médicas, visando à recuperação perceptual por conteúdo", Tese de Doutorado, Departamento de Ciências de Computação, Universidade de São Paulo, São Carlos, pp. 138, 2005a

[Felipe_2005b] Joaquim Cezar Felipe, Jonatas Bergamo Olioti, Agma Juci Machado Traina, Marcela Xavier Ribeiro, Elaine Parros Machado de Sousa, Caetano Traina, Jr., "A Low-cost Approach for Effective Shape-based Retrieval and Classification of Medical Images," Proceedings of First IEEE International Workshop on Multimedia Information Processing and Retrieval IEEE-MIPR 2005, Irvine, CA, 2005b.

[Felipe_2005c] Joaquim Cezar Felipe, Agma Juci Machado Traina, Caetano Traina, Jr.,

"Global Warp Metric Distance: Boosting Content-based Image Retrieval through Histograms," Proceedings of IEEE International Symposium on Multimedia-ISM2005, Irvine, CA, 2005c. 
[Felipe_2006a] Joaquim Cezar Felipe, Marcela Xavier Ribeiro, Elaine Parros Machado de Sousa, Agma Juci Machado Traina, Caetano Traina, Jr., "Effective Shapebased Retrieval and Classification of Mammograms," Proceedings of 21th ACM Symposium on Applied Computing (SAC), Dijon, France, 2006a.

[Felipe_2006b] Joaquim Cezar Felipe, Agma Juci Machado Traina, Caetano Traina, Jr., "A New Similarity Measure for Histograms Applied to Content-based Retrieval of Medical Images," Proceedings of 21th ACM Symposium on Applied Computing (SAC), Dijon, France, 2006b.

[Filardi_2008] Ana Lúcia Filardi ,Agma Juci Machado Traina, "Combinação de Técnicas de Interação Humano-Computador para Avaliação de Sistemas de Recuperação de Imagens por Conteúdo," Proceedings of XIV Simpósio Brasileiro de Sistemas Multimedia e Web (WebMedia 2008), Vila Velha, ES., 2008.

[Fischer_2008] Benedikt Fischer, Thomas M. Deserno, Bastian Ott, Rolf W. Günther, "Integration of a Research CBIR System with RIS and PACS for Radiological Routine," Proceedings of Medical Imaging 2008: PACS and Imaging Informatics, 2008.

[Furuie_2007] Sérgio S. Furuie, M. S. Rebelo, R. A. Moreno, M. Santos, N. Bertozzo, G. H. M. B. Motta, F. A. Pires, M. A. Gutierrez, "Managing Medical Images and Clinical Information: inCor's Experience," IEEE Transactions on Information Technology in Biomedicine, vol. 11,Jan 2007, pp. 17-24.

[Garland_1949] L. H. Garland, "On the scientific evaluation of diagnostic procedures," in Radiology, vol. 52, pp. 309-328.

[Gonzalez_2000] Rafael C. Gonzalez, Richard E. Woods, Processamento de Imagens Digitais: Editora Edgard Blücher Ltda, 2000.

[Guld_2007] Mark O. Guld, Benedikt Fischer, Christian Thies, Thomas M. Lehmann, "A generic concept for the implementation of medical image retrieval systems," International Journal of Medical Informatics, vol. 76,February-March 2007, pp. 252-259.

[Hadjidemetriou_2004] Efstathios Hadjidemetriou, Michael D. Grossberg, Shree K. Nayar, "Multiresolution Histograms and Their Use for Recognition," IEEE 
Transactions on Pattern Analysis and Machine Intelligence (PAMI), vol. 26,July 2004, pp. 831-847.

[Haralick_1973] R. M. Haralick, K. Shanmugam, I. Dinstein, "Textural features for image classification," IEEE Transactions on Systems, Man, and Cybernetics, vol. 3, pp. 610-621.

[Huang_2003] Po-Whei Huang ,S. K. Dai, "Image retrieval by texture similarity," Pattern Recognition Letters, vol. 36,March 2003, pp. 665-679.

[Jaimes_2006] A. Jaimes, N. Sebe, D. Gatica-Perez, "Human-centered computing: A multimedia perspective," Proceedings of Special Session on Human-Centered Multimedia, 2006.

[Kak_2002] Avi Kak ,Christina Pavlopoulou, "Content-Based Image Retrieval from Large Medical Databases," Proceedings of First International Symposium on 3D Data Processing Visualization and Transmission, 2002.

[Kim_2000] H. Kim ,J. Kim, “A modified zernike moment shape descriptor invariant to translation, rotation and scale for similarity-based image retrieval," Proceedings of Multimedia and Expo, IEEE International Conference, 2000.

[Lam_2007] M. Lam, T. Disney, M. Pham, D. Raicu, J. Furst, R. Susomboon, “Contentbased image retrieval for pulmonary computed tomography nodule images," Proceedings of, 2007.

[Lehmann_2006] Thomas M. Lehmann, T. Deselaers, H. Schubert, Mark O. Guld, Christian Thies, Benedikt Fischer, K. Spitzer, "IRMA - A content-based approach to Image Retrieval in Medical Applications," Proceedings of Information Resources Management Association International Conference, 2006.

[Lehmann_2003] Thomas M. Lehmann, Mark O. Guld, Christian Thies, “Content-based Image Retrieval in Medical Applications for Picture Archiving and Communication Systems," Proceedings of SPIE 2003, 2003.

[Lew_2006] Michael S. Lew, Nicu Sebe, Chabane Djeraba, Ramesh Jain, "ContentBased Multimedia Information Retrieval: State of the Art and Challenges," ACM Transactions on Multimedia Computing, Communications and Applications, vol. 2,February 2006, pp. 1-19. 
[Lopes_2000] A. A. Lopes, "Medicina Baseada em Evidências: a arte de aplicar o conhecimento científico na prática clínica," in Revista da Associação Médica Brasileira, vol. 46, July, pp. 285-288.

[Metz_2000] C. E. Metz, "Fundamental ROC analysis," in Handbook of medical imaging, vol. 1, J. Beutel, H. L. Kundel,R. L. Van Metter, Eds. Bellingham, Washington: SPIE Press, The International Society for Optical Engineering, 2000, pp. 751-770.

[Morioka_2005] C. A. Morioka, S. El-Saden, W. Pope, G. Duckwiler, A. Bui, H. Kangarloo, "Integration of HIS/RIS clinical document with PACS image studies for neuroradiology," Proceedings of SPIE International Symposium on Medical Imaging, San Diego, 2005.

[Müller_2004a] Henning Müller, Nicolas Michoux, David Bandon, Antoine Geissbuhler, “A Review of Content-based Image Retrieval Systems in Medical Applications-Clinical Benefits and Future Directions," International Journal of Medical Informatics, vol. 73,February 2004, pp. 1-23.

[Müller_2004b] Henning Müller, Antoine Rosset, Jean-Paul Vallée, François Terrier, Antoine Geissbuhler, "A reference data set for the evaluation of medical image retrieval systems," Computerized Medical Imaging and Graphics, vol. 28,September 2004, pp. 295-305.

[Pare_2005] Guy Pare, David Aubry, Luigi Lepanto, Claude Sicotte, "Evaluating PACS Success: A Multidimensional Model," Proceedings of 38th Annual Hawaii International Conference on System Sciences (HICSS'05) - Track 6, Big Island, HI, USA, 2005.

[Park_2002] Mira Park, Jesse S. Jin, Laurence S. Wilson, "Fast Content-Based Image Retrieval Using Quasi-Gabor Filter and Reduction of Image Feature Dimension," Proceedings of Fifth IEEE Southwest Symposium on Image Analysis and Interpretation (SSIAI02), Santa Fe, New Mexico, 2002.

[Pereira-Jr._2007] Roberto R. Pereira-Jr., Paulo Mazzoncini de Azevedo-Marques, Marcelo O. Honda, Sergio K. Kinoshita, Roger Engelmann, Chisako Muramatsu, kunio Doi, "Usefulness of Texture Analysis for Computerized 
Classification of Breast Lesions on Mammograms," Journal of Digital Imaging, vol. 20,September, pp. 248-255.

[Pietrzyk_2008] Marius W. Pietrzyk, David J. Manning, Alan Dix, Tim Donovan,

"Relations between physical properties of local and global image based elements and the performance of human observers in lung nodule detection," Proceedings of Medical Imaging 2008: Image Perception, Observer Performance, and Technology Assessment, 2008.

[Prasad_2008] M. N. Prasad, M. S. Brown, S. Ahmad, F. Abtin, J. Allen, I. da Costa, H. J. Kim, M. F. McNitt-Gray, J. G. Goldin, "Automatic segmentation of lung parenchyma based on curvature of ribs using HRCT images in scleroderma studies," Proceedings of Medical Imaging 2008: Computer-Aided Diagnosis, 2008 .

[Rosa_2002] Natália Abdala Rosa, Roberto Figueira Santos Filho, Josiane Maria Bueno, Agma Juci Machado Traina, Caetano Traina Jr., "Sistema de Recuperação de Imagens Similares em um Hospital Universitário," Proceedings of VIII Congresso Brasileiro de Informática em Saúde- CBIS'2002, Natal, RNBrazil, 2002.

[Rubin_2003] R.S. Rubin, Adilson Gonzaga, J.M. Alves, C.H. Barbieri, G. Barbieri, "Avaliação de Fraturas Ósseas através da análise de Texturas em Imagens Radiográficas," Proceedings of II Workshop Regional em Engenharia Biomédica e I Simpósio Regional de Instrumentação e Imagens Médicas, São Pedro, SP, 2003.

[Silva_2005] Jose Silvestre Serra da Silva, "Segmentação Pulmonar em Estudos de Tomografia Axial Computorizada", Tese de Doutorado, Departamento de Electrónica e Telecomunicações, Universidade de Aveiro, pp. 201, 2005

[Smeulders_2000] A. W. M. Smeulders, M. Worring, S. Santini, A. Gupta, Ramesh Jain, "Content-Based Image Retrieval at the End of the Early Years," IEEE Transactions on Pattern Analysis and Machine Intelligence (PAMI), vol. 22,Dec, pp. 1349-1380.

[Sonka_1999] M. Sonka, V. Hlavac, R. Boyle, Image Processing, Analysis, and Machine Vision, 2nd ed. CA, USA: Brooks/Cole Publishing Company, 1999. 
[Souza-Jr_2002] Artur Soares Souza-Jr, Cesar de Araujo-Neto, Dany Jasinovodolinsky, Edson Marchiori, Jorge Kavakama, Klaus L. Irion, Luiz Felipe Nobre, Marcelo Funari, Marcelo Chaves, Mário Terra-Filho, et al., "Terminologia para a Descrição de Tomografia Computadorizada do Tórax," in Radiologia Brasileira - Educação em Radiologia, vol. 35, pp. 125-128.

[Tan_2006] Yongqiang Tan, Jianguo Zhang, Yanging Hua, Guozhen Zhang, H. K. Huang, "Content-based image retrieval in picture archiving and communication systems," Proceedings of Medical Imaging 2006: PACS and Imaging Informatics, 2006.

[Tao_2007] Y. Tao, S. -C. B. Lo, M. T. Freedman, J. Xuan, “A preliminary study of content-based mammographic masses retrieval," Proceedings of, 2007.

[Theodoridis_1999] S. Theodoridis ,K. Koutroumbas, "Pattern Recognition," in Academic Press. New York.

[Torres_2003] Ricardo S. Torres, Eduardo M. Picado, Alexandre X. Falcão, Luciano Fontoura da Costa, "Effective Image Retrieval by Shape Saliences," Proceedings of Simpósio Brasileiro de Computação gráfica e Processamento de Imagens (SiBGraPI), São Carlos, SP, 2003.

[Traina_2004] Agma Juci Machado Traina, André Guilherme Ribeiro Balan, Luis Marcelo Bortolotti, Caetano Traina, Jr., "Content-based Image Retrieval Using Approximate Shape of Objects," Proceedings of 17th IEEE Symposium on Computer-Based Medical Systems (CBMS`04), Bethesda, Maryland, 2004.

[Traina_2003] Agma Juci Machado Traina, Caetano Traina Jr., Josiane Maria Bueno, Fábio Jun Takada Chino, Paulo Mazzoncini de Azevedo Marques, "Efficient Content-based Image Retrieval through Metric Histograms," World Wide Web Journal (WWWJ), vol. 6,June 2003, pp. 157-185.

[Traina_2002] Agma Juci Machado Traina, Caetano Traina Jr., Josiane Maria Bueno, Paulo Mazzoncini de Azevedo Marques, "The Metric Histogram: A New and Efficient Approach for Content-based Image Retrieval," Proceedings of Sixth IFIP Working Conference on Visual Database Systems, Brisbane, Australia, 2002. 
[Traina_2007] Caetano Traina, Jr., Roberto Figueira Santos Filho, Agma Juci Machado Traina, Marcos Rodrigues Vieira, Christos Faloutsos, "The OMNI-Family of AllPurpose Access Methods: A Simple and Effective Way to Make Similarity Search More Efficient," The International Journal on Very Large Databases, vol. 16, October 2007, pp. 483-505.

[Traina Jr._2002] Caetano Traina Jr., Agma Juci Machado Traina, Christos Faloutsos, Bernhard Seeger, "Fast Indexing and Visualization of Metric Datasets Using Slim-trees," IEEE Transactions on Knowledge and Data Engineering (TKDE), vol. 14,March/April 2002, pp. 244-260.

[Traina Jr._2000] Caetano Traina Jr., Agma Juci Machado Traina, Bernhard Seeger, Christos Faloutsos, "Slim-Trees: High Performance Metric Trees Minimizing Overlap Between Nodes," Proceedings of International Conference on Extending Database Technology (EDBT), Konstanz, Germany, 2000.

[Tversky_1977] A. Tversky, "Features of Similarity," Psychological Review, vol. 84,July 1977, pp. 327-352.

[Uchiyama_2003] Y. Uchiyama, S. Katsuragawa, H. Abe, J. Shiraishi, F. Li, Q. Li, C. T. Zhang, K. Suzuki, K. Doi, “Quantitative computerized analysis of diffuse lung disease in high-resolution computed tomography," Medical Physics, vol. 30,September 2003, pp. 2440-2454.

[Vasconcelos_2000] N. Vasconcelos ,A. Lippman, “A Unifying View of Image Similarity,” Proceedings of Intl Conf on Pattern Recognition (ICPR), 2000.

[Wang_2006] Jingbin Wang, Margrit Betke, Jane P. ko, "Pulmonary fissure segmentation on CT," Medical Image Analysis, vol. 10,May 2006, pp. 530-547.

[Wangenheim_2003] Christiane Gresse von Wangenheim ,Aldo von Wangenheim, Raciocínio Baseado em Casos, vol. 1. Curitiba: Editora Manole, 2003.

[Webb_2002] W. Richard Webb, Nestor L. Muller, David P. Naidich, TC de Alta Resolução do Pulmão, 3 ed: Guanabara Koogan, 2002.

[Xue_2007] Z. Xue, Sameer Antani, Rodney Long, J. Jeronimo, George R. Thomas, "Investigating CBIR techniques for cervicographic images," Proceedings of, 2007. 
[Yin_2004] T.-K Yin ,N.-T Chiu, “A computer-aided diagnosis for locating abnormalities in bone scintigraphy by a fuzzy system with a three-step minimization approach," IEEE Transactions on Medical Imaging, vol. 23, pp. 639-654.

[Zhang_2001] D. S. Zhang ,Guojun Lu, “Content-Based Shape Retrieval Using Different Shape Descriptors: A Comparative Study," Proceedings of IEEE Conference on Multimedia and Expo (ICME'01), Tokyo, Japan, 2001. 